NASA/TP-2003-212265

AFDD/TR-04-003
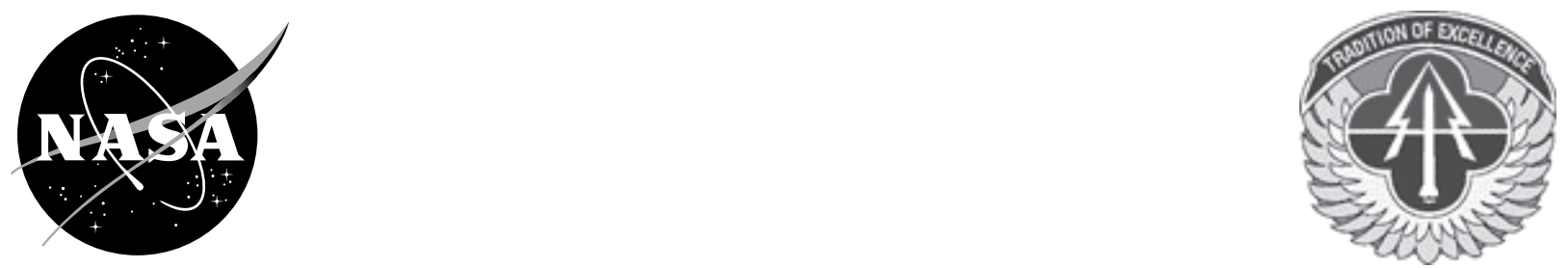

\title{
Aerodynamic Characteristics of SC1095 and SC1094 R8 Airfoils
}

William G. Bousman 
Since its founding, NASA has been dedicated to the advancement of aeronautics and space science. The NASA Scientific and Technical Information (STI) Program Office plays a key part in helping NASA maintain this important role.

The NASA STI Program Office is operated by Langley Research Center, the Lead Center for NASA's scientific and technical information. The NASA STI Program Office provides access to the NASA STI Database, the largest collection of aeronautical and space science STI in the world. The Program Office is also NASA's institutional mechanism for disseminating the results of its research and development activities. These results are published by NASA in the NASA STI Report Series, which includes the following report types:

- TECHNICAL PUBLICATION. Reports of completed research or a major significant phase of research that present the results of NASA programs and include extensive data or theoretical analysis. Includes compilations of significant scientific and technical data and information deemed to be of continuing reference value. NASA's counterpart of peer-reviewed formal professional papers but has less stringent limitations on manuscript length and extent of graphic presentations.

- TECHNICAL MEMORANDUM. Scientific and technical findings that are preliminary or of specialized interest, e.g., quick release reports, working papers, and bibliographies that contain minimal annotation. Does not contain extensive analysis.

- CONTRACTOR REPORT. Scientific and technical findings by NASA-sponsored contractors and grantees.
- CONFERENCE PUBLICATION. Collected papers from scientific and technical conferences, symposia, seminars, or other meetings sponsored or cosponsored by NASA.

- SPECIAL PUBLICATION. Scientific, technical, or historical information from NASA programs, projects, and missions, often concerned with subjects having substantial public interest.

- TECHNICAL TRANSLATION. Englishlanguage translations of foreign scientific and technical material pertinent to NASA's mission.

Specialized services that complement the STI Program Office's diverse offerings include creating custom thesauri, building customized databases, organizing and publishing research results ... even providing videos.

For more information about the NASA STI Program Office, see the following:

- Access the NASA STI Program Home Page at http://www.sti.nasa.gov

- E-mail your question via the Internet to help@sti.nasa.gov

- Fax your question to the NASA Access Help Desk at (301) 621-0134

- Telephone the NASA Access Help Desk at (301) 621-0390

- Write to:

NASA Access Help Desk

NASA Center for AeroSpace Information 7121 Standard Drive Hanover, MD 21076-1320 
NASA/TP-2003-212265

AFDD/TR-04-003
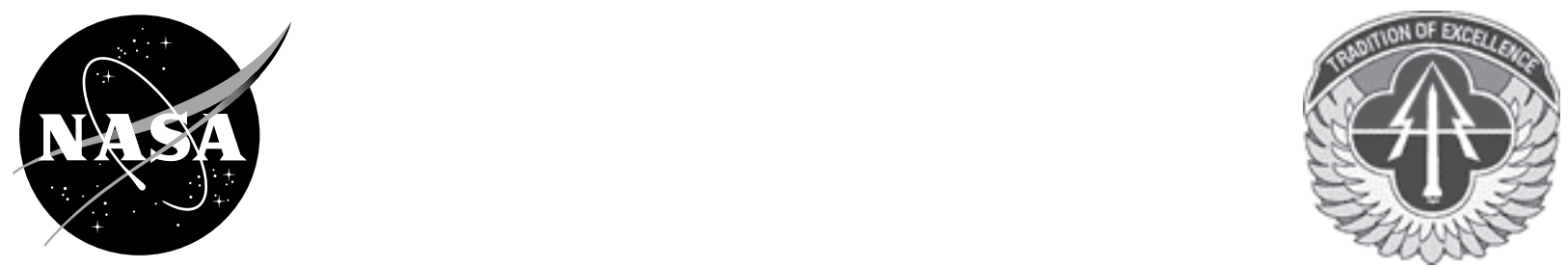

\section{Aerodynamic Characteristics of SC1095 and SC1094 R8 Airfoils}

William G. Bousman

Aeroflightdynamics Directorate

U.S. Army Research, Development, and Engineering Command

Ames Research Center

Moffett Field, California

National Aeronautics and

Space Administration

Ames Research Center

Moffett Field, California 94035-1000 
Available from:

NASA Center for AeroSpace Information 7121 Standard Drive

Hanover, MD 21076-1320

(301) 621-0390
National Technical Information Service 5285 Port Royal Road Springfield, VA 22161 (703) 487-4650 


\section{TABLE OF CONTENTS}

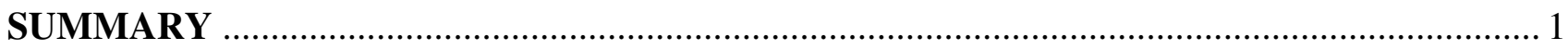

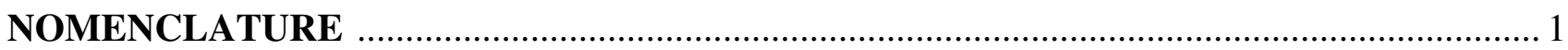

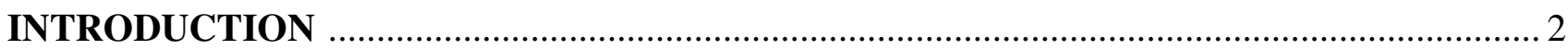

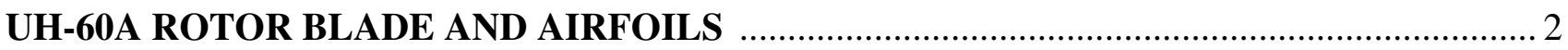

EVALUATION OF SECTION CHARACTERISTICS …………........................................ 7

ANGLE-OF-ATTACK AND MACH NUMBER DISTRIBUTIONS ……………………...... 9

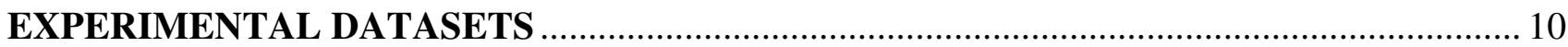

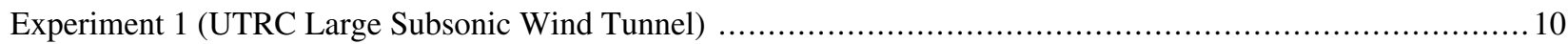

Experiment 2 (UTRC Large Subsonic Wind Tunnel) ........................................................... 12

Experiment 3 (Ohio State University Transonic 6- by 22-Inch Wind Tunnel) ….....................................13

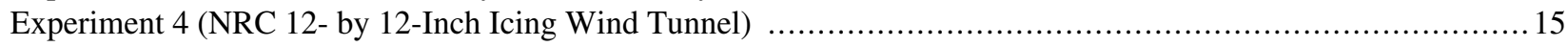

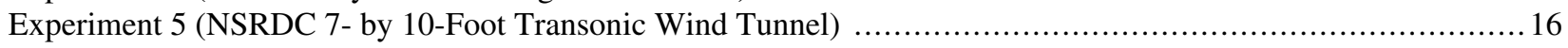

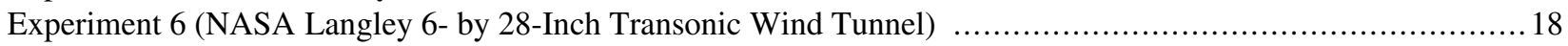

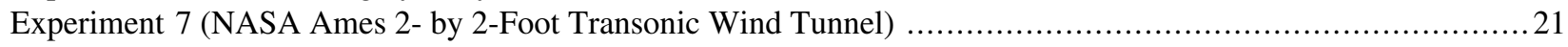

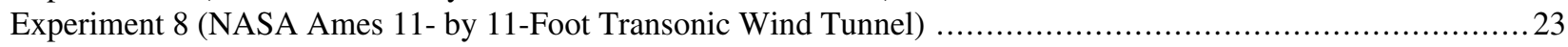

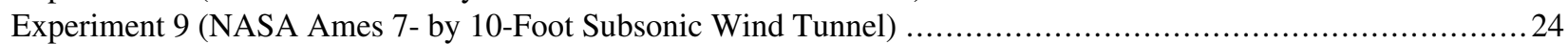

Experiment 10 (Glenn L. Martin 8- by 11-Foot Subsonic Wind Tunnel) ...............................................25

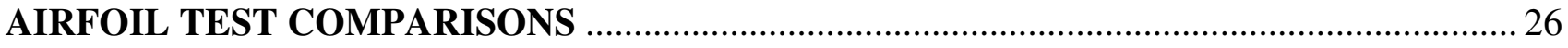

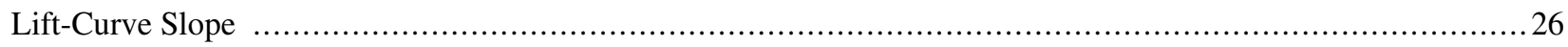

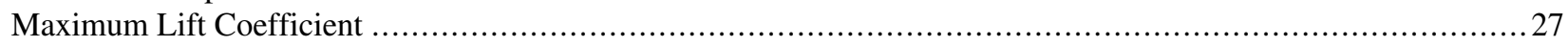

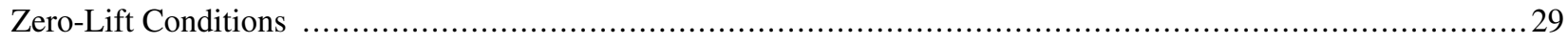

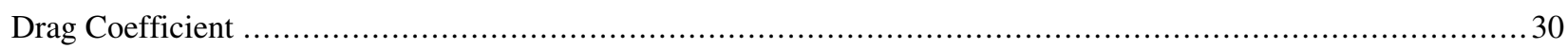

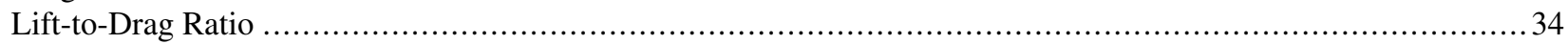

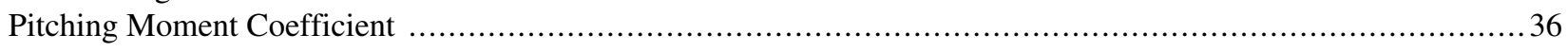

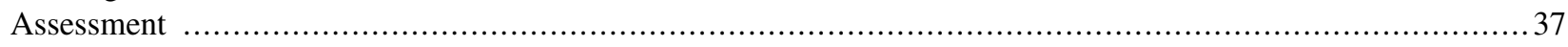

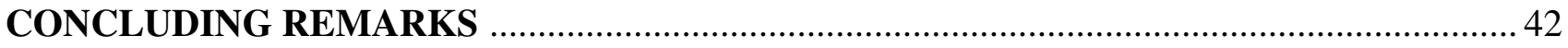

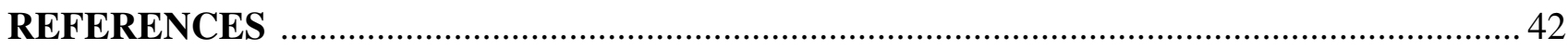





\title{
Aerodynamic Characteristics of SC1095 and SC1094 R8 Airfoils
}

\author{
WILLIAM G. BOUSMAN \\ Aeroflightdynamics Directorate \\ U.S. Army Research, Development, and Engineering Command \\ Ames Research Center
}

\section{SUMMARY}

Two airfoils are used on the main rotor blade of the UH-60A Black Hawk helicopter, the SC1095 and the SC1094 R8. Measurements of the section lift, drag, and pitching moment were obtained in ten wind tunnel tests for the SC1095 airfoil, and in five of these tests, measurements were also obtained for the SC1094 R8. The ten wind tunnel tests are characterized and described in the present study. Fundamental parameters derived from test measurements are compared and an assessment is made of the adequacy of the test data for use in look-up tables required by lifting-line calculation methods.

\section{NOMENCLATURE}

$a$

B.S.

$b$

$c$

$C_{d}$

$C_{d_{\text {min }}}$

$C_{d_{0}}$

$C_{l}$

$C_{l_{\max }}$

$C_{l_{\alpha}}$

$C_{l_{0}}$

$C_{m}$

$C_{m_{0}}$

$C_{m_{\alpha}}$

$C_{W}$

$h$

$L / D$

M rotor disk area, feet ${ }^{2}\left(\mathrm{ft}^{2}\right)$

speed of sound, $\mathrm{ft} / \mathrm{second}(\mathrm{ft} / \mathrm{sec})$

blade station (from hub center), inches (in.)

wind tunnel span, in.

blade chord, in.

section drag coefficient

minimum section drag coefficient

section drag coefficient at zero lift

section lift coefficient

maximum section lift coefficient

lift-curve slope, $d C_{l} / d \alpha$, degrees $^{-1}$

$$
\left(\operatorname{deg}^{-1}\right)
$$

section lift coefficient at zero angle of attack

section pitching moment coefficient

section pitching moment coefficient at zero lift

change in pitching moment with angle of attack

weight coefficient, $W / \rho A(\Omega R)^{2}$

wind tunnel height, in.

ratio of lift to drag

Mach number

\begin{tabular}{|c|c|}
\hline$M_{d d}$ & drag divergence Mach number \\
\hline$R$ & blade radius, $\mathrm{ft}$ \\
\hline$r$ & radial station, $\mathrm{ft}$ \\
\hline $\operatorname{Re}$ & Reynolds number, $\rho v(r, t) c / \mu_{v}$ \\
\hline$T$ & temperature, degrees Fahrenheit (deg F) \\
\hline$V$ & forward velocity, ft/sec \\
\hline$v(r, t)$ & section velocity, $\mathrm{ft} / \mathrm{sec}$ \\
\hline$W$ & weight, pounds (lb) \\
\hline$x$ & chordwise position, in. or ft \\
\hline$\alpha$ & angle of attack, deg \\
\hline$\alpha_{0}$ & angle of attack for zero lift, deg \\
\hline$\beta$ & Prandtl-Glauert correction, $\sqrt{1-M^{2}}$ \\
\hline$\Delta \alpha$ & $\begin{array}{l}\text { angle-of-attack correction for wall } \\
\text { effects, deg }\end{array}$ \\
\hline$\delta$ & correction parameter, equation (15) \\
\hline$\delta_{0} \delta_{1}$ & correction parameters, equation (9) \\
\hline$\delta_{\mathrm{tab}}$ & $\begin{array}{l}\text { airfoil tab deflection, positive trailing } \\
\text { edge down, deg }\end{array}$ \\
\hline$\mu$ & advance ratio, $V / \Omega R$ \\
\hline$\mu_{v}$ & absolute viscosity, $\mathrm{lb}-\mathrm{sec} / \mathrm{ft}^{2}$ \\
\hline$\rho$ & density, slugs $/ \mathrm{ft}^{3}$ \\
\hline$\sigma$ & rotor solidity \\
\hline$\Omega$ & rotor speed, radians/sec $(\mathrm{rad} / \mathrm{sec})$ \\
\hline
\end{tabular}




\section{INTRODUCTION}

The UH-60A Black Hawk is a four-bladed helicopter that is the primary troop-carrying transport for the U.S. Army. Developed in the 1970s, the first flight of the UH-60A prototype occurred in October 1974 and the aircraft was approved for production in October 1979 (ref. 1). As originally designed, the UH-60A prototype used a single airfoil section, the SC1095. During testing of the prototype aircraft, it was determined that the vehicle could not meet the Army's maneuverability requirements, and a cambered nose section was added to the SC1095 profile from $0.47 R$ to $0.85 R$ to increase the maximum rotor thrust in maneuvers (ref. 1). The modified SC1095 section is now referred to as the SC1094 R8.

To date the SC1095 section characteristics have been measured in at least ten wind tunnel tests (refs. 2-11), and the SC1094 R8 section characteristics have been measured in five of these tests (refs. 4, 5, 7, 9, and 11). Totah (ref. 12) assessed the lift and drag data for nine of the wind tunnel tests, using an approach similar to that used by McCroskey for the NACA 0012 (ref. 13). The present technical paper has three purposes: (1) to repeat Totah's original assessment with some modifications, (2) to extend the assessment to examine pitching moment data, and (3) to examine data from a wind tunnel test (ref. 11) obtained since Totah's assessment was published.

\section{UH-60A ROTOR BLADE AND AIRFOILS}

The SC1095 airfoil and the SC1094 R8 airfoil, modified from the SC1095 by adding droop at the leading edge, are illustrated in figure 1 . The effect of the nose droop was to extend the SC1095 chord from 20.76 in. to 20.965 in., thereby reducing the airfoil thickness from 9.5 percent to 9.4 percent (hence the change in the section nomenclature). The addition of nose droop also rotated the mean chordline by $-1 \mathrm{deg}$, as shown in figure 1 .

The two airfoil sections are compared on a nondimensional basis in figure 2. Both airfoils are shown referenced to their true chordlines. The chordline defined for the SC1095 airfoil is the same in all the test programs summarized in this report. However, the chordline definition of the SC1094 R8 airfoil is not treated consistently in the references, so care must be taken in using the data. For example, the data for the SC1094 R8 airfoil reported in references 7, 9, and 11 are referenced to the mean chordline of the SC1095 airfoil, whereas the data in references 4 and 5 are referenced to the mean chordline shown here. In the present report, the data from references 7, 9, and 11 have been adjusted so that all
SC1094 R8 data are referenced to the mean chordline shown in figure 2. Ordinates for the two airfoils are shown in tables 1 and 2.

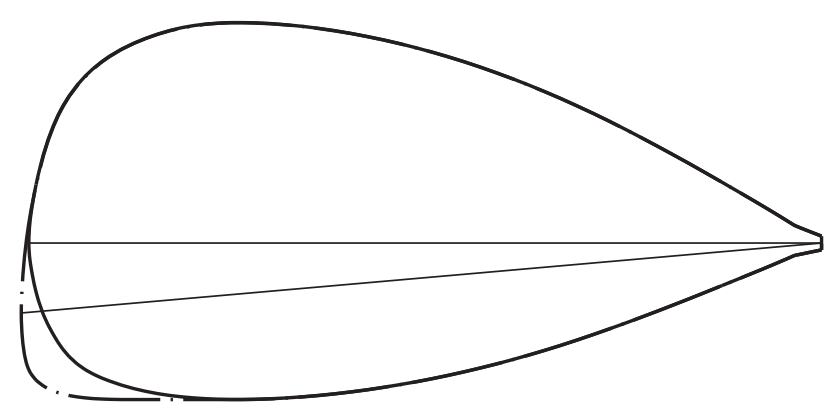

Figure 1. Overlay of SC1095 and SC1094 R8 airfoils with $5 X$ exaggerated vertical scale. Nose droop of SC1094 R8 increases airfoil chord from $20.76 \mathrm{in}$. to $20.965 \mathrm{in}$. and the mean chordline is rotated by 1 deg.

SC1095

$\mathrm{SC} 1094 \mathrm{R} 8$

Figure 2. Comparison of nondimensional blade ordinates for SC1095 and SC1094 R8 airfoils.

The planform of the UH-60A blade is illustrated in figure 3. The initiation of the $\mathrm{SC} 1095$ airfoil section is at B.S. 62.00 in. $(0.1925 R)$. Inboard of this point the airfoil thickens and becomes nonaerodynamic. The root cutout is at B.S. $42.00 \mathrm{in.}(0.1304 R)$. The inboard SC1095 section extends from B.S. 62.00 in. $(0.1925 R)$ to B.S. 150.00 in. $(0.4658 R)$. There is a linear transition between the SC1095 and SC1094 R8 sections from B.S. 150.00 in. $(0.4658 R)$ to B.S. 160.00 in. (0.4969R). The SC1094 R8 airfoil section then extends from B.S. 160.00 in. $(0.4969 R)$ to B.S. 265.00 in. $(0.8230 R)$. From B.S. $265.00 \mathrm{in} .(0.8230 R)$ to B.S. $275.00 \mathrm{in} .(0.8540 R)$ there is a linear transition between the SC1094 R8 and SC1095 airfoil sections. The SC1095 section is then used to the blade tip. 
Table 1. SC1095 coordinates; $c=20.76 \mathrm{in}$.

\begin{tabular}{|c|c|c|c|}
\hline \multicolumn{2}{|c|}{ Upper surface } & \multicolumn{2}{|c|}{ Lower surface } \\
\hline$x / c$ & $y / c$ & $x / c$ & $y / c$ \\
\hline 0.00000 & 0.00000 & 0.00000 & 0.00000 \\
\hline 0.00010 & 0.00147 & 0.00010 & -0.00112 \\
\hline 0.00081 & 0.00396 & 0.00081 & -0.00322 \\
\hline 0.00203 & 0.00626 & 0.00203 & -0.00510 \\
\hline 0.00407 & 0.00913 & 0.00407 & -0.00757 \\
\hline 0.00661 & 0.01215 & 0.00661 & -0.01020 \\
\hline 0.00915 & 0.01473 & 0.00915 & -0.01236 \\
\hline 0.01220 & 0.01748 & 0.01220 & -0.01453 \\
\hline 0.01830 & 0.02220 & 0.01830 & -0.01798 \\
\hline 0.02440 & 0.02608 & 0.02440 & -0.02066 \\
\hline 0.03050 & 0.02934 & 0.03050 & -0.02293 \\
\hline 0.03660 & 0.03208 & 0.03660 & -0.02494 \\
\hline 0.04271 & 0.03443 & 0.04271 & -0.02669 \\
\hline 0.05084 & 0.03707 & 0.05084 & -0.02862 \\
\hline 0.06101 & 0.03979 & 0.06101 & -0.03048 \\
\hline 0.07117 & 0.04205 & 0.07117 & -0.03191 \\
\hline 0.08134 & 0.04398 & 0.08134 & -0.03304 \\
\hline 0.09151 & 0.04562 & 0.09151 & -0.03397 \\
\hline 0.10168 & 0.04705 & 0.10168 & -0.03476 \\
\hline 0.11693 & 0.04885 & 0.11693 & -0.03580 \\
\hline 0.13218 & 0.05033 & 0.13218 & -0.03666 \\
\hline 0.14743 & 0.05158 & 0.14743 & -0.03737 \\
\hline 0.16268 & 0.05265 & 0.16268 & -0.03795 \\
\hline 0.17794 & 0.05354 & 0.17794 & -0.03841 \\
\hline 0.19319 & 0.05426 & 0.19319 & -0.03876 \\
\hline 0.20844 & 0.05480 & 0.20844 & -0.03903 \\
\hline 0.22369 & 0.05518 & 0.22369 & -0.03923 \\
\hline 0.23894 & 0.05541 & 0.23894 & -0.03935 \\
\hline 0.25419 & 0.05553 & 0.25419 & -0.03941 \\
\hline 0.26945 & 0.05554 & 0.26945 & -0.03941 \\
\hline 0.28470 & 0.05547 & 0.28470 & -0.03937 \\
\hline 0.30503 & 0.05528 & 0.30503 & -0.03924 \\
\hline 0.32537 & 0.05498 & 0.32537 & -0.03903 \\
\hline 0.34570 & 0.05458 & 0.34570 & -0.03874 \\
\hline 0.36604 & 0.05407 & 0.36604 & -0.03839 \\
\hline 0.38638 & 0.05348 & 0.38638 & -0.03797 \\
\hline 0.40671 & 0.05280 & 0.40671 & -0.03749 \\
\hline 0.42705 & 0.05203 & 0.42705 & -0.03695 \\
\hline 0.44738 & 0.05118 & 0.44738 & -0.03635 \\
\hline 0.46772 & 0.05024 & 0.46772 & -0.03569 \\
\hline 0.48805 & 0.04922 & 0.48805 & -0.03497 \\
\hline 0.50839 & 0.04812 & 0.50839 & -0.03419 \\
\hline 0.52872 & 0.04694 & 0.52872 & -0.03335 \\
\hline 0.54906 & 0.04568 & 0.54906 & -0.03245 \\
\hline 0.56940 & 0.04434 & 0.56940 & -0.03149 \\
\hline 0.58973 & 0.04291 & 0.58973 & -0.03047 \\
\hline 0.61007 & 0.04140 & 0.61007 & -0.02938 \\
\hline 0.63040 & 0.03982 & 0.63040 & -0.02824 \\
\hline
\end{tabular}


Table 1. SC1095 coordinates - concluded.

\begin{tabular}{cccc}
\hline \hline \multicolumn{2}{c}{ Upper surface } & \multicolumn{2}{c}{ Lower surface } \\
$x / c$ & $y / c$ & $x / c$ & $y / c$ \\
\hline 0.65074 & 0.03815 & 0.65074 & -0.02703 \\
0.67107 & 0.03640 & 0.67107 & -0.02577 \\
0.69141 & 0.03458 & 0.69141 & -0.02445 \\
0.71174 & 0.03267 & 0.71174 & -0.02308 \\
0.73208 & 0.03070 & 0.73208 & -0.02166 \\
0.75242 & 0.02865 & 0.75242 & -0.02019 \\
0.77275 & 0.02655 & 0.77275 & -0.01868 \\
0.79309 & 0.02439 & 0.79309 & -0.01714 \\
0.81342 & 0.02218 & 0.81342 & -0.01557 \\
0.83376 & 0.01993 & 0.83376 & -0.01397 \\
0.85409 & 0.01764 & 0.85409 & -0.01236 \\
0.87443 & 0.01532 & 0.87443 & -0.01072 \\
0.89476 & 0.01297 & 0.89476 & -0.00908 \\
0.91510 & 0.01060 & 0.91510 & -0.00742 \\
0.92527 & 0.00939 & 0.92527 & -0.00659 \\
0.93544 & 0.00818 & 0.93544 & -0.00575 \\
0.94560 & 0.00695 & 0.94560 & -0.00489 \\
0.95577 & 0.00570 & 0.95577 & -0.00402 \\
0.96594 & 0.00443 & 0.96594 & -0.00313 \\
0.97611 & 0.00360 & 0.97611 & -0.00271 \\
0.98627 & 0.00281 & 0.98627 & -0.00229 \\
0.99644 & 0.00201 & 0.99644 & -0.00188 \\
1.00000 & 0.00173 & 1.00000 & -0.00173 \\
\hline \hline
\end{tabular}

Table 2. SC1094 R8 coordinates; $c=20.965$ in.

\begin{tabular}{cccc}
\hline \hline \multicolumn{2}{c}{ Upper surface } & \multicolumn{2}{c}{ Lower surface } \\
$x / c$ & $y / c$ & $x / c$ & $y / c$ \\
\hline 0.00000 & 0.00000 & 0.00000 & 0.00000 \\
0.00013 & 0.00185 & 0.00007 & -0.00180 \\
0.00090 & 0.00559 & 0.00072 & -0.00501 \\
0.00218 & 0.00945 & 0.00188 & -0.00773 \\
0.00427 & 0.01398 & 0.00384 & -0.01053 \\
0.00686 & 0.01825 & 0.00632 & -0.01277 \\
0.00944 & 0.02174 & 0.00881 & -0.01419 \\
0.01252 & 0.02532 & 0.01181 & -0.01540 \\
0.01867 & 0.03126 & 0.01783 & -0.01702 \\
0.02245 & 0.03441 & 0.02154 & -0.01773 \\
0.02857 & 0.03890 & 0.02757 & -0.01872 \\
0.03468 & 0.04264 & 0.03360 & -0.01953 \\
0.04077 & 0.04576 & 0.03963 & -0.02017 \\
0.04686 & 0.04837 & 0.04566 & -0.02070 \\
0.05294 & 0.05058 & 0.05169 & -0.02115 \\
0.06104 & 0.05306 & 0.05974 & -0.02166 \\
\hline
\end{tabular}


Table 2. SC1094 R8 coordinates - continued.

\begin{tabular}{|c|c|c|c|}
\hline \multicolumn{2}{|c|}{ Upper surface } & \multicolumn{2}{|c|}{ Lower surface } \\
\hline$x / c$ & $y / c$ & $x / c$ & $y / c$ \\
\hline 0.07115 & 0.05558 & 0.06980 & -0.02218 \\
\hline 0.08125 & 0.05764 & 0.07986 & -0.02260 \\
\hline 0.09135 & 0.05937 & 0.08992 & -0.02294 \\
\hline 0.10145 & 0.06083 & 0.09998 & -0.02323 \\
\hline 0.11154 & 0.06206 & 0.11005 & -0.02348 \\
\hline 0.12666 & 0.06359 & 0.12514 & -0.02379 \\
\hline 0.14179 & 0.06479 & 0.14024 & -0.02406 \\
\hline 0.15691 & 0.06576 & 0.15534 & -0.02432 \\
\hline 0.17202 & 0.06656 & 0.17044 & -0.02459 \\
\hline 0.18714 & 0.06718 & 0.18554 & -0.02485 \\
\hline 0.20225 & 0.06762 & 0.20063 & -0.02512 \\
\hline 0.21735 & 0.06790 & 0.21573 & -0.02538 \\
\hline 0.23246 & 0.06801 & 0.23083 & -0.02564 \\
\hline 0.24756 & 0.06798 & 0.24593 & -0.02591 \\
\hline 0.26266 & 0.06783 & 0.26103 & -0.02617 \\
\hline 0.27776 & 0.06758 & 0.27612 & -0.02643 \\
\hline 0.29286 & 0.06725 & 0.29122 & -0.02665 \\
\hline 0.31298 & 0.06671 & 0.31136 & -0.02687 \\
\hline 0.33311 & 0.06606 & 0.33149 & -0.02701 \\
\hline 0.35323 & 0.06531 & 0.35163 & -0.02708 \\
\hline 0.37336 & 0.06446 & 0.37176 & -0.02709 \\
\hline 0.39348 & 0.06352 & 0.39190 & -0.02702 \\
\hline 0.41360 & 0.06250 & 0.41204 & -0.02690 \\
\hline 0.43371 & 0.06139 & 0.43218 & -0.02671 \\
\hline 0.45383 & 0.06019 & 0.45232 & -0.02647 \\
\hline 0.47394 & 0.05892 & 0.47246 & -0.02616 \\
\hline 0.49406 & 0.05756 & 0.49261 & -0.02580 \\
\hline 0.51417 & 0.05612 & 0.51275 & -0.02537 \\
\hline 0.53428 & 0.05460 & 0.53290 & -0.02489 \\
\hline 0.55439 & 0.05300 & 0.55304 & -0.02435 \\
\hline 0.57450 & 0.05132 & 0.57319 & -0.02375 \\
\hline 0.59460 & 0.04955 & 0.59334 & -0.02309 \\
\hline 0.61471 & 0.04771 & 0.61349 & -0.02237 \\
\hline 0.63481 & 0.04579 & 0.63364 & -0.02159 \\
\hline 0.65491 & 0.04379 & 0.65379 & -0.02075 \\
\hline 0.67501 & 0.04171 & 0.67394 & -0.01985 \\
\hline 0.69511 & 0.03955 & 0.69409 & -0.01889 \\
\hline 0.71521 & 0.03732 & 0.71425 & -0.01788 \\
\hline 0.73531 & 0.03501 & 0.73440 & -0.01682 \\
\hline 0.75540 & 0.03263 & 0.75456 & -0.01572 \\
\hline 0.77550 & 0.03020 & 0.77472 & -0.01458 \\
\hline 0.79559 & 0.02771 & 0.79487 & -0.01340 \\
\hline 0.81568 & 0.02518 & 0.81503 & -0.01220 \\
\hline 0.83577 & 0.02260 & 0.83519 & -0.01097 \\
\hline 0.85587 & 0.01998 & 0.85535 & -0.00972 \\
\hline 0.87596 & 0.01733 & 0.87551 & -0.00845 \\
\hline 0.89605 & 0.01466 & 0.89567 & -0.00718 \\
\hline 0.91614 & 0.01195 & 0.91583 & -0.00589 \\
\hline
\end{tabular}


Table 2. SC1094 R8 coordinates - concluded.

\begin{tabular}{cccc}
\hline \hline \multicolumn{2}{c}{ Upper surface } & \multicolumn{2}{c}{ Lower surface } \\
$x / c$ & $y / c$ & $x / c$ & $y / c$ \\
\hline 0.92618 & 0.01059 & 0.92591 & -0.00524 \\
0.93623 & 0.00921 & 0.93599 & -0.00458 \\
0.94627 & 0.00782 & 0.94607 & -0.00390 \\
0.95631 & 0.00641 & 0.95615 & -0.00322 \\
0.96636 & 0.00498 & 0.96623 & -0.00251 \\
0.97641 & 0.00398 & 0.97630 & -0.00227 \\
0.98646 & 0.00301 & 0.98637 & -0.00203 \\
0.99651 & 0.00205 & 0.99644 & -0.00180 \\
1.00000 & 0.00171 & 1.00000 & -0.00171 \\
\hline \hline
\end{tabular}

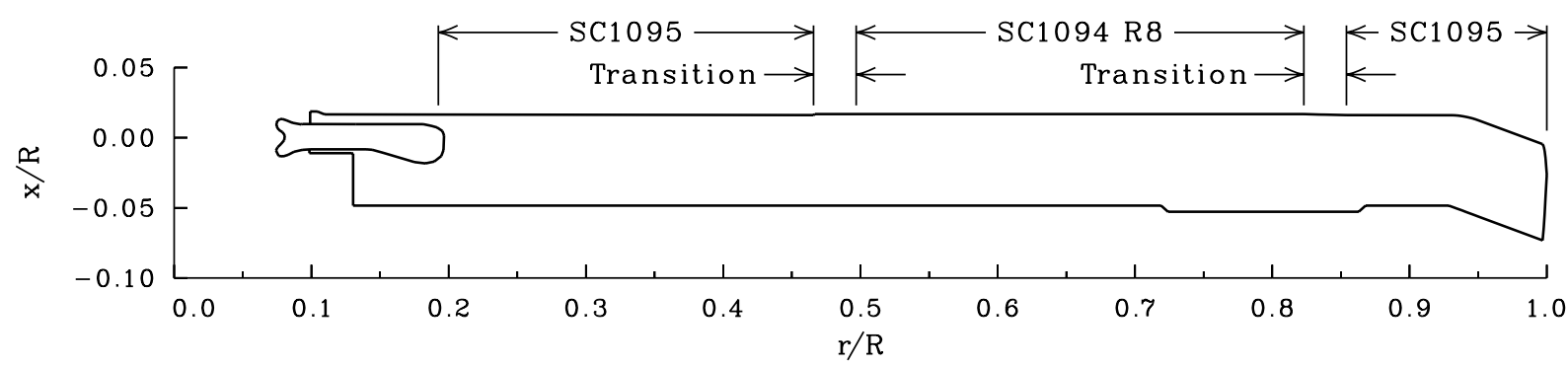

Figure 3. Layout of SC1095 and SC1094 R8 airfoils on UH-60A blade planform.

The increase in the SC1094 R8 chord, from 20.76 to $20.965 \mathrm{in}$., is the result of modifying the SC1095 on the lower surface near the leading edge, as illustrated in figure 1. All of this increased chord is at the airfoil leading edge and, therefore, the quarter chord of the SC1094 R8 is shifted 0.154 in. forward with respect to the SC1095 quarter-chord location.

As shown on the UH-60A planform in figure 3, there is a trim tab on the outer portion of the blade. At its inner and outer edges, the trim tab transitions from the blade chord to the tabbed chord at a 45 -deg angle. The full chord of the trim tab extends from B.S. 236.91 in. $(0.7316 R)$ to B.S. 277.86 in. $(0.8629 R)$. Over most of this extent the tab increases the chord of the SC1094 R8 airfoil by $1.352 \mathrm{in}$. to provide a chord of $22.317 \mathrm{in}$. Over this range, the quarter chord of the airfoil is, therefore, 0.184 in. aft of the SC1095 quarter-chord location.

The tip section of the UH-60A blade is swept by $20 \mathrm{deg}$. The sweep is initiated at B.S. $299.00 \mathrm{in}$.

$(0.9286 \mathrm{R})$. The swept section is defined by rotating the SC1095 section about its trailing edge until the section is perpendicular to the swept axis. Hence, the airfoil section over the swept tip in a plane normal to the pitch axis has the chord increased by $1 / \cos 20^{\circ}$, and is $22.092 \mathrm{in}$. Because the airfoil thickness is unchanged over this span, the airfoil thickness ratio is reduced from 9.5 percent to 8.9 percent. The outer inch of the blade is a rotated section profile. The radial distribution of section characteristics is summarized in table 3 .

The distribution of blade aerodynamic twist is shown in figure 4 . In this figure the twist angle is defined by the airfoil section mean chordline and, therefore, there is a-1-deg shift for the radial stations that use the SC1094 R8 airfoil. It is important to note that there is no equivalent twist offset in the structural spar over the span where the SC1094 R8 airfoil is used. If calculations are made using SC1094 R8 airfoil tables that are referenced to the SC1095 mean chordline, then the twist offset shown in figure 4 should not be used. However, if the SC1094 R8 airfoil tables are referenced to their own chordline, as is the normal convention, then the twist angle shown in figure 4 should be used. 
Table 3. Radial distribution of section characteristics.

\begin{tabular}{lccc}
\hline \hline \multicolumn{1}{c}{ Section characteristic } & Radial location, in. & Chord, in. & Quarter chord, in. ${ }^{a}$ \\
\hline Root cutout & 42.00 & 20.760 & 0.000 \\
SC1095 (inner) & 62.00 & 20.760 & 0.000 \\
SC1095 (outer) & 150.00 & 20.760 & 0.000 \\
SC1094 R8 (inner) & 160.00 & 20.965 & 0.154 \\
SC1094 R8 (tab, inner) & 236.91 & 22.317 & -0.184 \\
SC1094 R8 (outer) & 265.00 & 22.317 & -0.184 \\
SC1095 (inner) & 275.00 & 22.112 & -0.338 \\
SC1095 (tab, outer) & 277.86 & 22.112 & -0.338 \\
SC1095 (sweep, inner) & 299.00 & 20.760 & 0.000 \\
SC1095 (sweep, tip) & 322.00 & 22.092 & -12.562 \\
\hline \hline
\end{tabular}

${ }^{a}$ Relative to SC1095 quarter chord, positive forward.

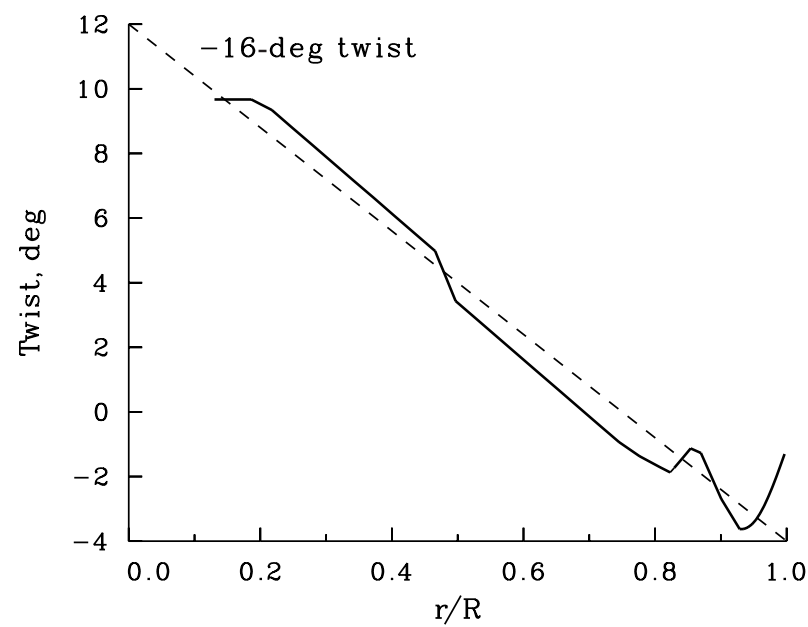

Figure 4. Aerodynamic twist of $\mathrm{UH}-60 \mathrm{~A}$ blade based on mean chordline.

\section{EVALUATION OF SECTION CHARACTERISTICS}

The measurement of airfoil lift, drag, and moment remains a difficult problem, and disparate results are obtained when these section characteristics are compared among different wind tunnel tests. McCroskey has proposed in reference 13 that an appropriate filtering process for the examination of test data should start from two basic "facts" relative to airfoil behavior in subsonic flow and at small angles of attack. First, the lift-curve slope with the Prandtl-Glauert correction is independent of Mach number and only weakly dependent upon Reynolds number for Reynolds numbers above approximately a million. Second, the zero-lift drag coefficient, $C_{d_{0}}$, is also independent of Mach number and, again, only weakly dependent upon Reynolds number at higher Reynolds numbers. Using the most trustworthy data for the NACA 0012 airfoil obtained from more than 40 wind tunnel tests, McCroskey proposed that the lift-curve slope for this airfoil should be expressed as

$$
\beta C_{l_{\alpha}}=0.1025+0.00485 \log \left(\operatorname{Re} / 10^{6}\right)
$$

per degree. For the drag-coefficient data obtained with a boundary layer trip

$$
C_{d_{0}}=0.0044+0.018 \mathrm{Re}^{-0.15}
$$

and for untripped data

$$
C_{d_{0}}=0.0017+\frac{0.91}{(\log \operatorname{Re})^{2.58}}
$$

In arriving at these formulae, McCroskey organized the NACA 0012 test data into five groups. The most trustworthy data, those in group 1, agreed with the expression for $\beta C_{l_{\alpha}}$ in equation (1) to a tolerance of \pm 0.0005 , while the drag data agreed with the expressions for $C_{d_{0}}$ in equations (2) and (3) to a tolerance of \pm 0.0002 . Group 2 data were defined as those tests where a tolerance of \pm 0.0040 was achieved for $\beta C_{l_{\alpha}}$, and a tolerance of \pm 0.0010 was obtained for $C_{d_{0}}$. Group 3 data were defined as data that met the group 1 criteria for either $\beta C_{l_{\alpha}}$ or $C_{d_{0}}$, but not for both. The definition of group 4 data included test results that met group 1,2, or 3 criteria, but evidenced other significant problems. Finally, data that did not meet any of the group 1 to 4 criteria were not considered further by McCroskey and were termed group 5 data.

The criteria for group 1 used by McCroskey were very stringent. For instance, only four experiments achieved this level of accuracy, and these were limited in the range of either test Mach numbers or angles of attack. In this sense none of the group 1 data would be suitable 

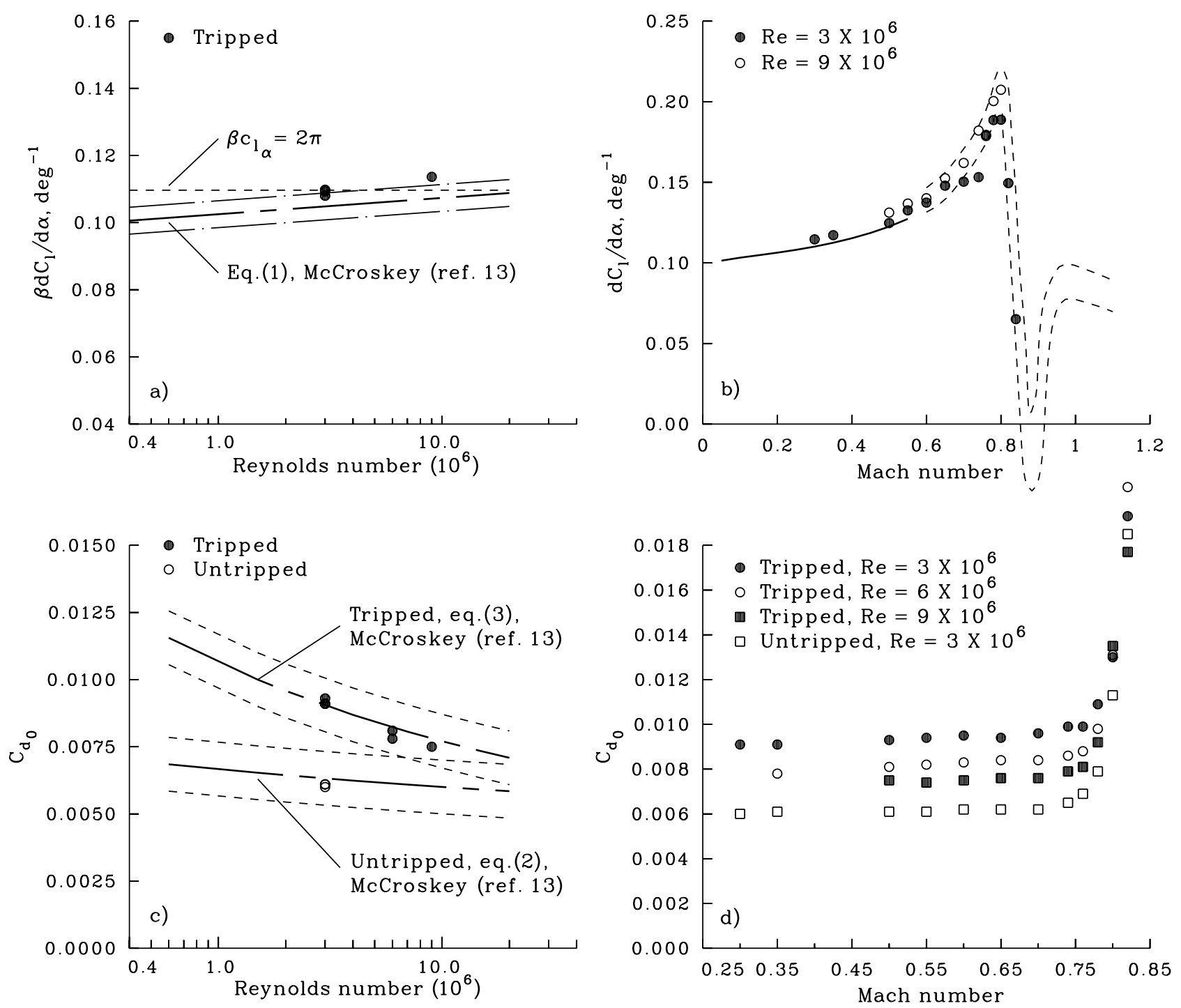

Figure 5. Primary NACA 0012 evaluation criteria used by McCroskey in reference 13; data from Harris (ref. 14). a) $\beta C_{l_{\alpha}}$ as a function of Reynolds number; fit based on group 1 data shown by equation (1); bounds are for group $2, M<0.55$. b) Liftcurve slope as a function of Mach number; solid curve is equation (1); dashed curve is best estimate of bounds for liftcurve slope at high Mach number. c) $C_{d_{0}}$ as a function of Reynolds number; equations (2) and (3) are best fits of tripped and untripped group 1 data; bounds are for group 2; $M<0.55$. d) $C_{d_{0}}$ as a function of Mach number.

for helicopter computations where tabular data are required over an extensive range of Mach numbers and angles of attack to include stall. The group 1 criteria were relaxed in establishing criteria for group 2. The tolerance was opened by a factor of eight for $\beta C_{l_{\alpha}}$ and a factor of five for $C_{d_{0}}$. For the NACA 0012, there were six group 2 datasets, and these provided a significantly greater range of Mach numbers and angles of attack. Notable among the group 2 tests were data obtained by Harris in the Langley 8-Foot Transonic Pressure Tunnel (ref. 14). These data extend from $M=0.30$ to $M=0.86$, and angles of attack to include stall.
McCroskey's approach to determining the best available airfoil data from multiple tests is probably suitable for any typical helicopter airfoil section, although confidence in the process is reduced when only a few datasets are available. This approach was the basis of Totah's evaluation (ref. 12) and also constitutes the basis of evaluation in this report. McCroskey's basic criteria are illustrated in figure 5, using the Harris data as an example. Figure 5a shows the dependency of $\beta C_{l_{\alpha}}$ on Reynolds number. The classical value for the lift-curve slope of $2 \pi$ is independent of Reynolds number, but the 
Table 4. UH-60A flight conditions for angle-of-attack and Mach number distributions (refs. 16, 17)

\begin{tabular}{cccc}
\hline \hline$\mu$ & $C_{W} / \sigma$ & $\rho$, slugs $/ \mathrm{ft}^{3}$ & $T, \operatorname{deg} \mathrm{F}$ \\
\hline 0.097 & 0.0795 & 0.00197 & 45.1 \\
0.144 & 0.0794 & 0.00199 & 45.8 \\
0.221 & 0.0794 & 0.00208 & 51.6 \\
0.300 & 0.0792 & 0.00205 & 52.7 \\
0.355 & 0.0798 & 0.00202 & 52.3 \\
\hline \hline
\end{tabular}

group 1 expression, equation (1), shows a slight increase with increasing Reynolds number. The group 2 bounds are shown in this figure, and it is seen that the Harris data are near the edge of the higher bound. Lift-curve slope is sensitive to the angle-of-attack corrections that are generally needed in porous-wall wind tunnels and the correction recommended by Harris,

$$
\Delta \alpha=-1.15 C_{n}
$$

is quite large, so the generally good agreement observed in figure $5 \mathrm{a}$ is welcome. The lift-curve slope as a function of Mach number is shown in figure $5 \mathrm{~b}$ and compared to the Harris data for two Reynolds numbers. The solid line in figure $5 \mathrm{~b}$ is the group 1 fit, equation (1). The dashed line is McCroskey's estimate of the bounds of the better NACA 0012 data obtained at high Mach numbers where regions of supersonic flow and shocks induce strong nonlinearities.

McCroskey separated the group 1 data into cases with either tripped or untripped boundary layers. Figure $5 \mathrm{c}$ shows the group 1 fits, equations (2) and (3), but the bounds are for group 2. The effect of Reynolds number on the drag coefficient is quite strong for turbulent (tripped) data, but less so for the laminar (untripped) data. The Harris data show good agreement with the group 1 results. The importance of Reynolds number is illustrated in figure $5 \mathrm{~d}$, which shows that the drag below $M=0.70$ is largely dependent upon Reynolds number and the effects of compressibility do not become important until higher Mach numbers are reached.

\section{ANGLE-OF-ATTACK AND MACH NUMBER DISTRIBUTIONS}

The experimental measurements discussed in this report extend over a range of angles of attack, Mach numbers, and Reynolds numbers. When assessing the adequacy of the test data, it is useful to estimate the angles of attack, Mach numbers, and Reynolds numbers that actually occur on the flight vehicle. Limited test data were obtained during flight experiments with a UH-60A aircraft in 1987 (ref. 15), and these data were used to examine blade vibratory and torsion loads by Bousman and Maier (refs. 16, 17) using the comprehensive analysis CAMRAD/JA (ref. 18). Calculations were made for five airspeeds using a free wake analysis, as described in table 4 . Because the blade was modeled with 18 aerodynamic panels and the aerodynamics were evaluated at every $15 \mathrm{deg}$ of blade azimuth, $2160 \alpha-M$ pairs were computed for the five airspeed conditions.

Figure 6 plots these $\alpha-M$ calculation pairs, with approximately 1320 pairs shown for the SC1095 and 840 pairs shown for the SC1094 R8. (Twenty-four $\alpha-M$ pairs are not shown for the SC1095 because they are outside the plot limits. All the unplotted pairs are at low Mach numbers, in no case greater than $M=0.06$.) What is observed in figure 6 is that the $\alpha-M$ pairs cluster together, with an angle-of-attack range of 8 to $12 \mathrm{deg}$ at $M=0.2$, decreasing to angles of attack close to 0 at $M=0.7$ or $M=0.8$. The clustering of the calculated values corresponds approximately to the airfoil maximum $L / D$.

An examination of figure 6 shows that the development of an adequate set of airfoil tables requires that the test envelope encompass the pairs shown here. Beyond the values shown, however, it is important also to obtain data at higher Mach numbers, corresponding to limit dive-speed conditions for the aircraft, as well as at higher angles of attack that define the airfoil stall limits.

Reynolds number varies directly with Mach number for a helicopter in flight

$$
R e=\frac{\rho c a}{\mu_{v}} M
$$

For sea level, standard day conditions, the constant of proportionality is 12.4 million. For the flight conditions in table 4 , this constant varies from 10.2 to 10.7 million. 
Table 5. Wind tunnels and airfoils for the ten experimental datasets.

\begin{tabular}{lllc}
\hline \hline Test & \multicolumn{1}{c}{ Wind tunnel } & \multicolumn{1}{c}{ Airfoils tested } & Reference \\
\hline Exp. 1 & UTRC Large Subsonic W. T. & SC1095 & 2 \\
Exp. 2 & UTRC Large Subsonic W. T. & SC1095 & 3 \\
Exp. 3 & OSU 6- by 22-Inch Transonic W. T. & SC1095, SC1094 R8 & 4 \\
Exp. 4 & NRC 12- by 12-Inch Icing W. T. & SC1095, SC1094 R8 & 5 \\
Exp. 5 & NSRDC 7- by 10-Foot Transonic W. T. & SC1095 & 6 \\
Exp. 6 & Langley 6- by 28-Inch Transonic W. T. & SC1095, SC1094 R8 & 7 \\
Exp. 7 & Ames 2- by 2-Foot Transonic W. T. & SC1095 & 8 \\
Exp. 8 & Ames 11- by 11-Foot Transonic W. T. & SC1095, SC1094 R8 & 9 \\
Exp.9 & Ames 7- by 10-Foot Subsonic W. T. & SC1095 & 10 \\
Exp. 10 & UMd 8- by 11-Foot Subsonic W. T. & SC1095, SC1094 R8 & 11 \\
\hline \hline
\end{tabular}
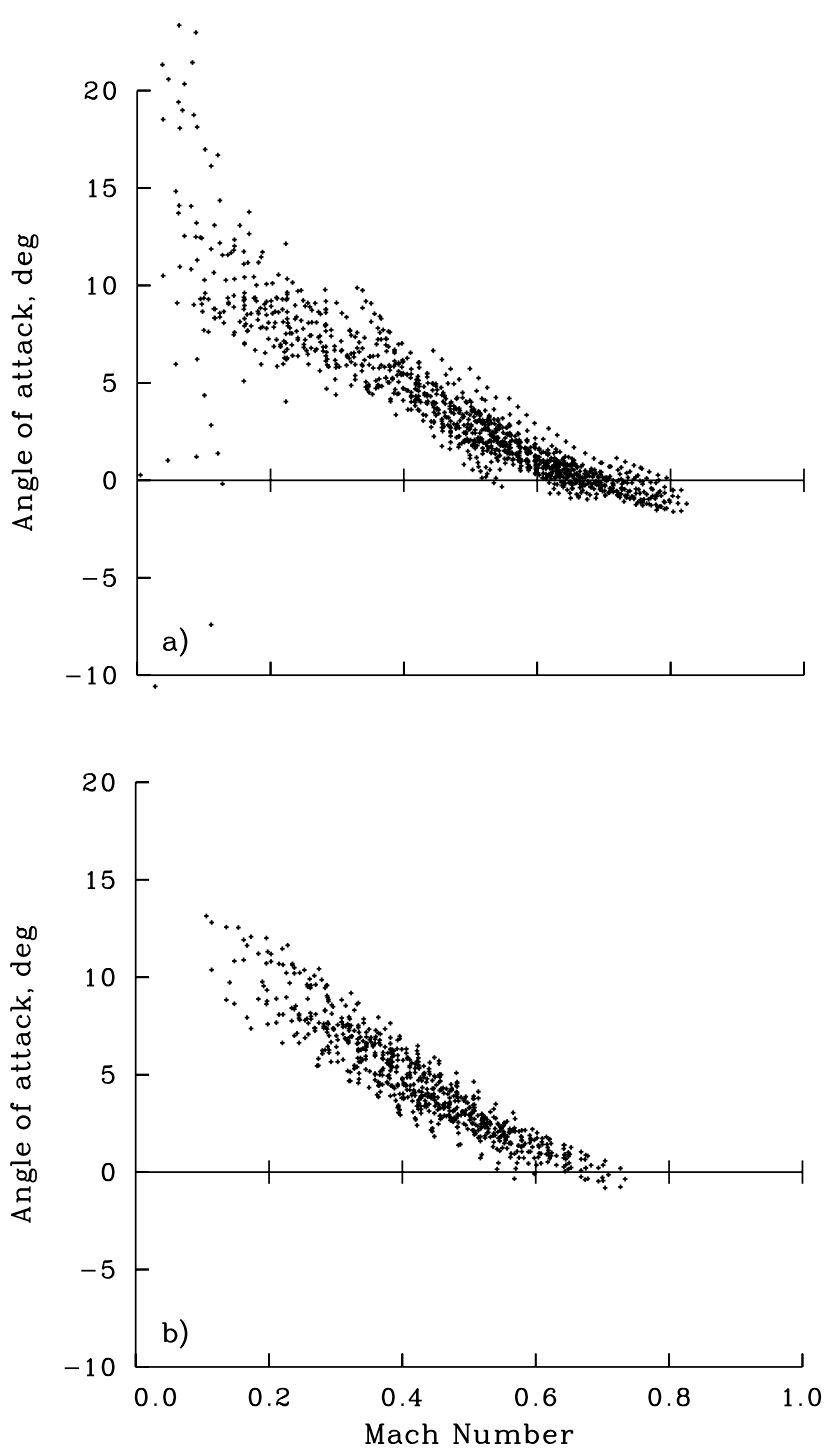

Figure 6. Calculated angles of attack and Mach numbers for UH-60A airfoils at five airspeeds (refs. 16, 17).

a) SC1095; b) SC1094 R8.

\section{EXPERIMENTAL DATASETS}

The ten experimental datasets that contain airfoil coefficient data for either the SC1095 airfoil or both the SC1095 and SC1094 R8 airfoils are examined here. The ten datasets are summarized in table 5. The terminology "experiment 1," "experiment 2," and so forth, follows Totah (ref. 12).

\section{Experiment 1 (UTRC Large Subsonic Wind Tunnel)}

The SC1095 airfoil was tested in the 8-foot test section of the UTRC Large Subsonic Wind Tunnel in July and August 1973 (ref. 2). No data were obtained for the SC1094 R8 section. The data from this test are proprietary to the United Technologies Corporation and have not been reported in the open literature. For these tests an insert was used in the test section, referred to as the Two-Dimensional Channel (TDC). General characteristics of this test are shown in figure 7. The outline of the normal octagonal 8-foot section for the UTRC tunnel is shown as a dashed line.

The maximum Mach number obtained in this test was 0.75 , which covers most of the operational range of the UH-60A, but leaves some uncertainty for the aerodynamic characteristics near the blade tip on the advancing side. The TDC shown in figure 7 has walls about 4.5 in. thick that contain support bearings for the airfoil and linkages that connect the airfoil to the wind tunnel balance. Teflon seals were used between the airfoil and the channel side walls to avoid leakage effects. The measured balance forces were transferred to the quarter chord of the airfoil to provide the section lift, drag, and moment. In addition to these balance measurements, a total pressure survey rake was installed downstream of the airfoil to measure the wake deficit to allow a 

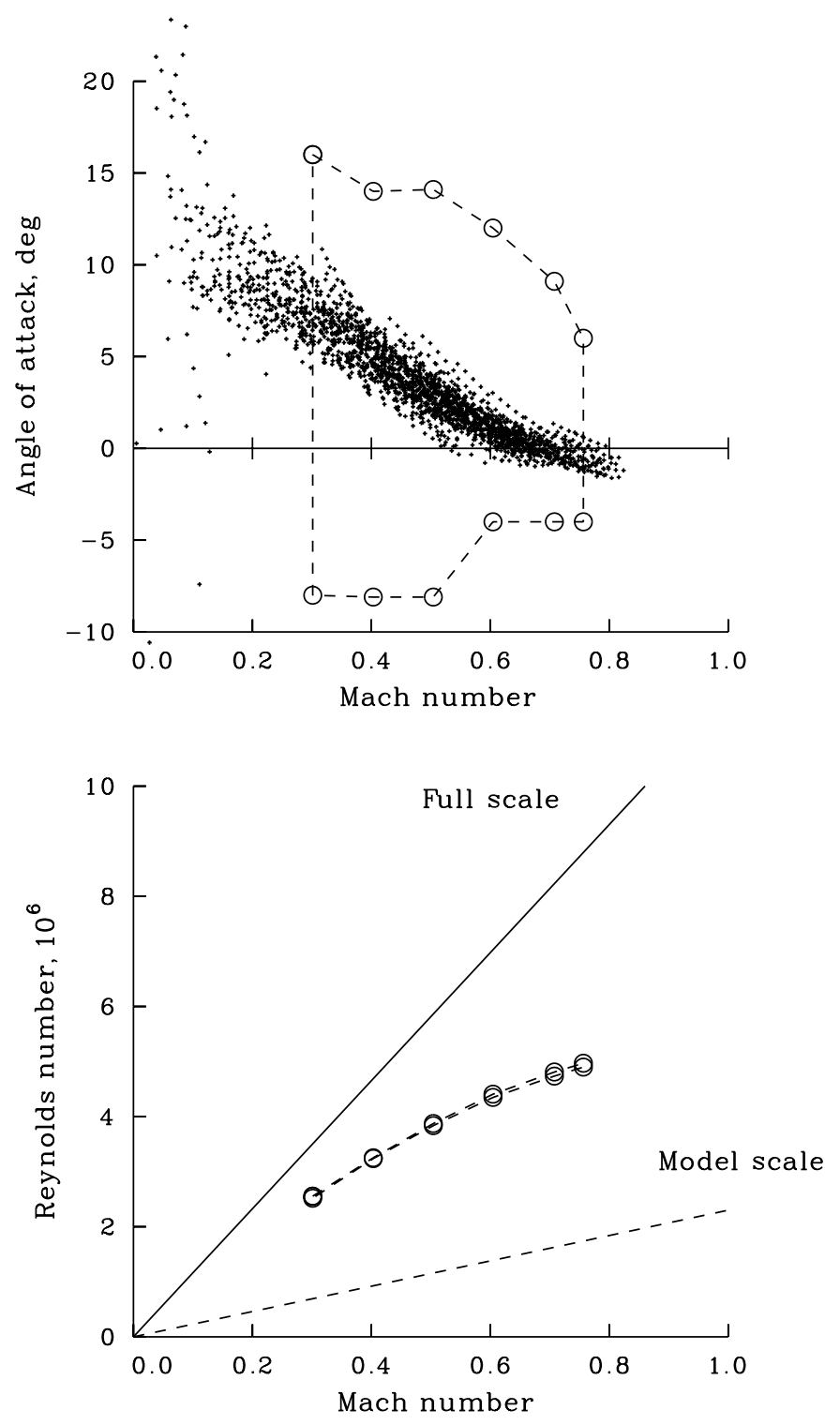

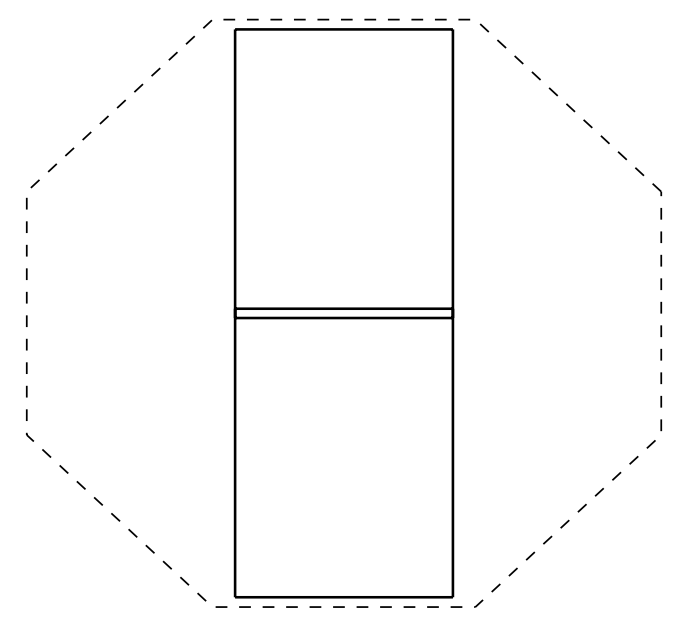

Wind tunnel test parameters

$\mathrm{c}=16.0 \mathrm{in}$.

$\mathrm{b} / \mathrm{c}=2.06$

$\mathrm{h} / \mathrm{c}=5.80$

Porosity $=0.0 \%$

Figure 7. Test conditions for experiment 1; TDC in the UTRC Large Subsonic Wind Tunnel (ref. 2).

determination of drag. The survey probes were located 0.125 in. apart, which is a vertical spacing of about 8.2 percent of the airfoil thickness. The wake survey rig was mounted 1.9 chords behind the airfoil trailing edge. The measurements examined here were made without a boundary layer trip.

The Mach number, Reynolds number, dynamic pressure, angle of attack, and section forces and moments were corrected for wall effects based on the standard compressibility corrections for solid wall tunnels (ref. 19). The effects of these corrections are shown in figure 8 . Small changes are seen for the lift-curve slope multiplied by the Prandtl-Glauert correction, as seen in figure $8 \mathrm{a}$. This figure also includes the NACA 0012 best fit from
McCroskey (ref. 13), equation (1), and McCroskey's group 2 bounds. It is observed that the effects of the wall corrections are small; this is not unexpected because a key factor in the reference 19 corrections is the $h / c$ ratio, which is nearly 6 for this test. The angle-of-attack change for these data is

$$
\Delta \alpha \cong 0.056 C_{l}
$$

which, at the greatest lift coefficients, is less than $0.1 \mathrm{deg}$. The change in lift-curve slope with Mach number is shown in figure $8 \mathrm{~b}$ and is compared to the NACA 0012 characteristics shown previously in figure 5. The effects of the wall corrections are generally small. 

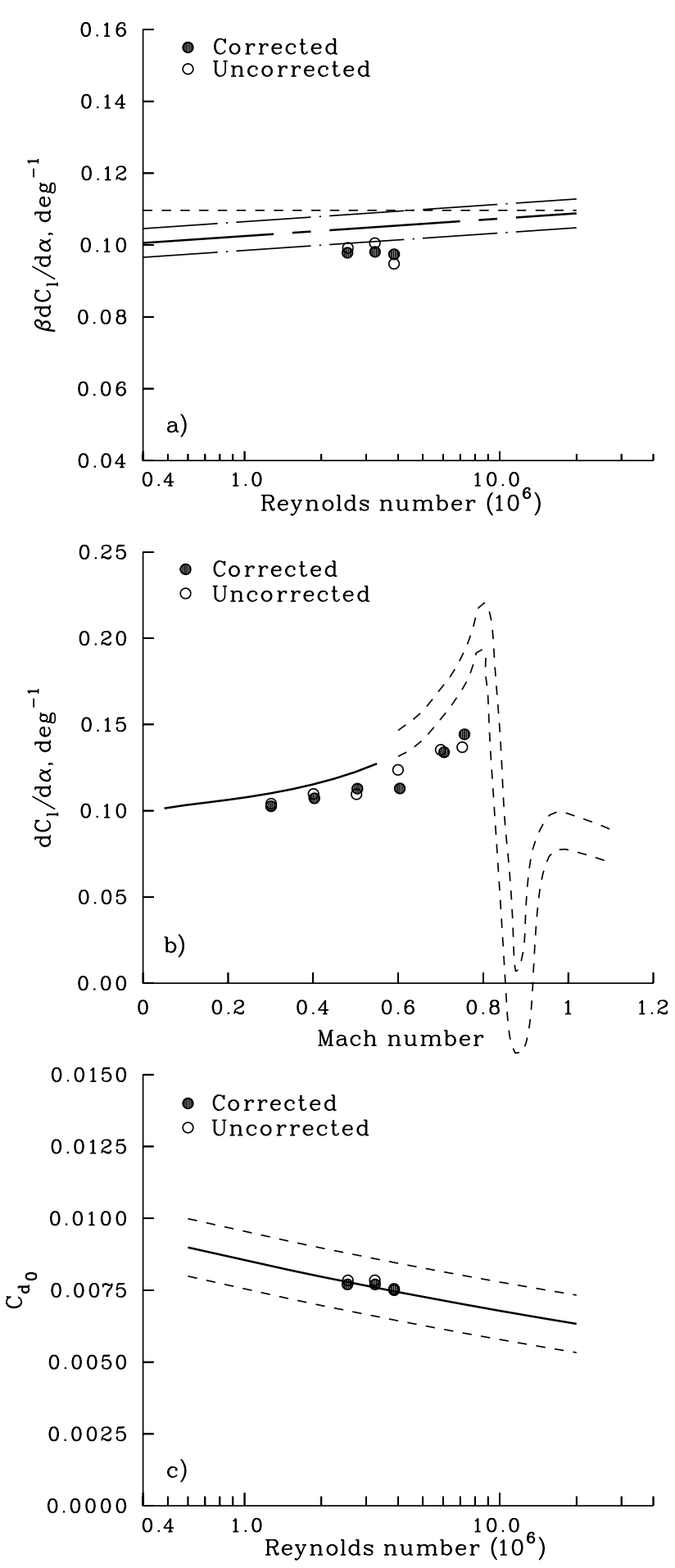

Figure 8. Comparison of corrected and uncorrected data for Experiment 1. $\beta C_{l_{\alpha}}$ and $C_{l_{\alpha}}$ reference lines for NACA 0012 (ref. 13). $C_{d_{0}}$ fit for SC1095 airfoil, with group 2 bounds from reference 13.
The SC1095 is reduced in thickness compared to the NACA 0012 section, and the zero-lift drag coefficient is expected to be lower. Figure 8c compares the corrected and uncorrected drag coefficients to the equation

$$
C_{d_{0}}=\frac{0.034}{\operatorname{Re}^{0.1}}
$$

which differs from both of McCroskey's expressions, equations (2) and (3). This form of Reynolds number dependency is discussed later in this report when the drag data for all the experiments are compared. The bounds shown in figure 8c, however, are McCroskey's group 2 bounds. The wall corrections for this experiment show little influence on the drag coefficient. The corrected data from reference 2 are used for all evaluations in this report.

\section{Experiment 2 (UTRC Large Subsonic Wind Tunnel)}

The SC1095 airfoil was tested in the same wind tunnel as that used for experiment 1 , except that the airfoil was mounted on a test rig that spanned the full 8-foot octagonal section of the tunnel (ref. 3). No data were obtained for the SC1094 R8 section. The full-span test rig was referred to as the Tunnel Spanning Wing (TSW). As with the experiment 1, the test data are proprietary to United Technologies Corporation and have not been published. General characteristics of this test are illustrated in figure 9. With the use of the TSW, the spanto-chord ratio, $b / c$, is substantially increased over that for experiment 1 . The height-to-chord ratio, $h / c$, is increased slightly. Note that the tabulations for $b / c$ and $h / c$ in reference 12 for this experiment are incorrect.

The methods used to measure the lift, drag, and pitching moment were substantially changed in experiment 2 compared to the TDC used in experiment 1 . A metric section was located at the TSW centerline, a half-chord in width. This metric section was supported with 2 six-component balances, which measured the lift, drag, and pitching moment. One chord to one side of the TSW centerline, on the nonmetric section, a chordwise array of pressure transducers was installed, with 16 transducers mounted on the upper surface and 9 on the lower surface. The pressures were integrated to provide lift, drag (pressure), and pitching moment. Standard drag measurements were made with a wake survey rig, as well as using drag estimates from the balance and the integration of the pressure measurements. It is assumed that the same wake survey rig was used for experiment 2 as for experiment 1, although this is not discussed in reference 3. Measurements were made without a boundary layer trip. There is no discussion in reference 3 of the use of wind tunnel wall correction methods, and the data are used as published for the present evaluation. 

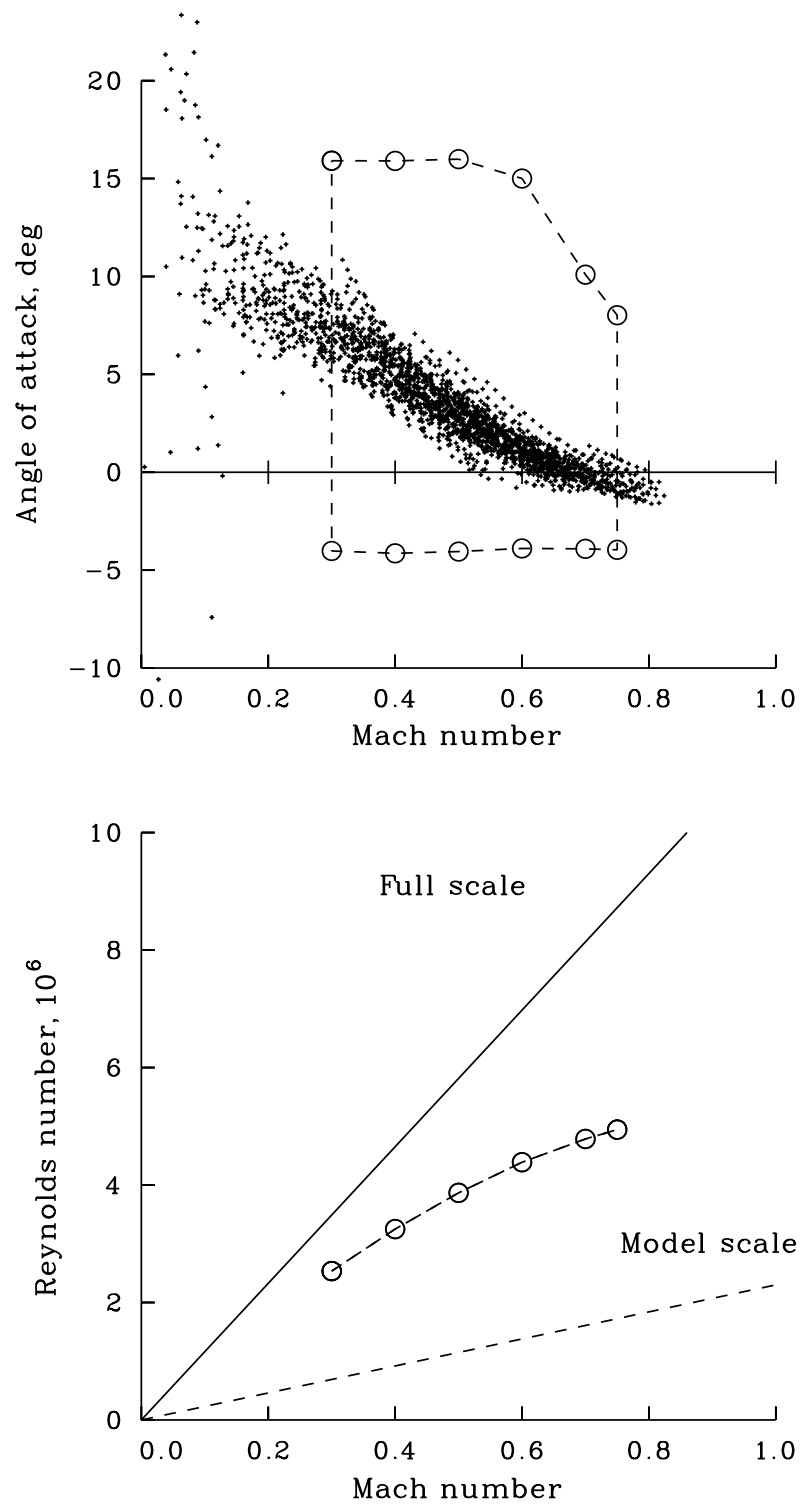

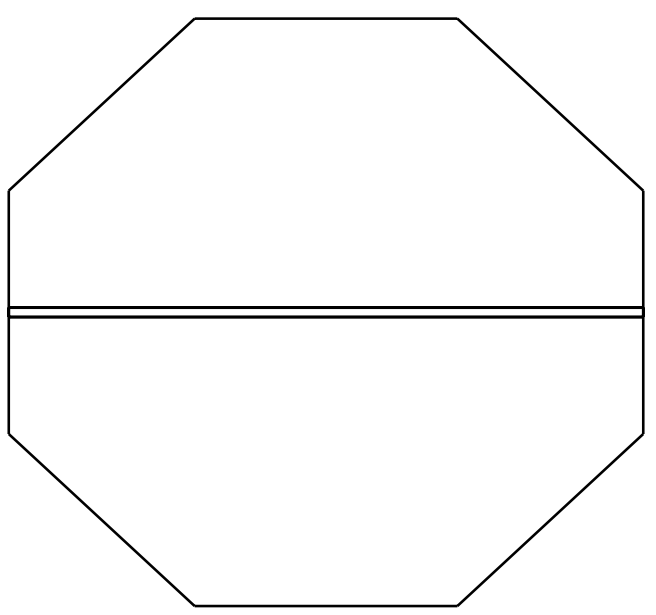

Wind tunnel test parameters

$\mathrm{c}=16.0 \mathrm{in}$.

$\mathrm{b} / \mathrm{c}=6.00$

$\mathrm{h} / \mathrm{c}=6.00$

Porosity $=0.0 \%$

Figure 9. Test conditions for experiment 2; TSW in the UTRC Large Subsonic Wind Tunnel (ref. 3).

\section{Experiment 3 (Ohio State University Transonic 6- by 22-Inch Wind Tunnel)}

Both the SC1095 and SC1094 R8 airfoils were tested in the 6- by 22-Inch Transonic Wind Tunnel at Ohio State University (ref. 4). The wind tunnel test report is proprietary to the United Technologies Corporation. Basic features of this test are shown in figure 10 .

The Ohio State tunnel is a blowdown facility, and Mach and Reynolds numbers can be independently varied. The Mach number is set by using a choke that is mounted in the diffuser. The test range for Mach number is generally from 0.2 to 1.1 . Reynolds number is controlled by setting the total pressure in the stagnation chamber. For the 6.0-inch model chord tested, Reynolds number can be varied from about 1 to 3 million at low Mach numbers and to 3 to 12 million at high Mach numbers. For these tests, the Reynolds number was set to provide values appropriate for the midspan of the fullscale blade. There was some variation in the Reynolds number during the test program, and this is indicated in figure 10 by upper and lower boundaries. Data were obtained at Mach numbers up to 0.85 , covering the full range of Mach numbers expected in level flight (see fig. 10). Each test point was a separate model run, and the 

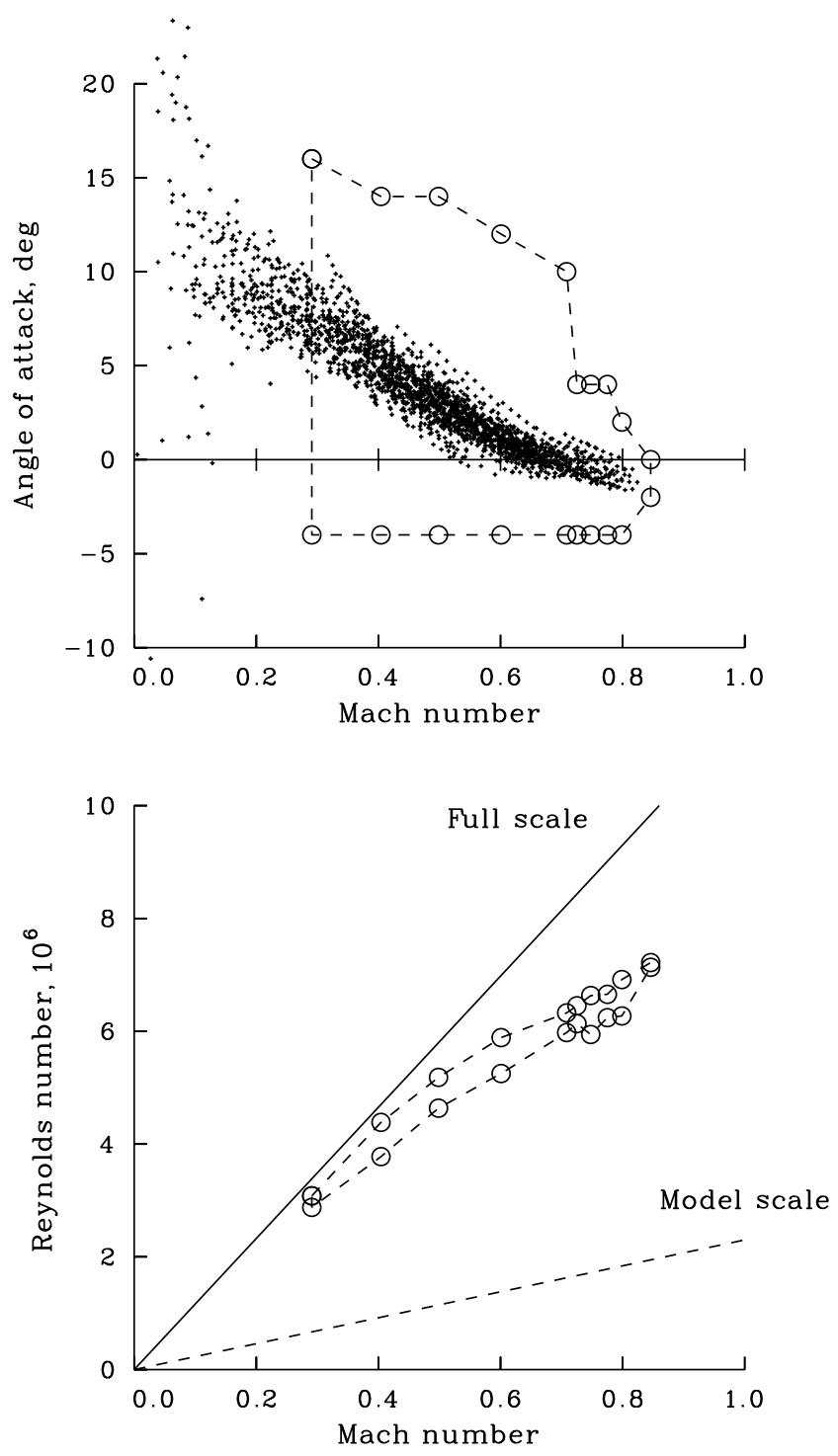

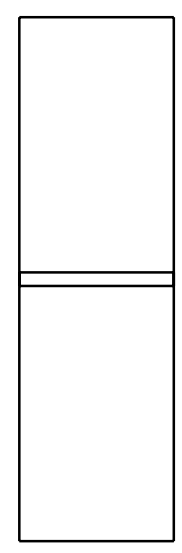

Wind tunnel test parameters $\mathrm{c}=6.0 \mathrm{in}$.

$\mathrm{b} / \mathrm{c}=1.00$

$\mathrm{h} / \mathrm{c}=3.67$

Porosity $=10.0 \%$

Figure 10. Test conditions for experiment 3; Ohio State University 6- by 22-Inch Transonic Wind Tunnel (ref. 4).

angle of attack was set manually between runs. The side walls on this tunnel are solid, but the upper and lower walls are perforated with a porosity of 10 percent. Plenums behind the upper and lower walls are connected to the mixing zone downstream of the test section to reduce interference effects.

Surface pressures were measured on the airfoils at 42 locations. The pressures were integrated to provide lift and pitching moment. Wake-deficit measurements were obtained with a traversing probe that sampled continuously as it moved behind the airfoil. The probe was located about 1.7 chords aft of the airfoil trailing edge. Most of the test data were obtained without a boundary layer trip. However, for a reduced set of Mach numbers, tripped data were obtained at 0 angle of attack and for one or two angles of attack near the maximum lift coefficient. The trip that was applied was an adhesive tape that extended equally on the upper and lower surfaces and tripped the boundary layer at the aft-facing step of the adhesive strip. The measured angle of attack for the SC1094 R8 airfoil was referred to the chordline of the actual airfoil rather than the chordline of the SC1095, so none of these data have been adjusted.

The only wall corrections made to the data were for angle of attack. The angle of attack was corrected by

$$
\Delta \alpha=-0.16 C_{l}
$$



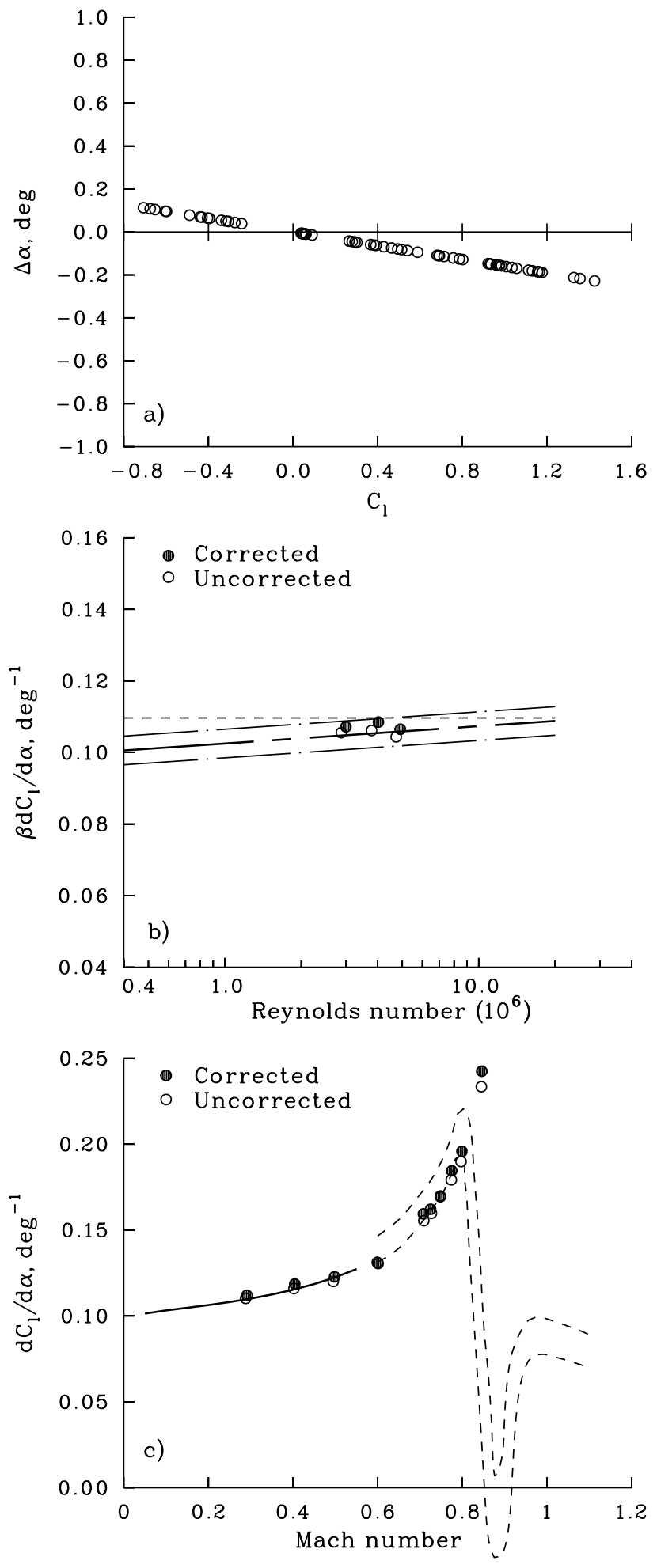

Figure 11. Comparison of corrected and uncorrected data for experiment 3. $\beta C_{l_{\alpha}}$ and $C_{l_{\alpha}}$ reference lines for NACA 0012 (ref. 13). based on previous experimental measurements made in this facility (ref. 4). The effect of these corrections is shown in figure 11. These corrections are quite small and, although the uncorrected lift data show slightly better agreement with equation (1), the difference appears within the data scatter. The corrected data published in reference 4 are used for the evaluations in this report.

\section{Experiment 4 (NRC 12- by 12-Inch Icing Wind Tunnel)}

Both the SC1095 and SC1094 R8 airfoils were tested in Canada's National Research Council (NRC) 12- by 12-Inch Icing Wind Tunnel, which is located at the NRC wind tunnel complex outside of Ottawa (ref. 5). The data report is restricted by NASA to U.S. Government agencies and their contractors. The basic properties of the test are shown in figure 12 .

The NRC Icing Tunnel was designed to provide test data under icing conditions, and most of the data in reference 5 are for various cases of icing on the airfoils. In the present report, only baseline data obtained in icefree conditions are examined. The NCR Icing Tunnel is a closed-return wind tunnel, and data were obtained for Mach numbers up to about 0.7. The associated Reynolds number tested is equivalent to model scale rather than full scale. The side walls for this tunnel are solid, but based on testing in the Ohio State University wind tunnel (ref. 4), the floor and ceiling were modified to provide 10-percent porosity and the floor and ceiling plenums were connected in the same manner as for reference 4.

The testing reported in reference 5 was accomplished in three phases. The data in phases 1 and 3 were obtained in the NRC tunnel, whereas the data in phase 2 were obtained in the OSU Transonic Wind Tunnel and, in this sense, duplicate data to that obtained in reference 4. The examination in this report is limited to data obtained in phase 1 in the NRC Icing Tunnel. Note that in reference 12, Totah evaluated the phase 2 data from the OSU test, rather than the data from the NRC tunnel.

Forty pressure transducers were installed on the airfoil upper and lower surfaces, and these pressures were integrated to provide the section lift and pitching moment. A wake survey rig was used to measure the total pressure deficit behind the airfoil and thereby provide an estimate of airfoil drag. No boundary layer trip was used for these tests. The data obtained on the SC1094 R8 airfoil were referenced to the actual chordline of that airfoil rather than the SC1095 airfoil's chordline. Therefore, no corrections have been made to the measurements. Turbulence levels 

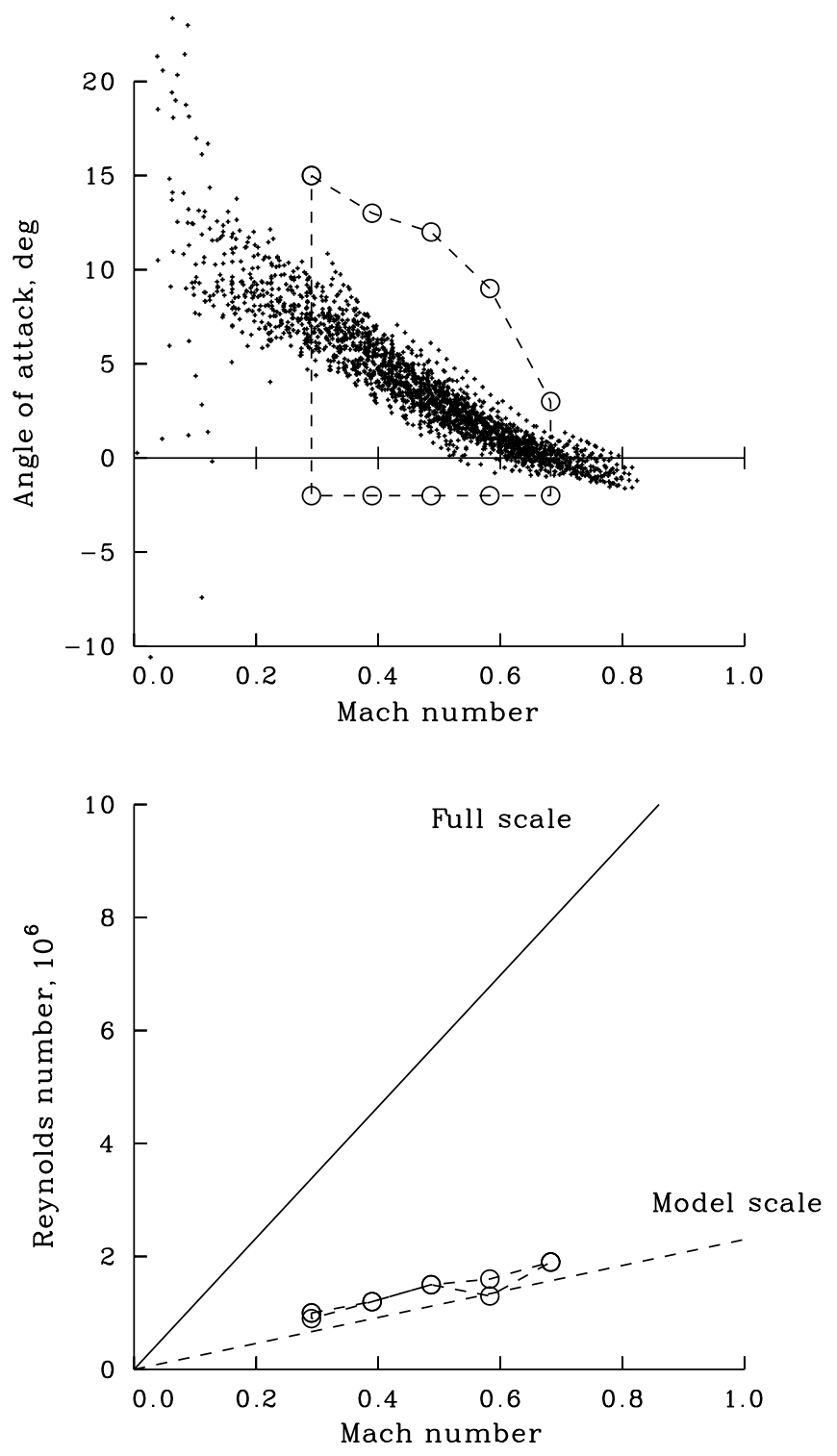

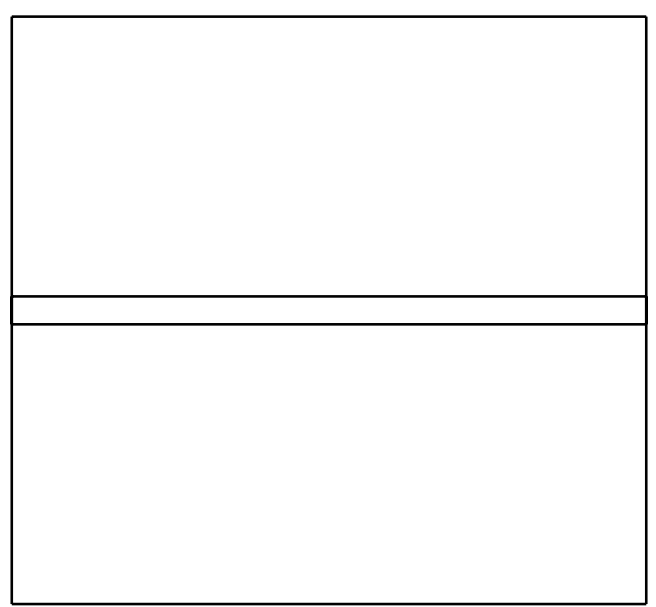

Wind tunnel test parameters

$$
\begin{aligned}
& c=6.0 \mathrm{in} . \\
& b / c=2.00 \\
& h / c=2.00 \\
& \text { Porosity }=10.0 \%
\end{aligned}
$$

Figure 12. Test conditions for experiment 4; NRC (Canada) 12- by 12-Inch Icing Wind Tunnel (ref. 5).

were measured in the NRC wind tunnel and ranged from 1.6 to 2.0 percent. These levels are approximately 4 times higher than the turbulence levels measured in the OSU tunnel. No wall corrections were made to angle of attack or the measured coefficient data.

\section{Experiment 5 (NSRDC 7- by 10-Foot Transonic Wind Tunnel)}

The SC1095 airfoil section was tested in the Naval Ship Research and Development Center (NSRDC) 7- by 10-Foot Transonic Wind Tunnel in 1973 (ref. 6). The basic features of this test are illustrated in figure 13. There are no restrictions on these data.
The NSRDC transonic tunnel is a pressurized tunnel that can obtain Mach numbers as high as 1.17. As indicated in figure 13, the maximum Mach number tested was about 1.08, and this extends the range of Mach number data available for this airfoil. The Reynolds number for these tests varied between 1.5 and 2.0 million, which is equivalent to model scale. Limited data were obtained at a Reynolds number just under 4.0 million, but these data are not examined here. A tunnel spanning rig was used for these tests; it was similar to the TSW of reference 3 . The wing section chord was identical to the reference 3 tests, and a center metric section, supported on two balances, was used in the same fashion as for the tests in the UTRC Large Subsonic Wind Tunnel. 

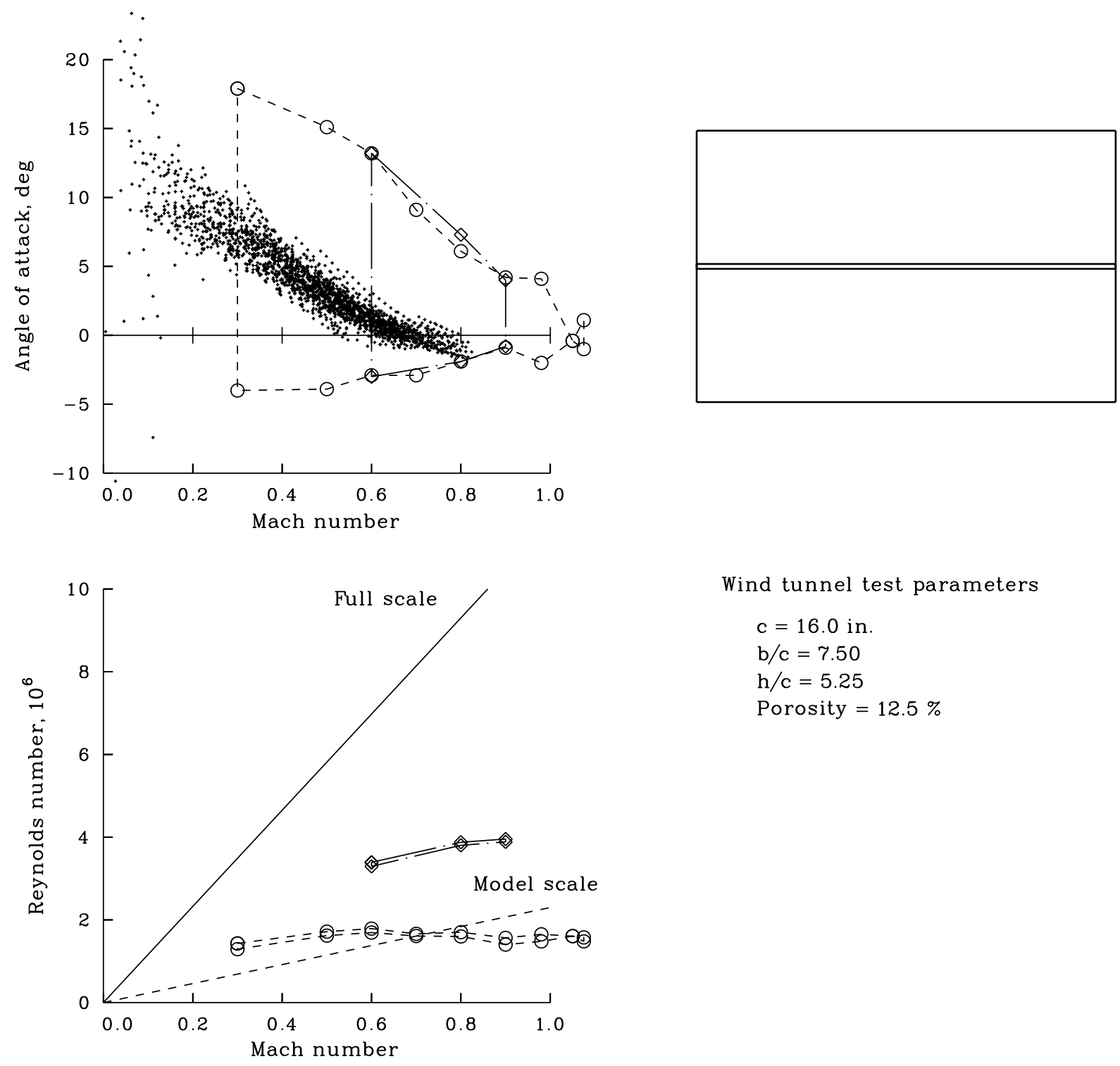

Wind tunnel test parameters

$\mathrm{c}=16.0 \mathrm{in}$.

$\mathrm{b} / \mathrm{c}=7.50$

$\mathrm{h} / \mathrm{c}=5.25$

Porosity $=12.5 \%$

Figure 13. Test conditions for experiment 5; NSRDC 7- by 10-Foot Transonic Wind Tunnel (ref. 6).

However, the span of the wing support was extended for the NSRDC tests to allow the rig to extend through the tunnel side walls. A second change from reference 3 is that the chordwise array of pressure transducers was installed on the metric section at the tunnel centerline, instead of being offset from the center as in reference 3 . Support struts were added to the tunnel spanning rig out of concern for the load capacity of the rig at high Mach numbers and angles of attack. Data with the struts were obtained at eight Mach numbers, whereas data with the struts off were obtained at four Mach numbers, and only one of these latter tests included wake-survey data. No significant difference was observed for the data without the struts, and these data are not examined further in the present work.

The metric section of the airfoil was supported by two balances as in reference 3 , and these were used to measure the section lift, drag, and pitching moment. The gap between the metric section and the rig was about $0.050 \mathrm{in}$. wide and was sealed with a strip of 50 durometer neoprene. Eighteen pressure taps were on the upper surface of the airfoil, and 9 were on the lower surface. These pressures were integrated to provide lift and pitching moment. Additional taps were located one chord to the left and right of the metric section to provide 

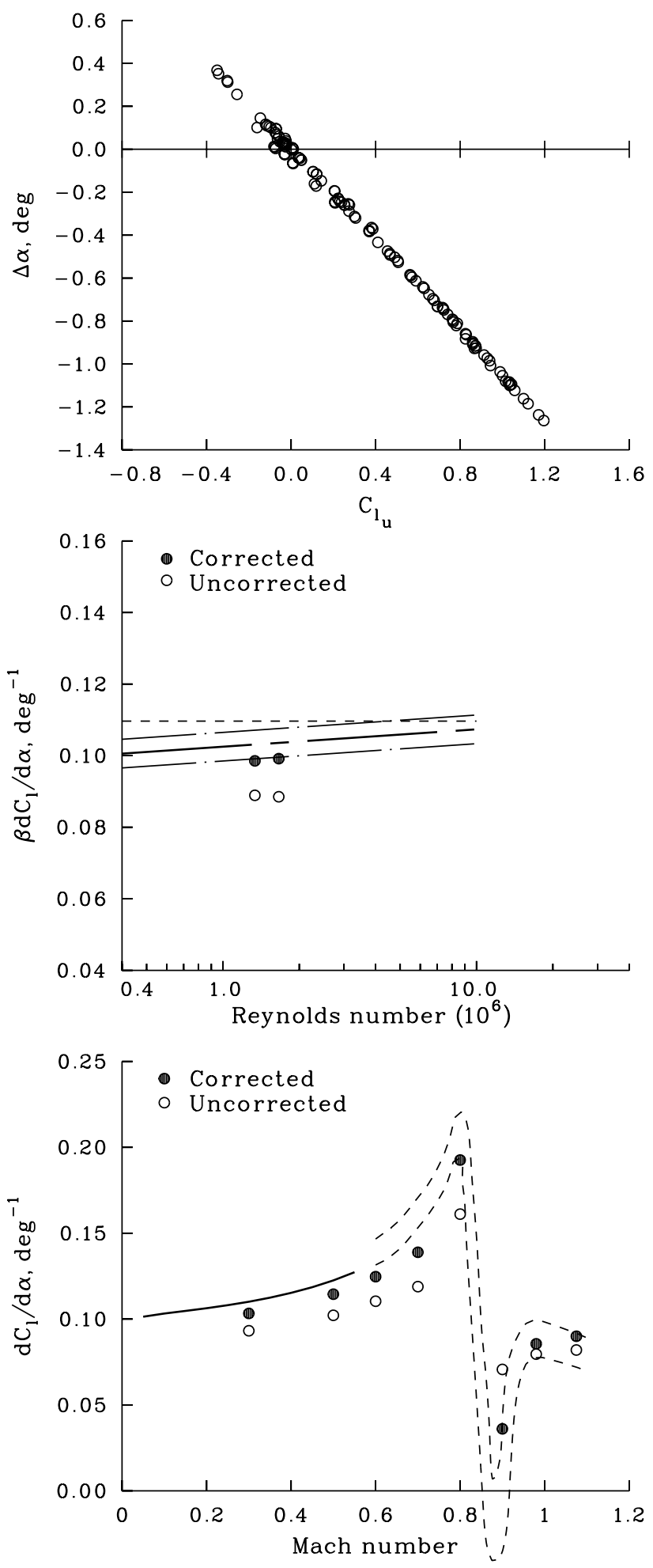

Figure 14. Comparison of corrected and uncorrected data for experiment 5. $\beta C_{l_{\alpha}}$ and $C_{l_{\alpha}}$ reference lines for NACA 0012 (ref. 13). information on the loading uniformity across the center of the rig span. No boundary layer trip was used for these tests. The wake deficit was measured with a moving total pressure probe that went from 1.1 chords above the airfoil midplane to 0.5 chord below the midplane in about 8 seconds.

The top and bottom walls of the NSRDC wind tunnel are slotted, and they had an effective porosity of 12.5 percent for these tests. The model blockage was about 2.3 percent, which is quite low, and it was estimated that the lift, drag, and pitching moment coefficient data errors were less than 1 percent, 0.5 percent, and 4 percent, respectively. Suitable angleof-attack wall corrections have not been established for this tunnel, so these data were not corrected. However, it was noted that porosity can have a substantial influence on the actual angle of attack and, based on reference 20, an angle-of-attack correction was suggested

$$
\Delta \alpha=\delta_{0}\left(\frac{c}{h}\right) C_{l}+\delta_{1}\left[\left(\frac{c}{h}\right)^{2}\left(\frac{1}{1-M^{2}}\right)\left(\frac{1}{4} C_{l}+C_{m}\right)\right]
$$

where $\delta_{0}=-0.1$ and $\delta_{1}=0.055$ for 12.5 -percent porosity. The effect of this correction is examined in figure 14; it is observed that the angle-of-attack correction is quite large

$$
\Delta \alpha=-1.04 C_{l_{u}}
$$

The lift-curve slope for the uncorrected data is well outside of the group 2 boundaries, as shown in figure 14, but with the angle-of-attack correction, the data fall within the bounds. Based on this improvement, the experiment 5 angle-of-attack data have been corrected before comparing these results with the other experiments.

\section{Experiment 6 (NASA Langley 6- by 28-Inch Transonic Wind Tunnel)}

The SC1095 and SC1094 R8 airfoils were both tested in the NASA Langley 6- by 28-Inch Transonic Wind Tunnel (ref. 7). The data obtained are unrestricted. The basic features of the test are illustrated in figure 15 .

The Langley 6- by 28-Inch Transonic Wind Tunnel is a blowdown tunnel with a slotted floor and ceiling and variable stagnation pressure. The tunnel stagnation pressure was chosen to provide two sets of Reynolds number data, one valid for full scale and the other for model scale. Testing was accomplished at Mach numbers up to 0.88 . 

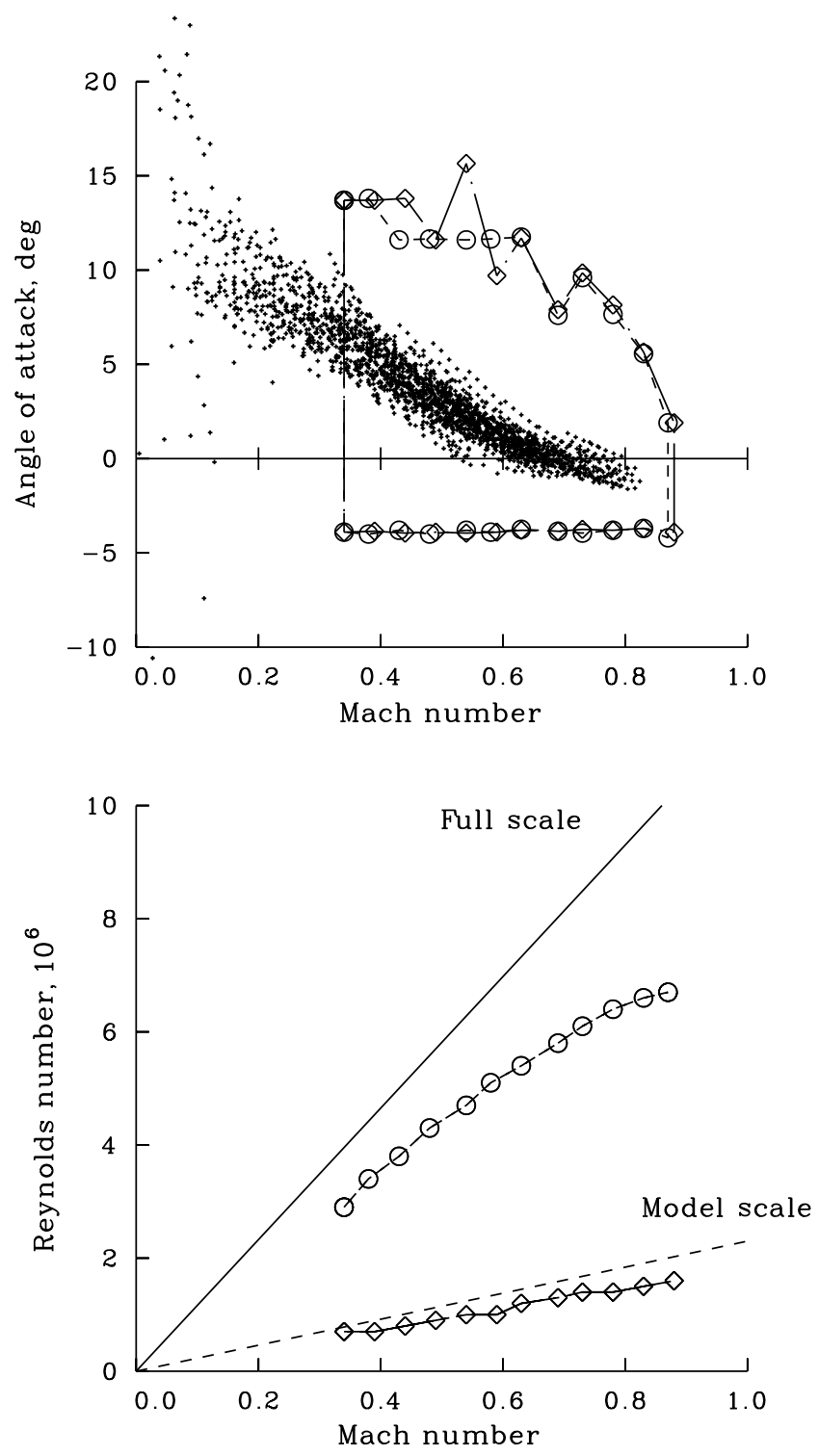

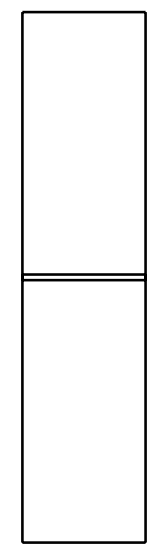

Wind tunnel test parameters

$$
\begin{aligned}
& c=3.1 \mathrm{in} . \\
& \mathrm{b} / \mathrm{c}=1.94 \\
& \mathrm{~h} / \mathrm{c}=9.03 \\
& \text { Porosity }=5.0 \%
\end{aligned}
$$

Figure 15. Test conditions for experiment 6; NASA Langley 6- by 28-Inch Transonic Wind Tunnel (ref. 7).

The basic SC1095 and SC1094 R8 airfoil sections were modified by adding a trailing-edge tab $0.03 c$ long. The increased chord reduced the airfoil thickness ratio from 9.5 to 9.1 percent for the $\mathrm{SC} 1095$ and from 9.4 to 9.0 percent for the SC1094 R8. The tabs were reflexed by -3 deg to reduce the pitching moment. This configuration is similar to the way these airfoils are used on the S-76 helicopter, but differs from how the airfoils are employed on the UH-60A.

Approximately 22 pressure orifices were used on both the upper and lower surfaces of both airfoils. The pressures were integrated to provide the lift and pitching moment coefficients. The drag coefficient was determined by a wake survey rig. No boundary layer trip was used.

No corrections were made to the lift, drag, and pitching moment data. However, the angle of attack was corrected by

$$
\Delta \alpha=-0.6296 C_{n}
$$

Figure 16 shows the corrected data of reference 7 plus uncorrected data that have been calculated by removing the angle-of-attack correction based on equation (11). Only the high Reynolds number results are shown in the figure. Based on comparisons with McCroskey's expression, 


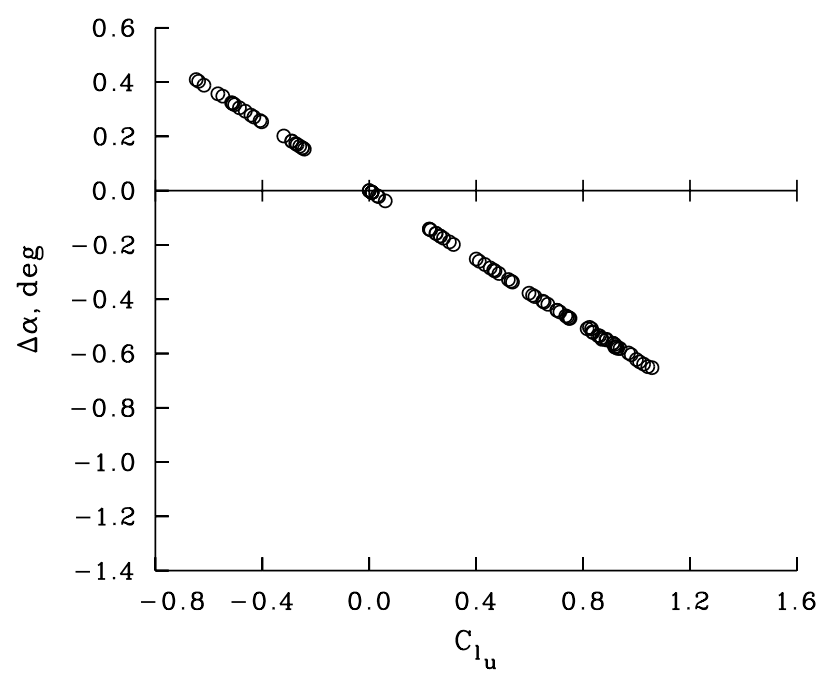

equation (1), the angle-of-attack correction provides more accurate results. All comparisons used in this report are based on the corrected data as published in reference 7 . However, the SC1094 R8 data in reference 7 were referred to the SC1095 mean chordline instead of the actual chordline and the angle-of-attack data have been adjusted by -1 deg so that they are referenced to the actual chordline of this airfoil.

The use of the reflexed tab on the two airfoils will influence some of the airfoil properties.

Conventional wisdom (ref. 21) holds that:

1) a reflexed tab will reduce camber and hence $C_{l_{\max }}$,

2) the angle of attack at zero lift, $\alpha_{0}$, will be reduced with reflex,

3) there is a rearward shift in aerodynamic center,

4) the center of pressure and, hence, pitching moment is significantly changed, and

5) for reflex angles less than $3 \mathrm{deg}$, there is no effect on drag.

Reference 21 includes measured airfoil properties for four airfoils that were tested with and without a deflected or reflexed tab (see table 6). These data have been used to evaluate the influence of the tab on the liftcurve slope, $\beta C_{l_{\alpha}}$, and drag, $C_{d_{0}}$, i.e., the two key parameters used by McCroskey as the basis for his assessment. All differences between the two tab positions for these airfoil pairs were within the data scatter and, in this restricted sense, there is no effect of a reflexed tab on these primary parameters. However, as noted previously, other airfoil properties are influenced by tab reflex, and they require correction before these data can be compared with the other datasets. The three properties that require correction for tab reflex are the maximum lift coefficient, the angle of attack at zero lift, and the pitching moment. Figure 17 shows the derivatives calculated for these three characteristics, based on the data summarized in reference 21. The derivatives are shown as a function of tab length.

Table 6. Deflected tab airfoil tests reported in reference 21 .

\begin{tabular}{lccc}
\hline \hline \multicolumn{1}{c}{ Airfoil } & $\begin{array}{c}\text { Tab } \\
\text { length }\end{array}$ & \multicolumn{2}{c}{ Tab deflection, } \\
deg & \\
& & Reference & Reflex \\
\hline NACA 0012 & $0.037 \mathrm{c}$ & 0.0 & -3.0 \\
V23010-1.58 & $0.040 \mathrm{c}$ & 0.0 & -3.0 \\
VR-7 & $0.050 \mathrm{c}$ & 0.0 & -3.1 \\
VR-7 & $0.050 \mathrm{c}$ & 0.0 & -5.9 \\
V43012-1.58 & $0.100 \mathrm{c}$ & 0.0 & -6.0 \\
\hline \hline
\end{tabular}




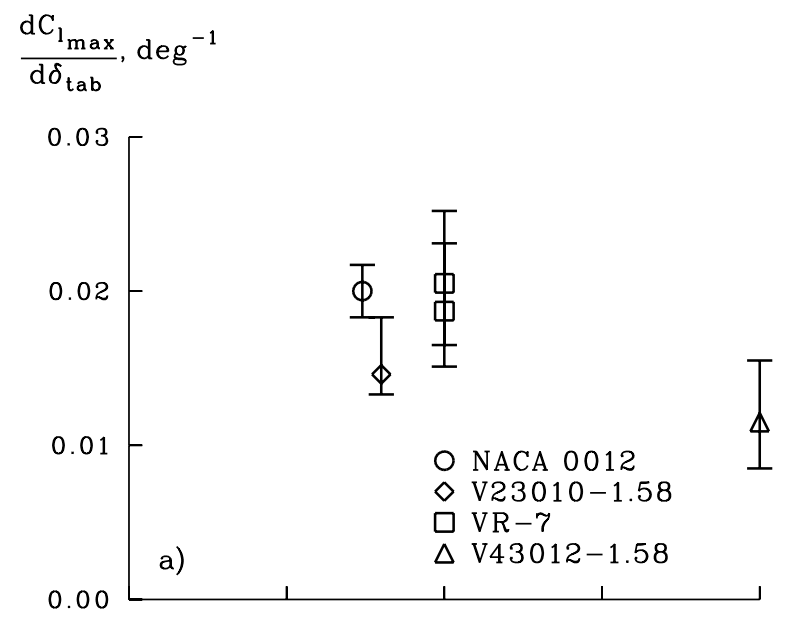

$\frac{\mathrm{d} \alpha_{0}}{\mathrm{~d} \delta_{\mathrm{tab}}}, \mathrm{deg}^{-1}$

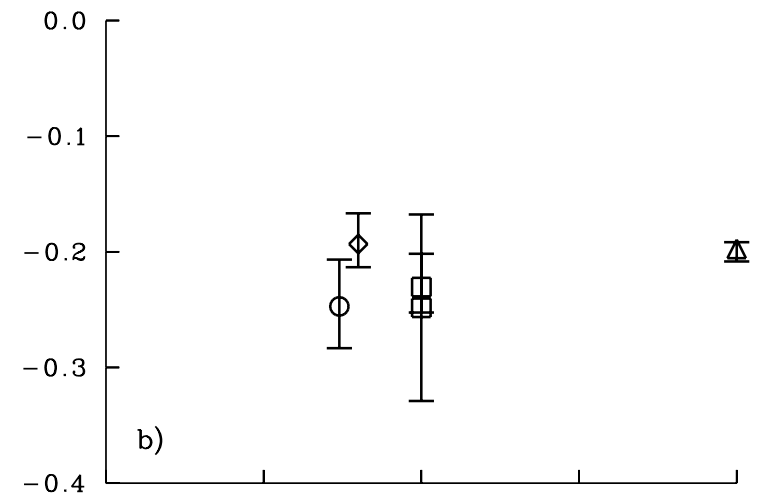

$\frac{\mathrm{dC}}{\mathrm{d} \delta_{\mathrm{tab}}}, \mathrm{deg}^{-1}$

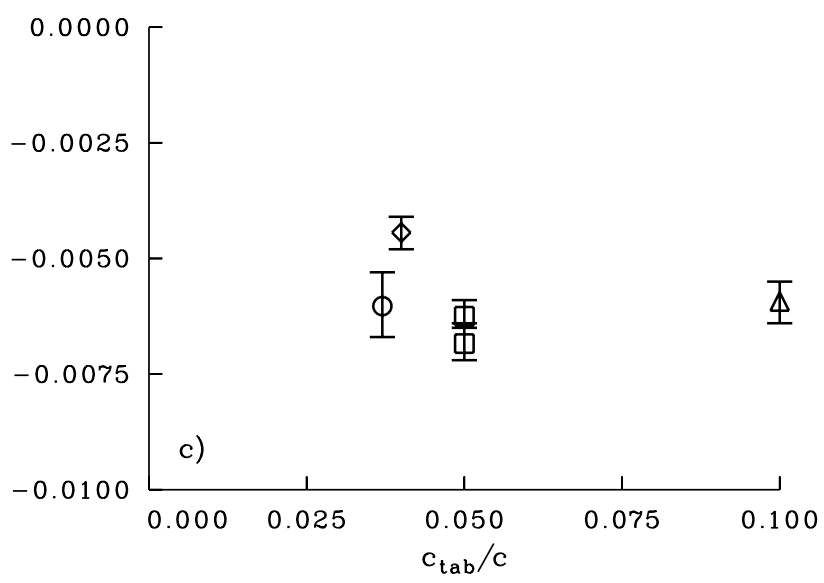

Figure 17. Corrections for tabs, based on airfoil test data (ref. 21). a) maximum lift coefficient as affected by tab deflection; b) zero-lift angle of attack as affected by tab deflection; c) pitching moment coefficient as affected by tab deflection.
The derivative shown in figure $17 \mathrm{a}$, the change in maximum lift coefficient with tab deflection, shows that $C_{l_{\max }}$ increases with positive deflections and decreases with negative deflections. It appears that this effect is slightly increased for shorter tabs. The tab length for experiment 6 is $0.029 c$, and the correction used here is

$$
\frac{d C_{l_{\max }}}{d \delta_{t a b}}=0.02
$$

This correction is used for Mach numbers up to 0.6, and then is linearly decreased to 0 at $M=0.75$, because the data do not indicate an effect of tab reflex at higher Mach numbers. The correction for the angle of attack at 0 lift, shown in figure $17 \mathrm{~b}$, appears to be slightly dependent on the tab length. The selected value of this derivative is

$$
\frac{d \alpha_{0}}{d \delta_{t a b}}=-0.235
$$

and is used for all Mach numbers. Finally, the correction of the pitching moment in figure $17 \mathrm{c}$ appears to be independent of the tab length. Three of the four airfoils are 12-percent thick, and the effect of the tab appears to be slightly greater for these airfoils. Because the SC1095 and SC1094 R8 sections are less than 10-percent thick, a derivative value closer to the V23010-1.58 is used

$$
\frac{d C_{m}}{d \delta_{t a b}}=-0.005
$$

This correction is used for all Mach numbers.

The addition of the tab to the SC1095 and SC1094 R8 airfoils tested in reference 7 increases the airfoil length and reduces the thickness ratio, as noted previously. No attempt has been made to correct for the reduced thickness ratio in using these data.

\section{Experiment 7 (NASA Ames 2- by 2-Foot Transonic Wind Tunnel)}

The SC1095 airfoil section was tested in the NASA Ames 2- by 2-Foot Transonic Wind Tunnel in 1985 (ref. 8). The basic features of this test are illustrated in figure 18. There are no restrictions on these data.

The 2- by 2-foot transonic tunnel, now decommissioned, was a pressurized, ventilated wind tunnel with a Mach number range from about 0.2 to 1.4. For the Experiment 7 tests the Mach number was varied up to 0.88 with Reynolds numbers between 2 and 4 million.

The airfoil model was made of stainless steel; 24 pressure orifices were drilled in the upper surface and 

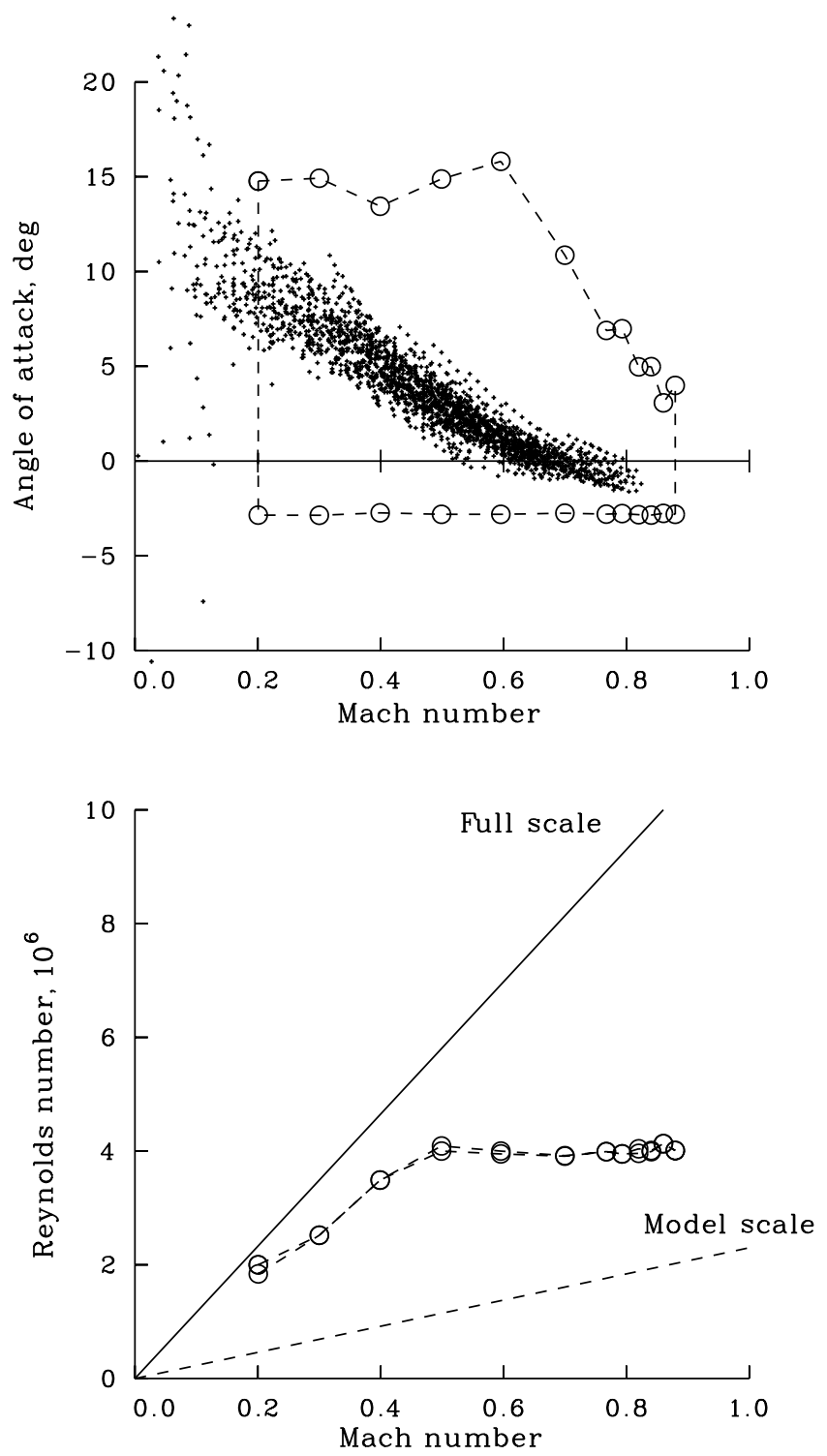

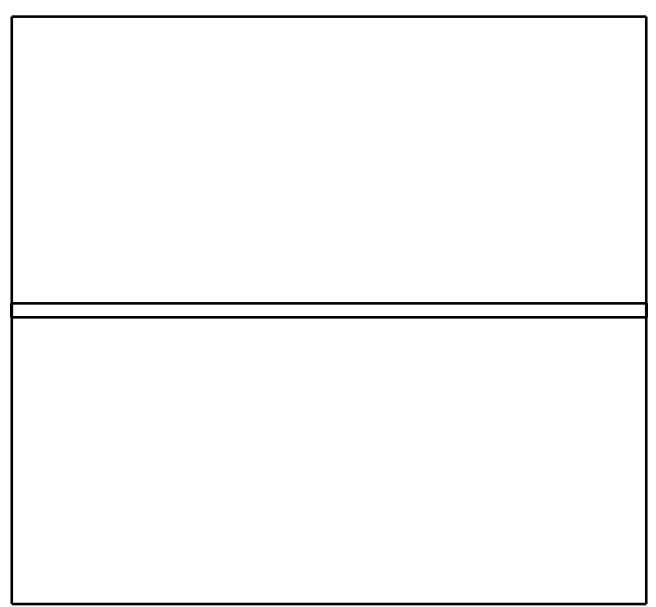

Wind tunnel test parameters

$\mathrm{c}=6.0 \mathrm{in}$.

$\mathrm{b} / \mathrm{c}=4.00$

$\mathrm{h} / \mathrm{c}=4.00$

Porosity $=21.0 \%$

Figure 18. Test conditions for experiment 7; NASA Ames 2- by 2-Foot Transonic Wind Tunnel (ref. 8).

22 on the lower surface. Airfoil lift and pitching moment were obtained by integrating the measured pressures. A wake-survey rake was used to determine the airfoil drag. No boundary layer trip was used.

Under normal operation, the floor and ceiling of the 2- by 2-foot tunnel are ventilated to a common plenum. The porosity for this test was set at 21 percent* No corrections were made to the lift, drag, or pitching moment coefficient data. An angle-of-attack correction was applied as a function of Mach number

\footnotetext{
${ }^{*}$ Raymond M. Hicks and James A. Laub, personal communications.
}

$$
\Delta \alpha=\delta\left(\frac{c}{h}\right) C_{l}
$$

where $\delta=5.4$ at $M=0.2$, increasing to 13.1 at $M=0.83$ in a nonlinear manner (see ref. 8). Figure 19 compares corrected and uncorrected data for this experiment. The angle-of-attack corrections shown in figure 19a are quite large at higher lift coefficients. In addition, unlike other ventilated tunnels, the slope of the angle-of-attack correction varies with Mach number. The effect of these large corrections results in excessive lift-curve slopes that are clearly erroneous whether shown as a function of Reynolds number or Mach number. Totah (ref. 12) concluded that the corrected data were unsuitable, and did not include them in his comparison. An examination of 

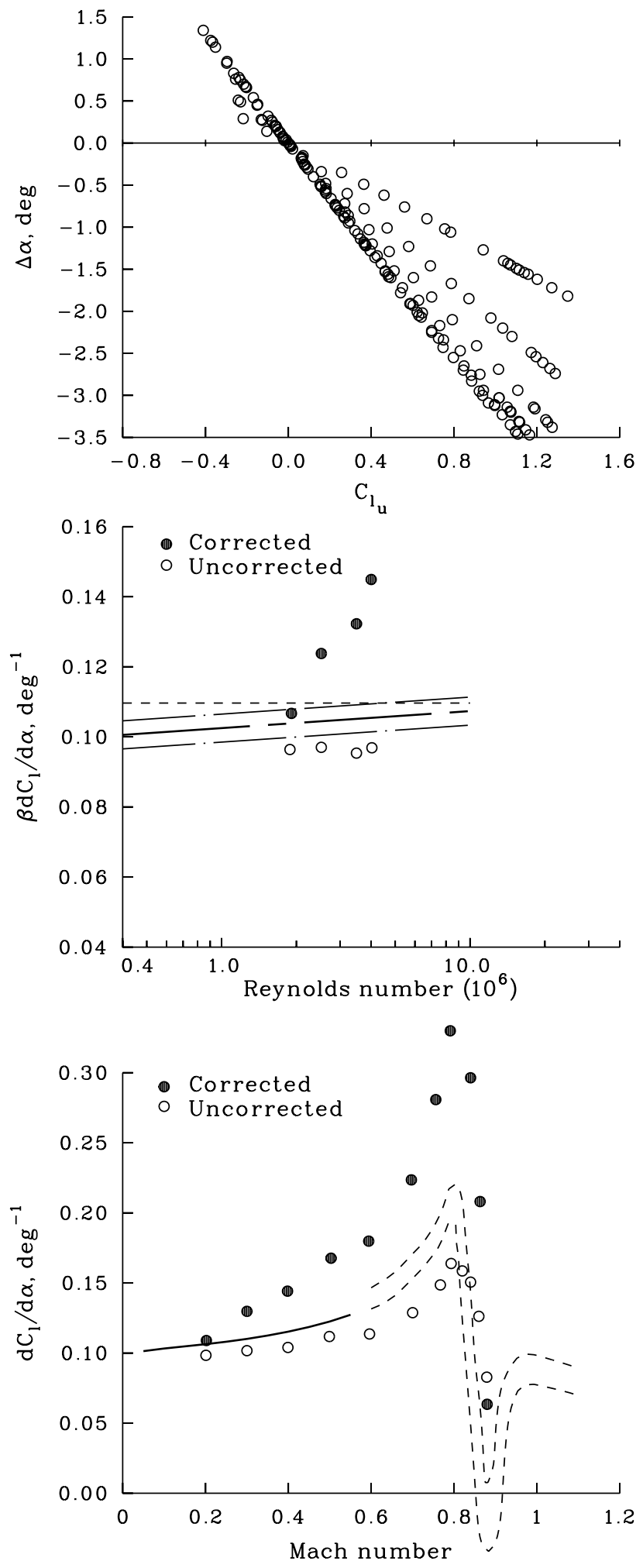

Figure 19. - Comparison of corrected and uncorrected data for Experiment 7. $\beta C_{l_{\alpha}}$ and $C_{l_{\alpha}}$ reference lines for NACA 0012 (ref. 13). the uncorrected data, however, suggests that they should be retained for the comparisons shown later in this report. Note, however, that the uncorrected data are outside of McCroskey's group 2 bounds. In subsequent comparisons shown here only the uncorrected data from experiment 7 are used.

\section{Experiment 8 (NASA Ames 11- by 11-Foot Transonic Wind Tunnel)}

SC1095 and SC1094 R8 airfoils were tested in the NASA Ames 11- by 11-Foot Transonic Wind Tunnel in 1982 using Sikorsky's Tunnel Spanning Apparatus (TSA) (ref. 9). The data obtained in this test are unrestricted. The basic features of the test are illustrated in figure 20 .

The NASA Ames 11- by 11-Foot Transonic Wind Tunnel is a closed-return, variable-density wind tunnel that is capable of testing at Mach numbers up to 1.4. Normally, the four walls are ventilated, resulting in a porosity of 6.1 percent. However, for this test the side walls in the vicinity of the airfoil were taped, reducing the porosity to 4.7 percent. The Mach numbers tested ranged from 0.31 to 1.07 , and the Reynolds numbers from 4 to 6 million.

The TSA was installed in the 11- by 11-foot tunnel in a vertical orientation. Two struts were used to provide partial support. A metric center section was used to measure lift, drag, and moment in a manner similar to the testing described in references 3 and 6 . Airfoil pressure measurements were made 6 in. above the tunnel centerline using 24 upper-surface and 11 lower-surface orifices. The measured pressures were integrated to provide airfoil lift, chord force, and pitching moment. The drag was measured with a wake-survey rake.

Wind tunnel wall corrections were applied based on reference 19. Because the height-to-chord ratio is large, these corrections were small. In general, there was an increase in Mach number of 1 percent, reductions in lift and drag coefficients of 1.5 percent, and small changes to pitching moment and angle of attack. The angle of attack was increased by about 2 percent to account for torsional deflection of the TSA. No angle-of-attack corrections based on the porosity were applied to these data. An examination of the SC1094 R8 data show that the mean chordline of the SC1095 was used as the reference line for angle of attack. Therefore, the angles of attack for this airfoil were all changed by -1 deg to allow consistent comparisons for the SC1094 R8 data in this report. 

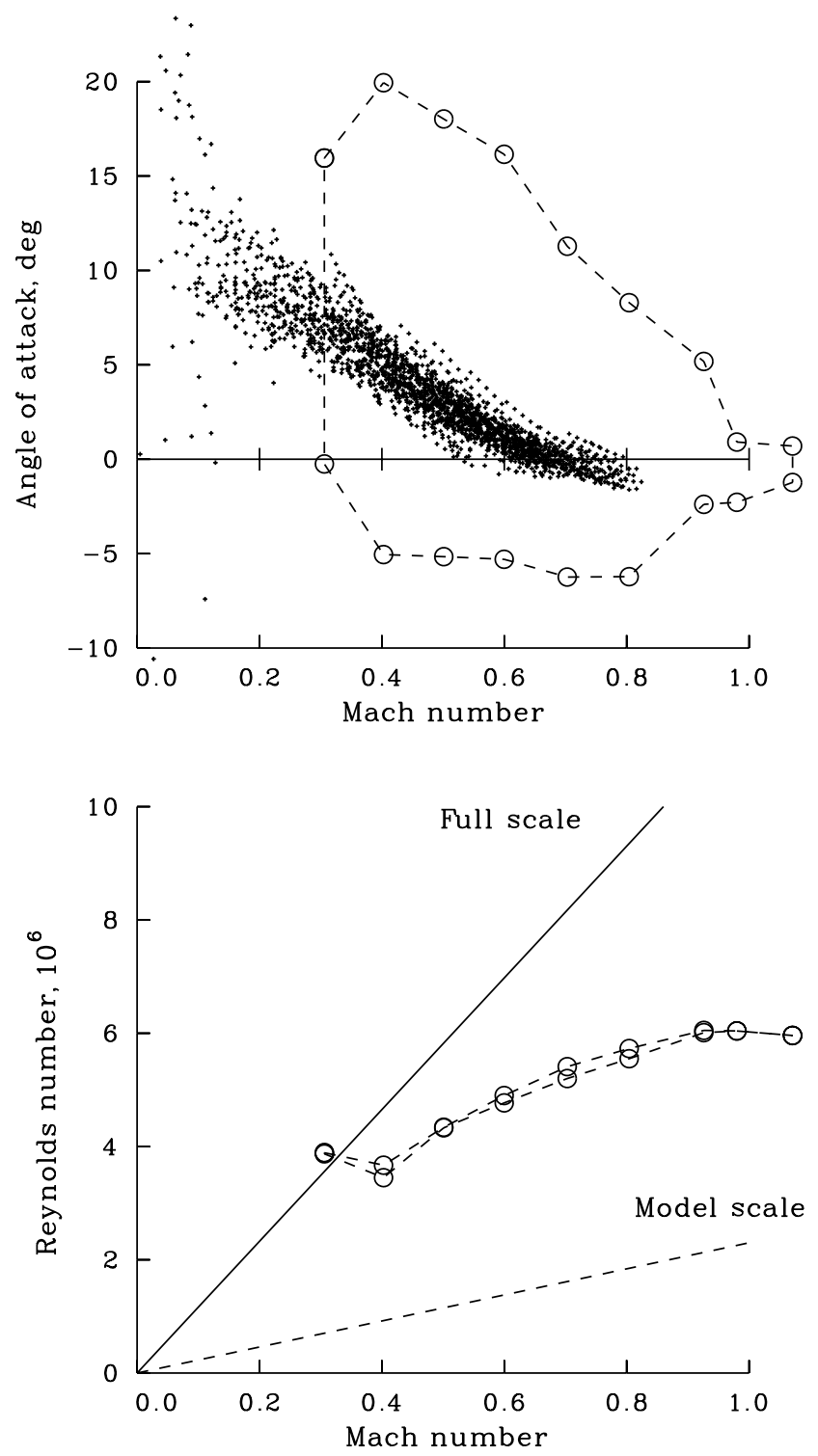

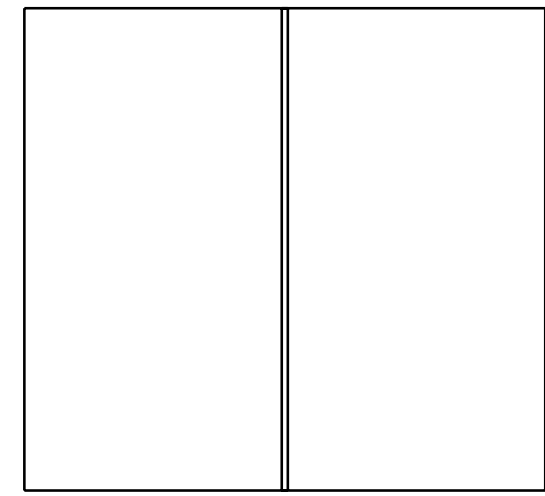

Wind tunnel test parameters

$$
\begin{aligned}
& c=16.0 \mathrm{in} . \\
& \mathrm{b} / \mathrm{c}=8.21 \\
& \mathrm{~h} / \mathrm{c}=8.21 \\
& \text { Porosity }=4.7 \%
\end{aligned}
$$

Figure 20. Test conditions for experiment 8; TSA in the NASA Ames 11- by 11-Foot Transonic Wind Tunnel (ref. 9).

\section{Experiment 9 (NASA Ames 7- by 10-Foot Subsonic Wind Tunnel)}

The SC1095 airfoil was tested in the NASA Ames 7- by 10-Foot Subsonic Wind Tunnel as a part of the basic investigation of dynamic stall using 8 different airfoils (ref. 10). There are no restrictions on the data obtained. This test is described in figure 21.

The NASA Ames 7- by 10-Foot Subsonic Wind Tunnel is a closed-return tunnel with solid walls. The maximum Mach number that can be obtained in this tunnel is about 0.30 . The $\mathrm{SC} 1095$ airfoil was mounted in a vertical orientation for these tests.

Surface pressures were measured on this airfoil using 16 absolute-pressure transducers on the upper surface and 10 on the lower surface. These pressures were integrated to provide airfoil normal and chord forces and the pitching moment. A wake survey was made to provide an accurate measurement of drag, but only for a Mach number of 0.30 . No wind tunnel wall corrections were made to these data. 

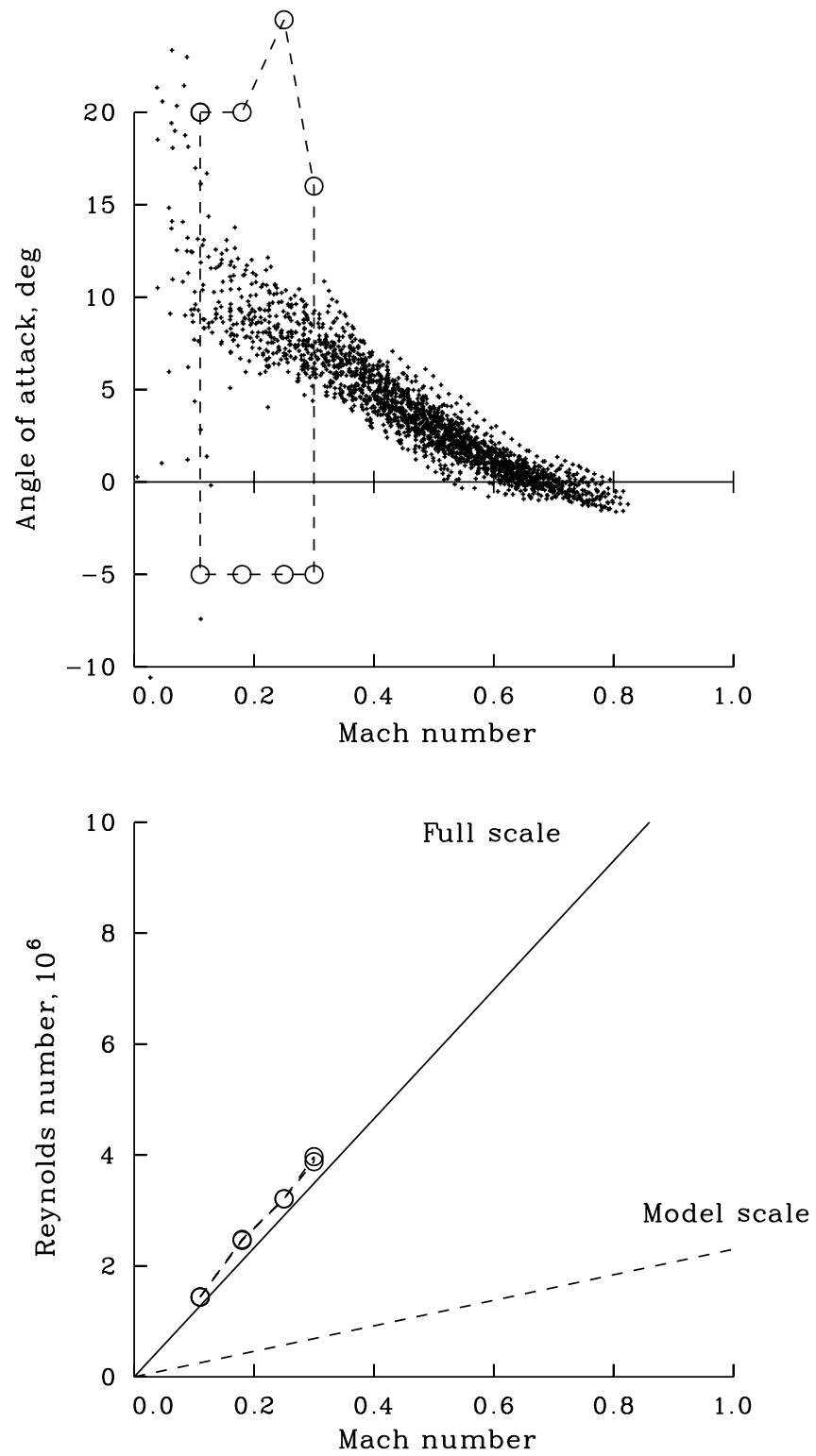

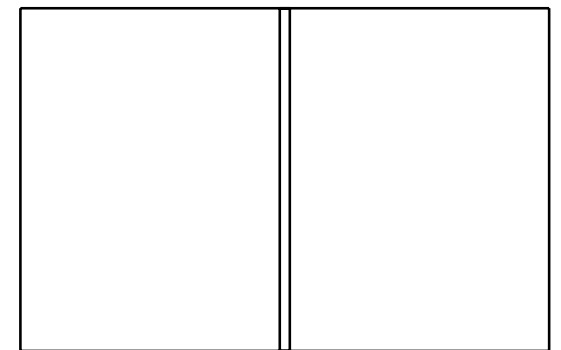

Wind tunnel test parameters

$$
\begin{aligned}
& c=24.0 \mathrm{in} . \\
& \mathrm{b} / \mathrm{c}=3.50 \\
& \mathrm{~h} / \mathrm{c}=5.00 \\
& \text { Porosity }=0.0 \%
\end{aligned}
$$

Figure 21. Test conditions for experiment 9; NASA Ames 7- by 10-Foot Subsonic Wind Tunnel (ref. 10).

\section{Experiment 10 (Glenn L. Martin 8- by 11-Foot Subsonic Wind Tunnel)}

The SC1095 and SC1094 R8 airfoils were tested in the Glenn L. Martin 8- by 11-Foot Subsonic Wind Tunnel at the University of Maryland (ref. 11). The primary purpose of this test was to determine the effects of battle damage on airfoil-section properties. Reference 11 provides a description of the experiment and some representative results, but the full data have not been published. The general features of the test are illustrated in figure 22.
The Glenn L. Martin 8- by 11-Foot Subsonic Wind Tunnel is a closed-return subsonic wind tunnel with solid walls. Airfoil testing in the facility was accomplished with a two-dimensional insert that spanned the tunnel vertical dimension and was $2 \mathrm{ft}$ wide. The maximum Mach number range tested was 0.08 to 0.24 and the Reynolds number range was 1 to 3 million. Because actual airfoils were used in these tests, the Reynolds number was equivalent to full scale.

A section of a rotor blade was installed on a 6-component balance within the two-dimensional insert. 

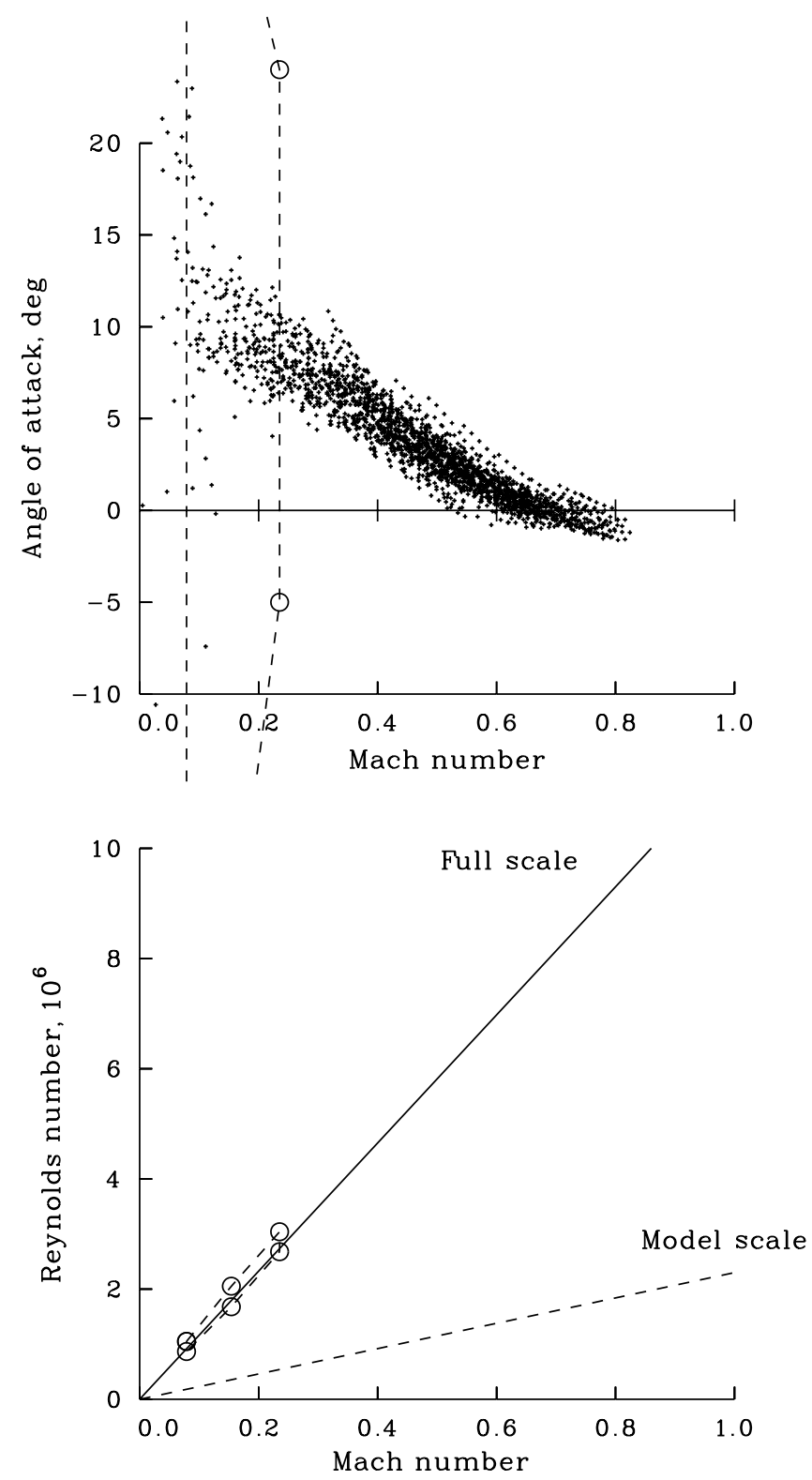

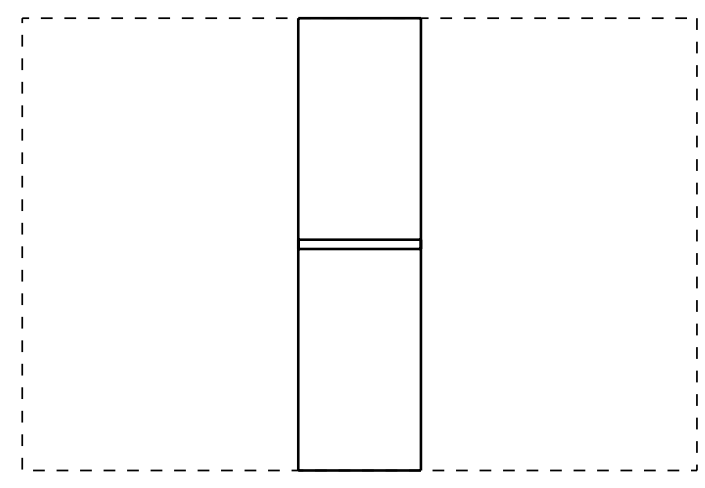

Wind tunnel test parameters

$$
c=20.8 \text { in. }
$$

$\mathrm{b} / \mathrm{c}=1.16$

$\mathrm{h} / \mathrm{c}=4.62$

Porosity $=0.0 \%$

Figure 22. Test conditions for experiment 10; Glenn L. Martin 8- by 11-Foot Subsonic Wind Tunnel (ref. 11).

Lift, drag, and pitching moment were determined from the balance measurements, but no wake survey results were obtained. Because an actual section of the rotor blade was used, there is residual twist of about 1.2 deg over the span of the model. No wind tunnel corrections were applied to the data. The reference chordline used in testing the SC1094 R8 airfoil was the SC1095 chordline. Thus, the angle-of-attack data for this airfoil have been shifted by -1 deg to allow comparison with the other SC1094 R8 data in this report.

\section{AIRFOIL TEST COMPARISONS}

\section{Lift-Curve Slope}

McCroskey's primary approach to the evaluation of experimental airfoil data was to examine the lift-curve slope, $\beta C_{l_{\alpha}}$, and the zero-lift drag coefficient, $C_{d_{0}}$, as a function of Reynolds number (ref. 13). In the comparisons shown here, the lift-curve slope has been estimated by fitting a straight line to the lift coefficient as a function of angle of attack for four to six test points 


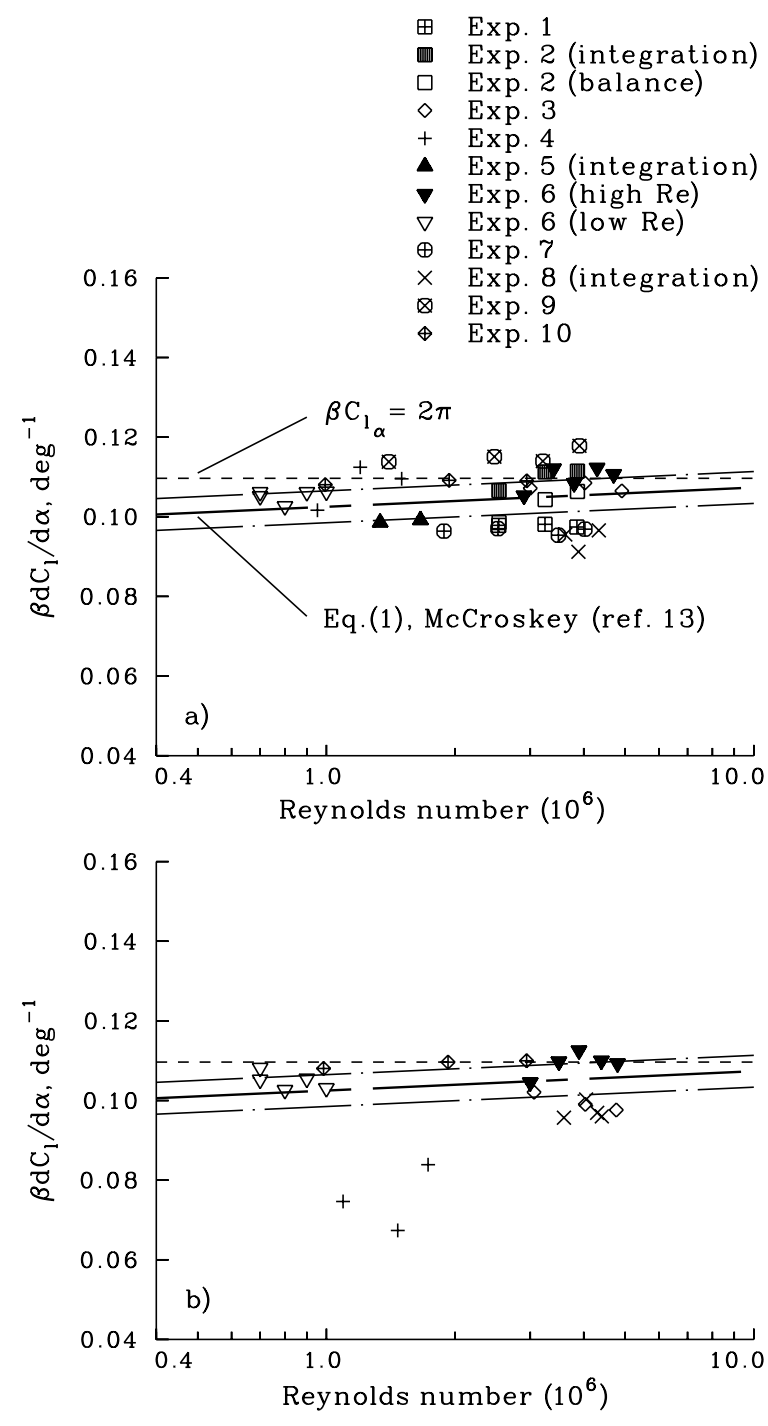

Figure 23. Lift-curve slope at zero lift as a function of Reynolds number; all experimental datasets, $M<0.55$. a) SC1095 airfoil; b) SC1094 R8 airfoil. $\beta C_{l_{\alpha}}$ reference lines for NACA 0012 (ref. 13).

around zero lift. Except at the highest Mach numbers, this method shows little scatter in the calculated lift-curve slope.

Figure 23 shows the $\beta C_{l_{\alpha}}$ from the 10 experiments as a function of Reynolds number. Also shown on this figure is McCroskey's best fit of the NACA 0012 data, along with his group 2 bounds and the classical result of $2 \pi$. Experiments 4 and 7 show scatter that exceeds $\pm 0.008 \beta C_{l_{\alpha}}$, twice the group 2 bounds. This level of scatter suggests that these data are not trustworthy, that is, they belong in group 5. The remaining datasets show acceptable scatter, but some are biased either high or low. The experiment 9 data for the
SC1095 are about 10-percent high compared to the NACA 0012 fit. McCroskey and his colleagues (ref. 10) have noted that the lift-curve slope and $C_{l_{\max }}$ were too high in experiment 9 , and they were unable to establish a suitable cause for the discrepancy. Many of the datasets show a lift-curve slope that is too low; these include experiments 1 and 8 . In the latter case, the reduced lift-curve slope is caused by tunnel porosity (ref. 9). By comparing with airfoil data from the UTRC Large Subsonic Wind Tunnel, Flemming has estimated that the lift-curve slope in this experiment is 8 to 17 percent below the actual value (ref. 9).

The data from experiments 2, 3, 5, 6, and 10 lie approximately within the group 2 boundaries based on McCroskey's fit of the NACA 0012 data.

Figure 24 shows the airfoil lift-curve slope as a function of Mach number. Below $M=0.55$, equation (1), based on a fit of the NACA 0012 data, is shown as a solid line. Above $M=0.60$, dashed lines are used to indicate the boundaries of the NACA 0012 data as shown by McCroskey (ref. 13). The SC1095 and SC1094 R8 experimental data of group 2 quality, based on figure 23, appear to show some departures from the NACA 0012 boundaries of reference 13 in the region from $M=0.55$ to $M=1.15$. Because the airfoil characteristics are nonlinear in this regime and are strongly influenced by the development of supercritical flow regions and shocks, differences from the NACA 0012 values are expected. The small amount of data above $M=0.8$, however, makes it difficult to establish the nonlinear characteristics of the SC1095 or SC1094 R8 with confidence.

\section{Maximum Lift Coefficient}

For each of the experimental datasets, the maximum lift coefficient was estimated by fitting a second-order polynomial to the lift coefficient as a function of angle of attack in the vicinity of the maximum measured lift. This approach provides a good estimate of $C_{l_{\max }}$ for $M<0.55$. However, above $M=$ 0.55 , there is generally no peak in the curve for lift coefficient as a function of angle of attack, and the values shown here are the lift coefficients at the highest angle of attack that was tested and are, therefore, arbitrary.

The maximum lift coefficients for the SC1095 and SC1094 R8 are shown in figure 25 as a function of Mach number. The $C_{l_{\max }}$ of the SC1095 is about 1.4 to 1.5 at low Mach numbers and then decreases with increasing Mach number as expected. As noted before, 


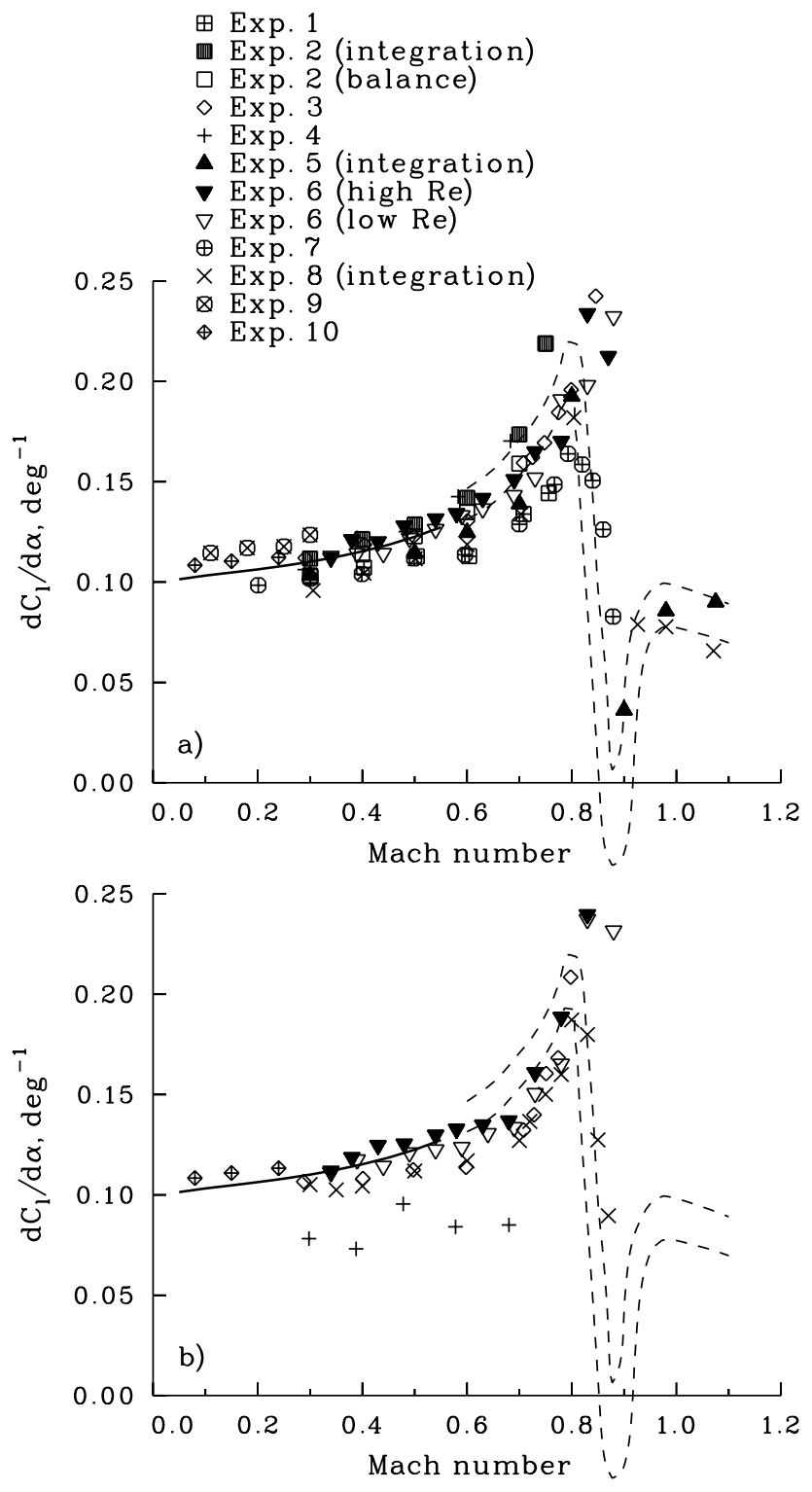

Figure 24. Lift-curve slope at zero lift as a function of Mach number; all experimental datasets. a) SC1095 airfoil;

b) SC1094 R8 airfoil. $C_{l_{\alpha}}$ reference lines for NACA 0012 (ref. 13).

the experiment 9 lift coefficients are known to be too high and are not appropriate for estimating the $C_{l}$ behavior. Only limited data were obtained for the SC1094 R8 airfoil at low Mach numbers, and these suggest a $C_{l_{\max }}$ between 1.5 and 1.8 .

The $C_{l_{\max }}$ values at $M=0.4$ are shown in tables 7 and 8 for the SC1095 and SC1094 R8 airfoils, respectively. In those cases where data were not obtained at $M=0.4$, the $C_{l_{\max }}$ has been calculated by linear interpolation from data at $M=0.3$ and $M=0.5$.
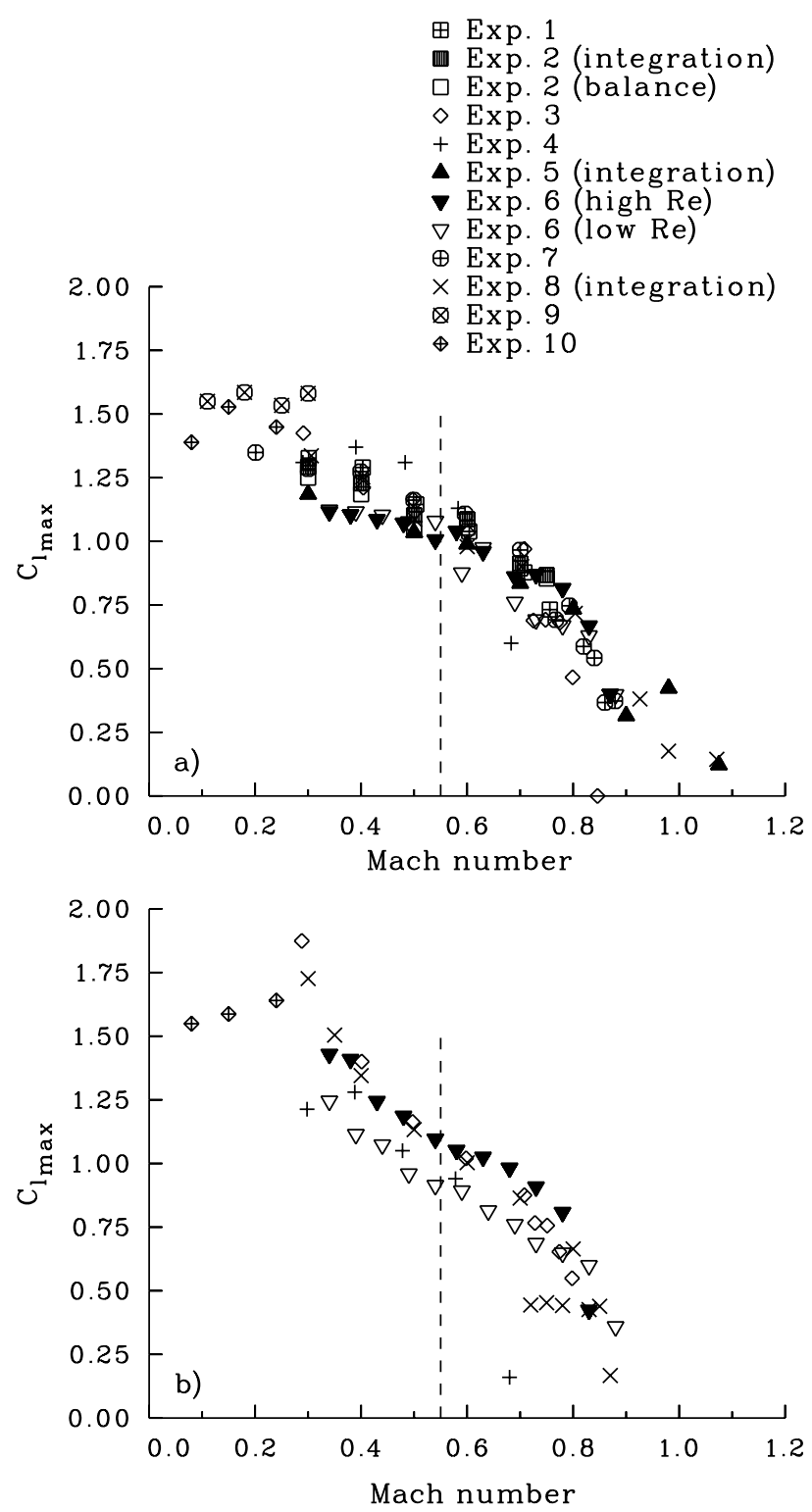

Figure 25. Maximum lift coefficient as a function of Mach number; all experimental datasets. a) SC1095 airfoil;

b) SC1094 R8 airfoil. $C_{I_{\max }}$ undefined beyond $\mathrm{M} \approx 0.55$.

The variation in $C_{l_{\max }}$ shown in tables 7 and 8 is large. As noted in the discussion of the lift-curve slope, the data scatter from experiments 4 and 7 is excessive and, on this basis, it is appropriate to exclude these data. The mean $C_{l_{\max }}$ for the SC1095 airfoil from table 7 is 1.19 with a standard deviation of 0.07. The mean $C_{I_{\max }}$ for the SC1094 $\mathrm{R} 8$ airfoil is 1.30 with a standard deviation of 0.13 .

The angle of attack at the maximum lift coefficient is shown in figure 26. This angle is defined only for $M<0.55$, but even for these conditions 
Table 7. Maximum lift coefficient of SC1095 airfoil at $M=0.4$.

\begin{tabular}{ll}
\hline \hline \multicolumn{1}{c}{ Experiment } & $C_{l_{\max }}$ \\
\hline 1 & 1.29 \\
2 (integration) & 1.23 \\
2 (balance) & 1.19 \\
3 & 1.21 \\
4 & 1.37 \\
5 (integration) $^{\text {(high Re) }}{ }^{\mathrm{a}}$ & 1.11 \\
6 (low Re) $^{\mathrm{a}}$ & 1.10 \\
7 & 1.11 \\
8 (integration) & 1.27 \\
Mean $^{\mathrm{b}}$ & 1.25 \\
Standard deviation $^{\mathrm{b}}$ & 1.19 \\
\hline \hline
\end{tabular}

a 0.06 added for -3 -deg reflexed tab.

${ }^{\mathrm{b}}$ Experiments 4 and 7 excluded.

Table 8. Maximum lift coefficient of SC1094 R8 airfoil at $M=0.4$.

\begin{tabular}{lc}
\hline \hline \multicolumn{1}{c}{ Experiment } & $C_{l_{\max }}$ \\
\hline 3 & 1.40 \\
4 & 1.25 \\
$6\left(\right.$ high Re) ${ }^{\mathrm{a}}$ & 1.34 \\
6 (low Re) $^{\mathrm{a}}$ & 1.11 \\
8 (integration) & 1.35 \\
mean $^{\mathrm{b}}$ & 1.30 \\
Standard deviation $^{\mathrm{b}}$ & 0.13 \\
\hline \hline
\end{tabular}

a 0.06 added for -3 -deg reflexed tab.

$\mathrm{b}$ Experiment 4 excluded.

considerable differences are seen between the experiments and, in some cases, within the experiments.

\section{Zero-Lift Conditions}

The lift coefficient at zero angle of attack is greater than zero for airfoils with positive camber, whereas the angle of attack for zero lift is less than zero. These two measures of airfoil lift for nominal zero-lift conditions are equivalent, that is,

$$
C_{l_{0}}=-\frac{d C_{l}}{d \alpha} \alpha_{0}
$$

For comparison purposes it is preferable to examine the measured angle of attack for zero lift, $\alpha_{0}$, rather than the
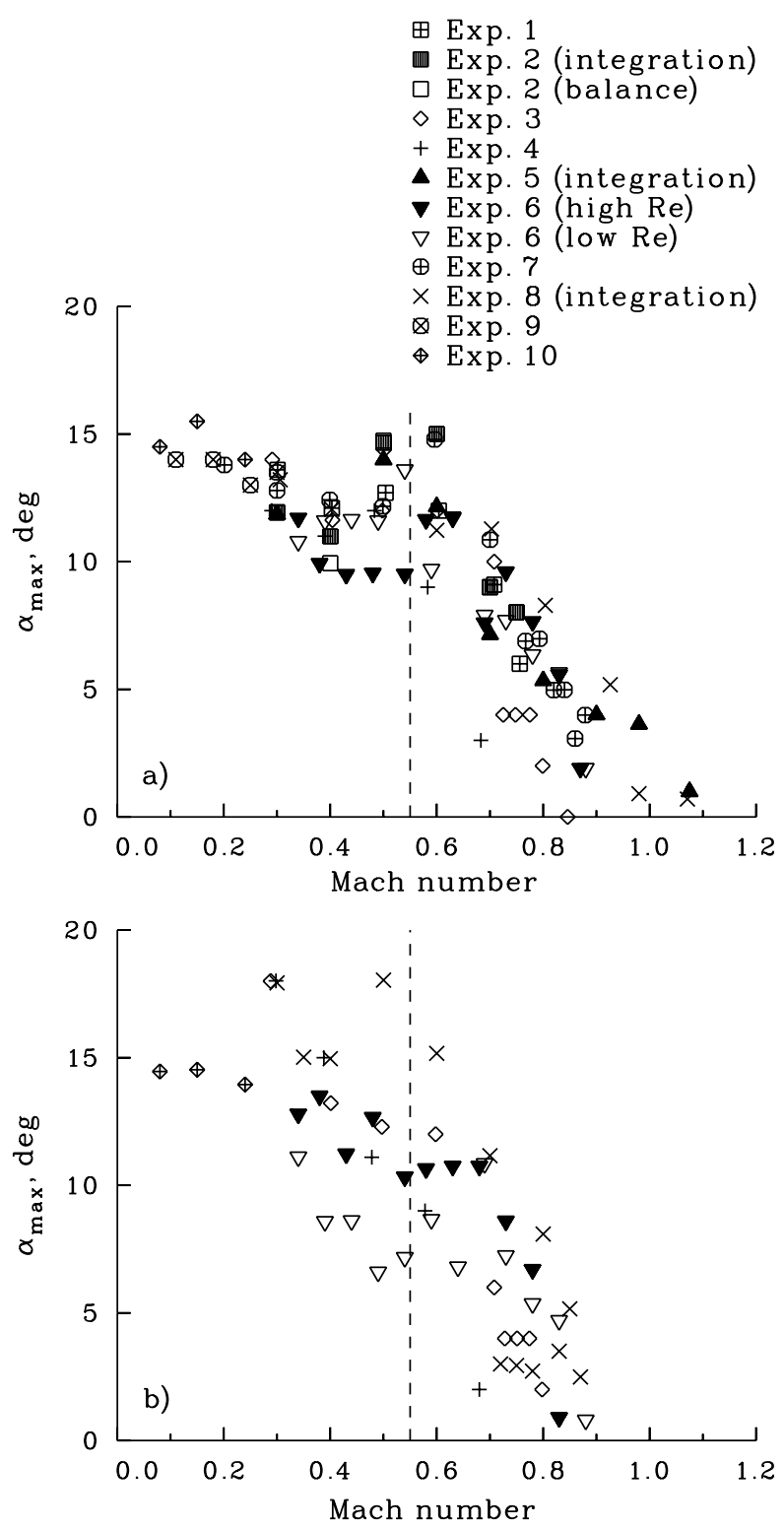

Figure 26. Angle of attack at maximum lift coefficient as a function of Mach number; all experimental datasets.

a) SC1095 airfoil; b) SC1094 R8 airfoil. $\alpha_{\max }$ undefined beyond $M \approx 0.55$.

lift coefficient at zero angle of attack, $C_{l_{0}}$, because the latter parameter is affected by lift-curve-slope changes with Mach number. The experimental data for angle of attack at zero lift are compared in figure 27.

The angles of attack for zero lift for the SC1095 airfoil range from about -0.1 to $-1.0 \mathrm{deg}$. For the SC1094 R8 airfoil, excluding the experiment 4 data, the range of the angles is from -1.4 to $-1.7 \mathrm{deg}$. To a substantial degree the measurement of the angle of attack at zero lift is independent of aerodynamic loading and 


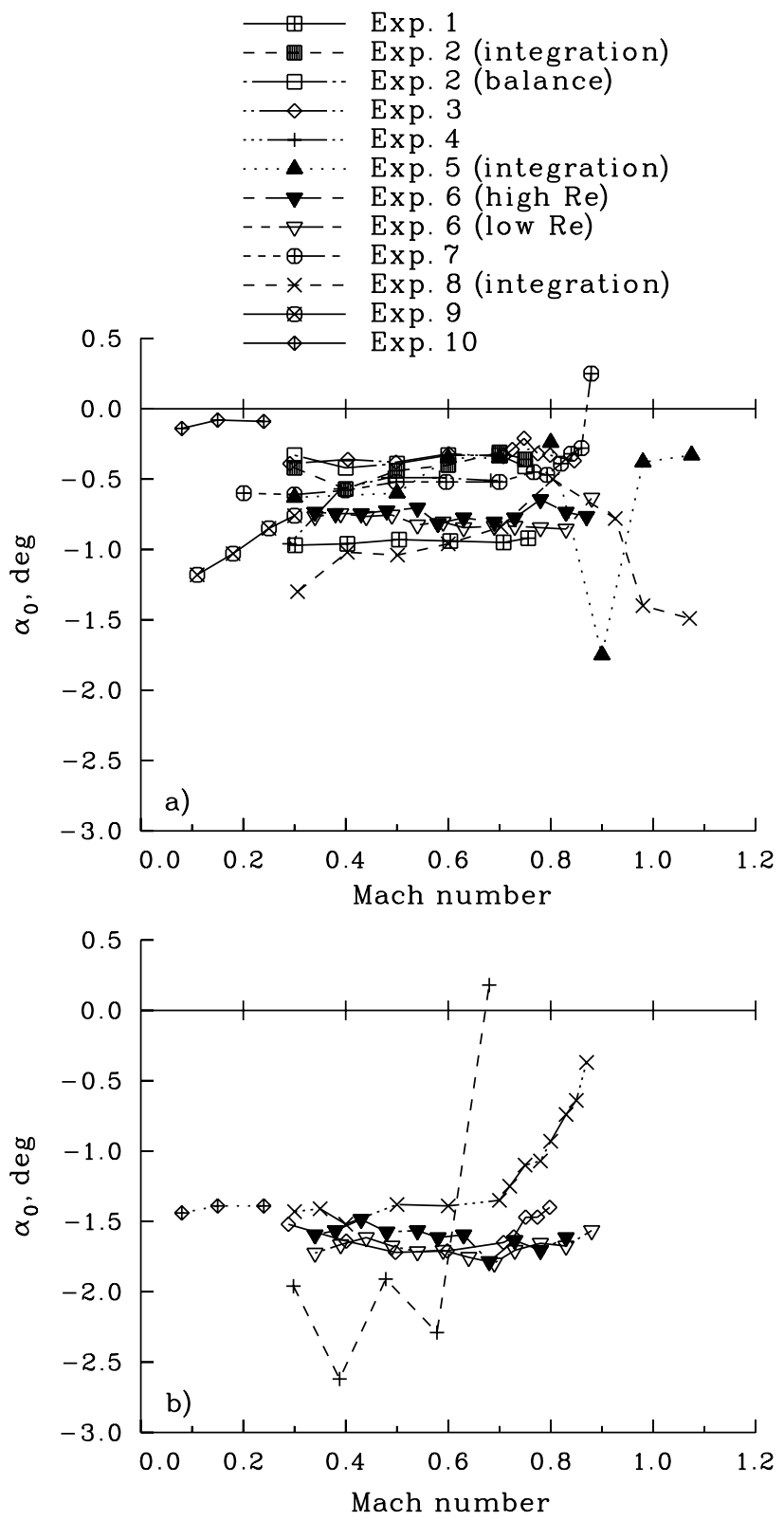

Figure 27. Angle of attack for zero lift coefficient as a function of Mach number; all experimental datasets. a) SC1095 airfoil; b) SC1094 R8 airfoil.

corrections for wall effects, at least within the regime of linear transonic aerodynamics. Rather, deviations in this measurement are evidence of bias errors in measuring the angle of attack or rigging errors. The SC1094 R8 data are seen to group quite closely (excepting experiment 4 ), but the SC1095 data show much more variation and the correct value is unclear.

\section{Drag Coefficient}

The drag coefficient at zero lift, $C_{d_{0}}$, is an appropriate representation of the basic drag for a symmetrical airfoil section. However, for cambered sections, the minimum drag coefficient, $C_{d_{\min }}$, may be a more appropriate measure. The difference between these two representations is illustrated in figure 28 , which compares the lift-drag polars for the SC1095 and SC1094 R8 airfoils at two Mach numbers. At lower Mach numbers, for instance at $M=0.48$, the differences between $C_{d_{0}}$ and $C_{d_{\min }}$ are small. For the SC1095, the two coefficients are identical. For the SC1094 R8, the zerolift drag coefficient is slightly greater than the minimum drag coefficient, 0.0085 compared to 0.0078 . As the Mach number increases, however, the drag bucket narrows and significant differences develop between $C_{d_{0}}$ and $C_{d_{\text {min }}}$ for the more highly cambered SC1094 R8. As seen in figure 28 at $M=0.69, C_{d_{\min }}$ is considerably less than $C_{d_{0}}, 0.0079$ compared to 0.0119 . The differences between these two coefficients becomes particularly important in determining the drag divergence Mach number, as discussed later in this document.

The drag coefficient at zero lift is shown in figure 29 as a function of Reynolds number for the two airfoils. The drag coefficients of the SC1095 and SC1094 R8 airfoils are not expected to be the same as the NACA 0012 drag coefficients, so the expressions used by McCroskey for that airfoil, equations (2) and (3), are not directly applicable. However, his group 2 bounds, based on the NACA 0012 data, do provide a means of identifying poorer-quality data, and these bounds are included in figure 29.

The zero-lift drag data in figure 29 were fit with

$$
C_{d_{0}}=\frac{0.026}{\operatorname{Re}^{0.08}}
$$

for the SC1095 airfoil and

$$
C_{d_{0}}=\frac{0.17}{\mathrm{Re}^{0.2}}
$$

for the SC1094 R8 airfoil. The general form of this function follows Keys et al. (ref. 22).

The SC1095 data shown in figure 29 generally lie between McCroskey's tripped and untripped equations for the NACA 0012. The drag data shown in figure 29 were obtained without using a boundary layer trip. The only test that also obtained tripped data was experiment 3 . In that test, the difference between the tripped and untripped data for the SC1095 was about half that found for the NACA 0012. 

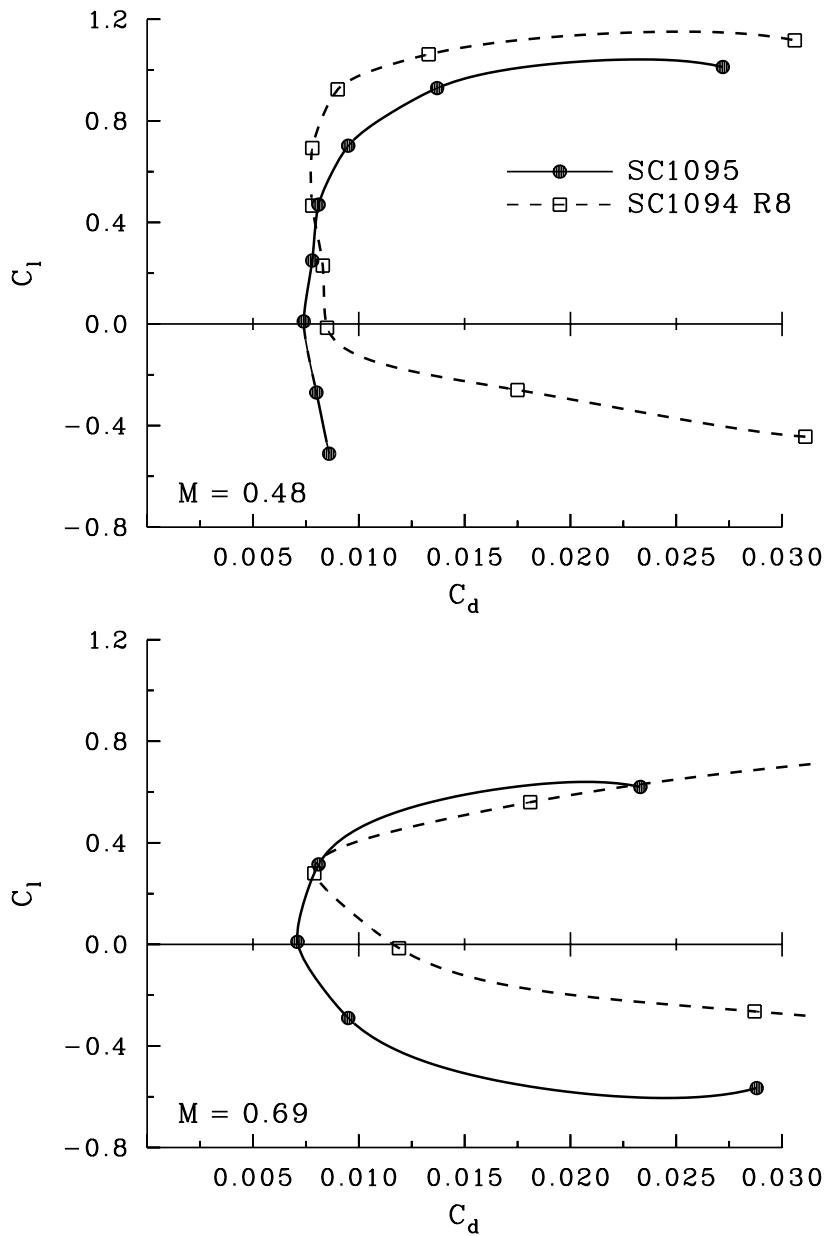

Figure 28. Comparison of SC1095 and SC1094 R8 liftdrag polars at two Mach numbers. Data from experiment 6 for high Reynolds number (reference 7).

The minimum drag-coefficient data as a function of Reynolds number are shown in figure 30 for the two airfoil sections. As for the zero-lift drag-coefficient data, a best fit of $C_{d_{\min }}$ with Reynolds number was determined using the approach of Keys et al. (ref. 22). The fit for the SC1095 is

$$
C_{d_{\min }}=\frac{0.034}{\operatorname{Re}^{0.1}}
$$

and for the SC1094 R8 is

$$
C_{d_{\min }}=\frac{0.037}{\operatorname{Re}^{0.1}}
$$

A comparison of figures 29 and 30 shows little difference between $C_{d_{0}}$ and $C_{d_{\min }}$ for the SC1095 airfoil. However, $C_{d_{0}}$ shows a greater dependence on Reynolds number than $C_{d_{\min }}$ for the SC1094 R8 airfoil.

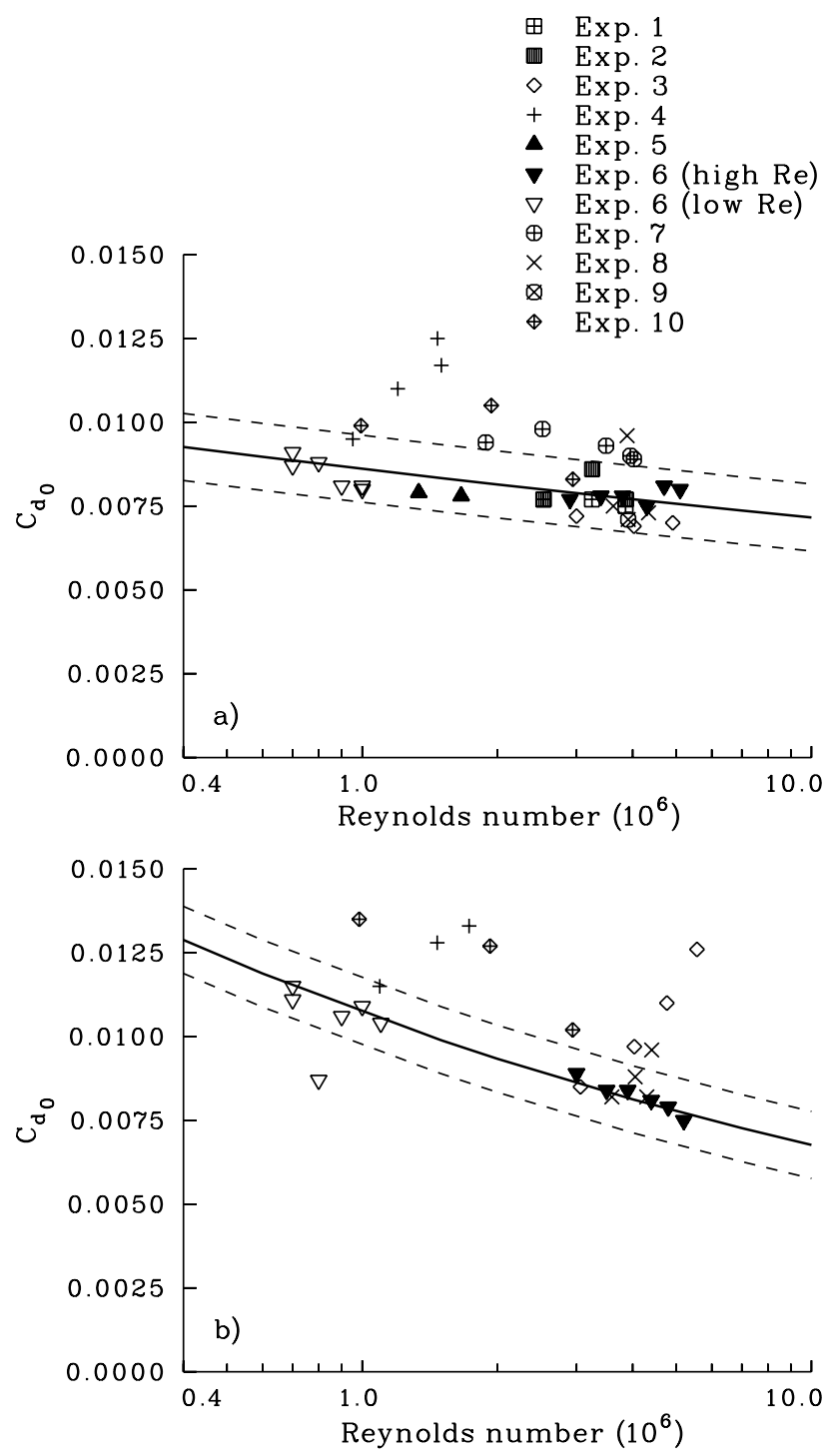

Figure 29. Drag coefficient at zero lift coefficient as a function of Reynolds number; all experimental datasets, $M<0.6$. a) SC1095 airfoil; b) SC1094 R8 airfoil.

The drag coefficient at zero lift is shown as a function of Mach number in figure 31. There is fairly good agreement between the various experiments for the SC1095 if the experiment 4 data are excluded. Below $M=0.70$, there is a small reduction in $C_{d_{0}}$ as Mach number increases; this is a result of the increasing Reynolds number (see equation (17)). In the case of the SC1094 R8 airfoil, greater scatter is seen, partly because both the low and high Reynolds number datasets from experiment 6 are included.

The minimum drag coefficient, $C_{d_{\text {min }}}$, is shown as a function of Mach number in figure 32. Little 


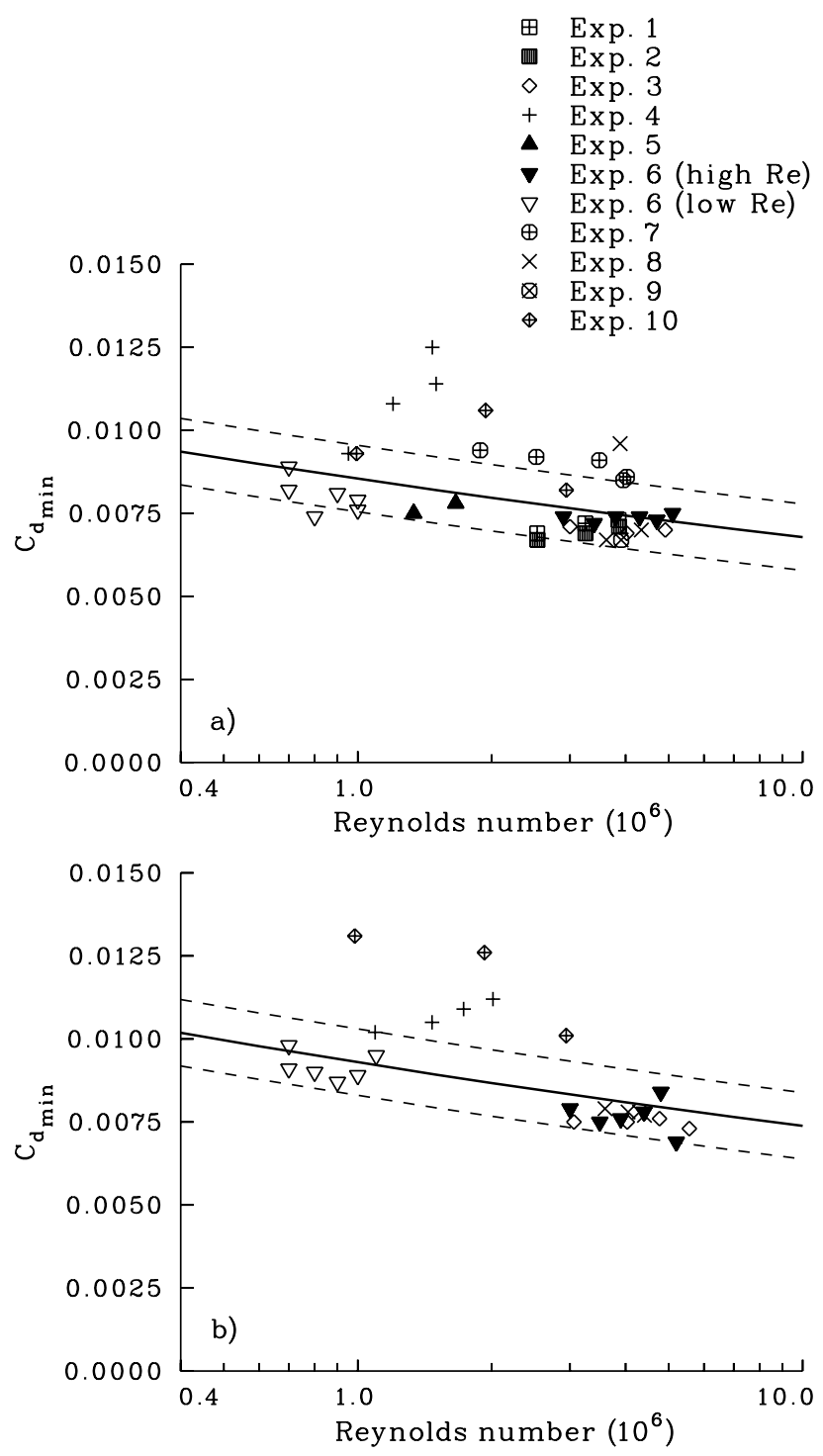

Figure 30. Minimum drag coefficient as a function of Reynolds number; all experimental datasets, $M<0.6$. a) SC1095 airfoil; b) SC1094 R8 airfoil.

difference is observed between $C_{d_{0}}$ and $C_{d_{\min }}$ for the SC1095 section, but differences are seen for the SC1094 R8. For this section, the drag rise with Mach number is more gradual based on $C_{d_{0}}$ when compared to the drag rise noted using $C_{d_{\text {min }}}$.

The behavior of $C_{d_{0}}$ and $C_{d_{\min }}$, particularly near the drag divergence boundary, can be better visualized by removing the mean drag coefficient. An incremental drag, $\Delta C_{d_{0}}$ and $\Delta C_{d_{\text {min }}}$, is determined by subtracting the mean of the drag-coefficient data measurements below $M=0.7$ from the original coefficient data. The incremental zerolift drag coefficient is shown in figure 33, and the incremental minimum drag coefficient is shown in
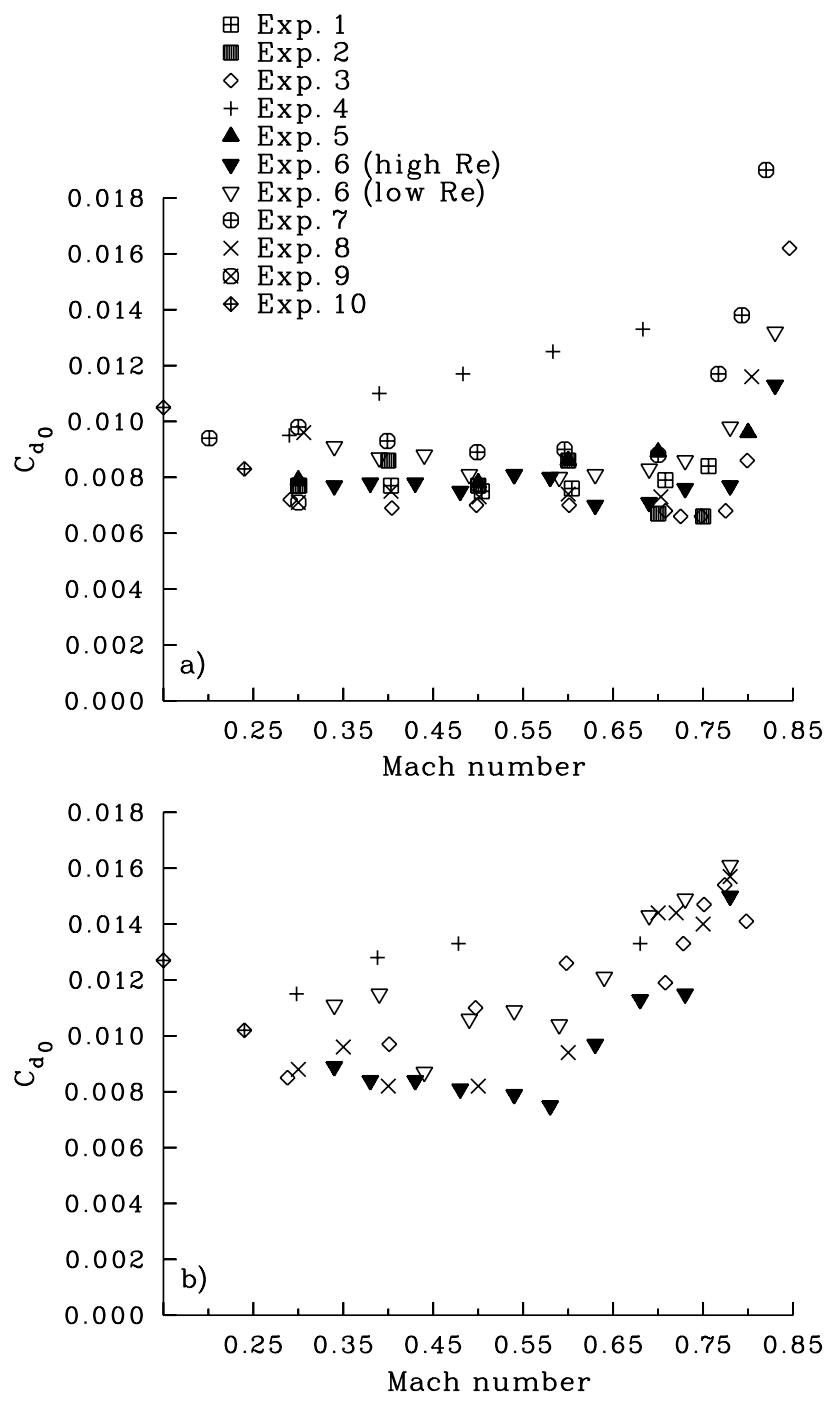

Figure 31. Drag coefficient at zero lift coefficient as a function of Mach number; all experimental datasets. a) SC1095 airfoil; b) SC1094 R8 airfoil.

figure 34. Drag-coefficient boundaries of \pm 0.0005 are included in the figure to indicate the amount of scatter in the data.

The drag-divergence Mach number was determined in many of the experimental studies discussed herein. The value of $M_{d d}$ was based on the zero-lift dragcoefficient variation with Mach number. The calculation of the drag-divergence Mach number requires two interpolations of the data. First, the measured drag coefficients must be fit with a curve to estimate $C_{d_{0}}$ at zero lift for each Mach number, and second, the $C_{d_{0}}$ as a function of $M$ values must be interpolated to find the dragdivergence Mach number. Values of $M_{d d}$ are shown in tables 9 and 10 for the two airfoils. These tables include the $M_{d d}$ values published by the original investigators 


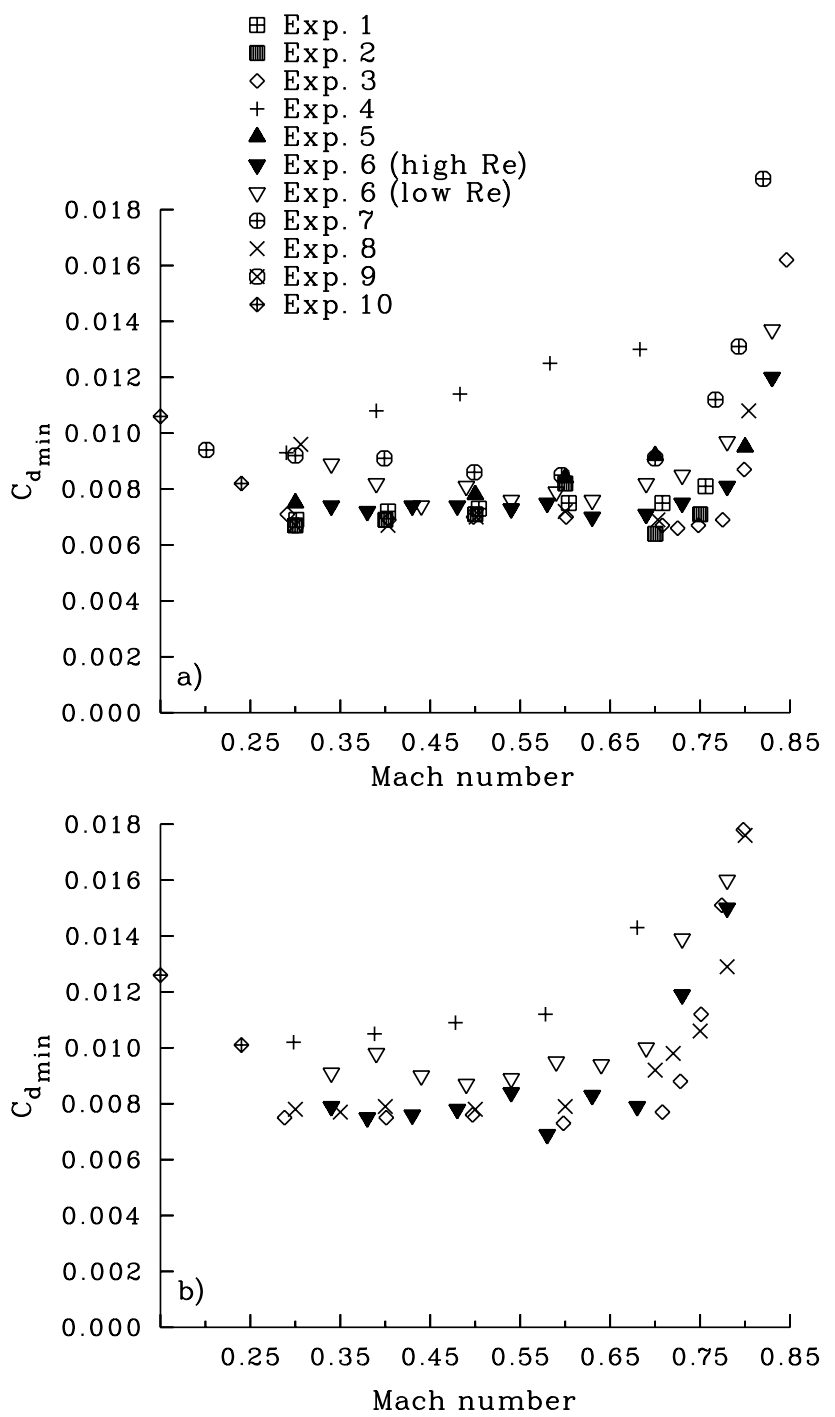

Figure 32. Minimum drag coefficient as a function of Mach number; all experimental datasets. a) SC1095 airfoil; b) SC1094 R8 airfoil.

Table 9. SC1095 airfoil drag-divergence Mach number.

\begin{tabular}{lcc}
\hline \hline \multicolumn{1}{c}{ Experiment } & Published $M_{d d}$ & Analyzed $M_{d d}$ \\
\hline 3 & - & 0.798 \\
6 (high Re) & 0.816 & 0.825 \\
6 (low Re) & 0.821 & 0.841 \\
7 & 0.800 & 0.785 \\
8 & 0.800 & 0.819 \\
Mean & 0.809 & 0.814 \\
Standard deviation & 0.011 & 0.022 \\
\hline \hline
\end{tabular}
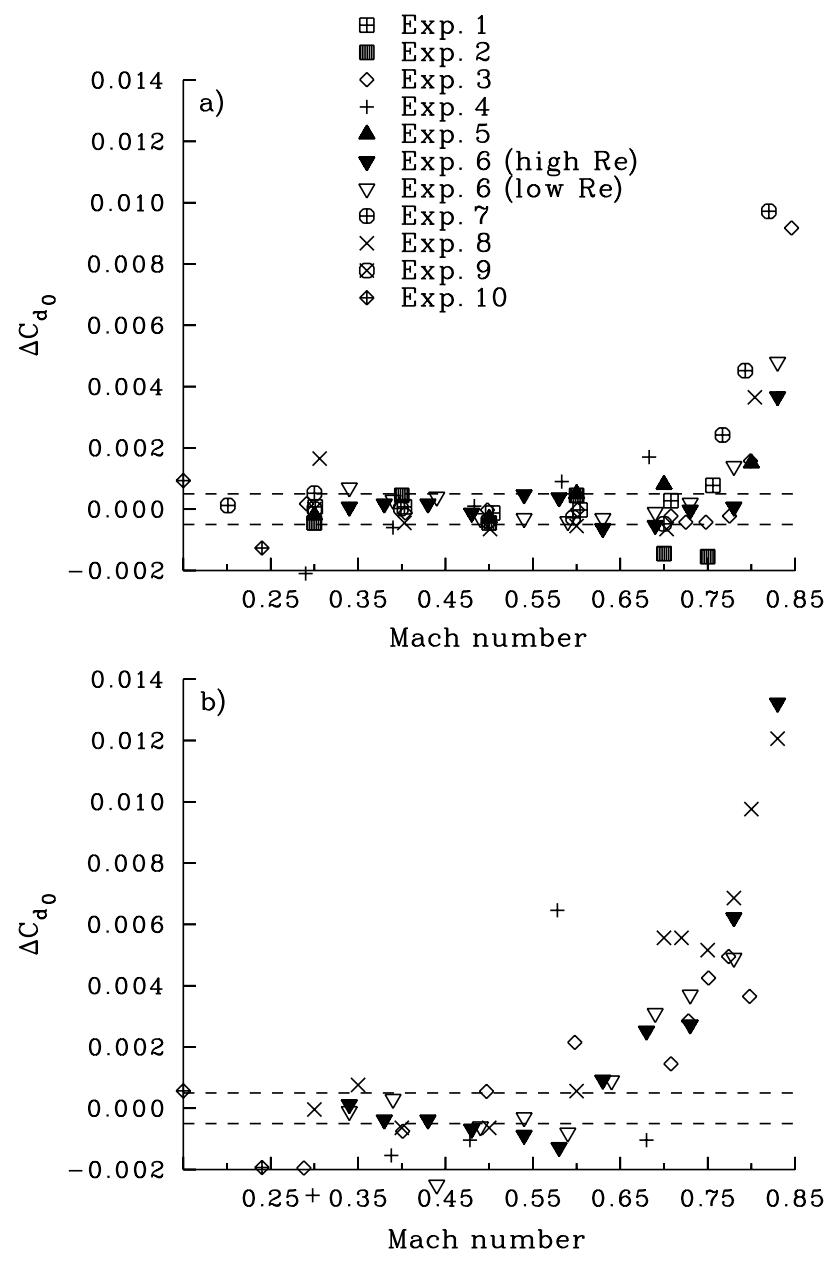

Figure 33. Drag coefficient at zero lift with mean value removed as a function of Mach number; all experimental datasets; mean computed for $M<0.7$. a) SC1095 airfoil; b) SC1094 R8 airfoil.

Table 10. SC1094 R8 airfoil drag-divergence Mach number.

\begin{tabular}{lcc}
\hline \hline \multicolumn{1}{c}{ Experiment } & Published $M_{d d}$ & Analyzed $M_{d d}$ \\
\hline 3 & 0.780 & 0.820 \\
6 (high Re) & 0.782 & 0.784 \\
6 (low Re) & 0.801 & 0.798 \\
8 & 0.780 & 0.788 \\
Mean & 0.786 & 0.798 \\
Standard deviation & 0.010 & 0.016 \\
\hline \hline
\end{tabular}



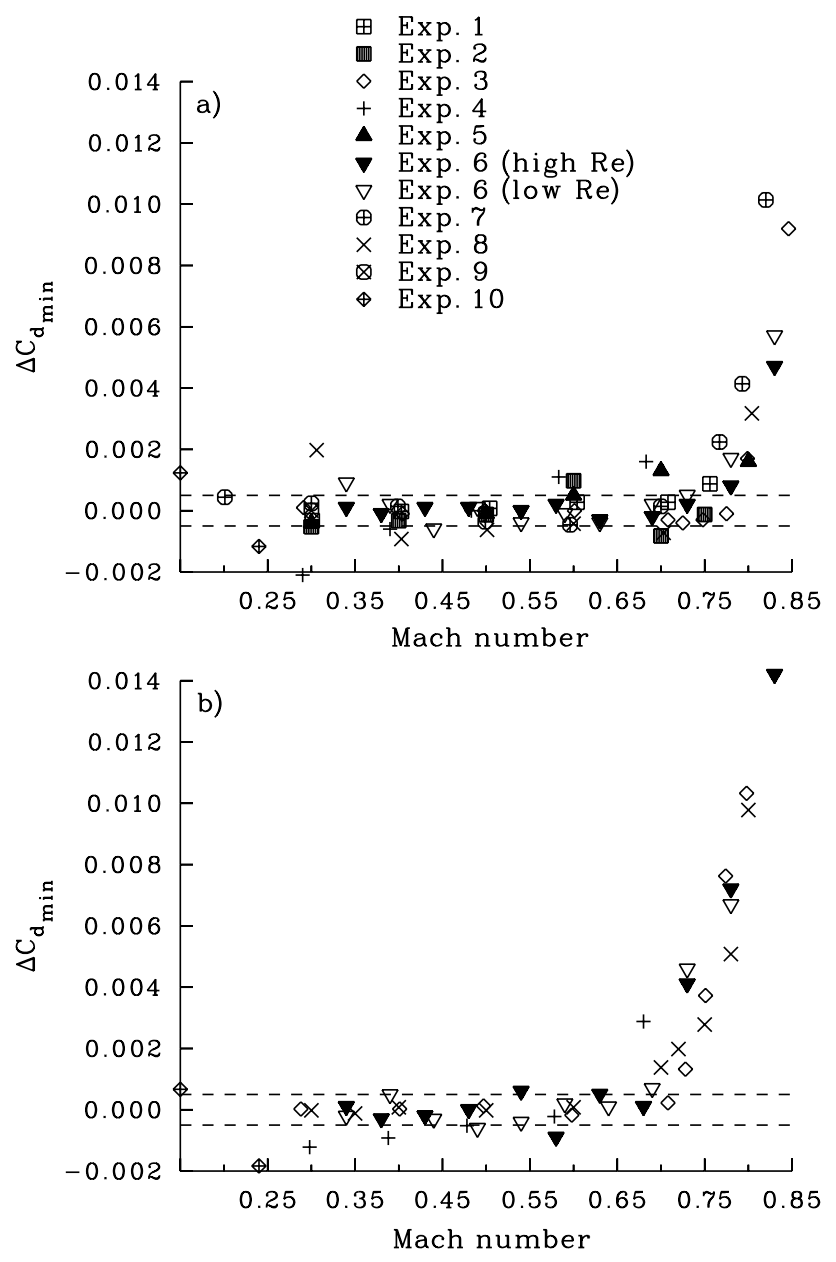

Figure 34. Minimum drag coefficient with mean value removed as a function of Mach number; all experimental datasets, mean computed for $M<0.7$. a) SC1095 airfoil; b) SC1094 R8 airfoil.

as well as a re-analysis of the data for this study. Note that the divergence Mach number was not estimated in experiments 1 and 2 because the test Mach number range was below the drag-divergence Mach number.

The drag-coefficient behavior at high Mach number, after the drag rise, is shown in figure 35 for the two airfoils. The dashed lines show the estimated boundaries at high Mach number for the NACA 0012 (ref. 13). From the limited data at higher Mach numbers in this figure it appears that the drag for the SC1095 airfoil is slightly lower than the drag of the NACA 0012 in the transonic regime. This appears reasonable because the SC1095 section is 9.5-percent thick compared to the 12-percent thickness of the NACA 0012.
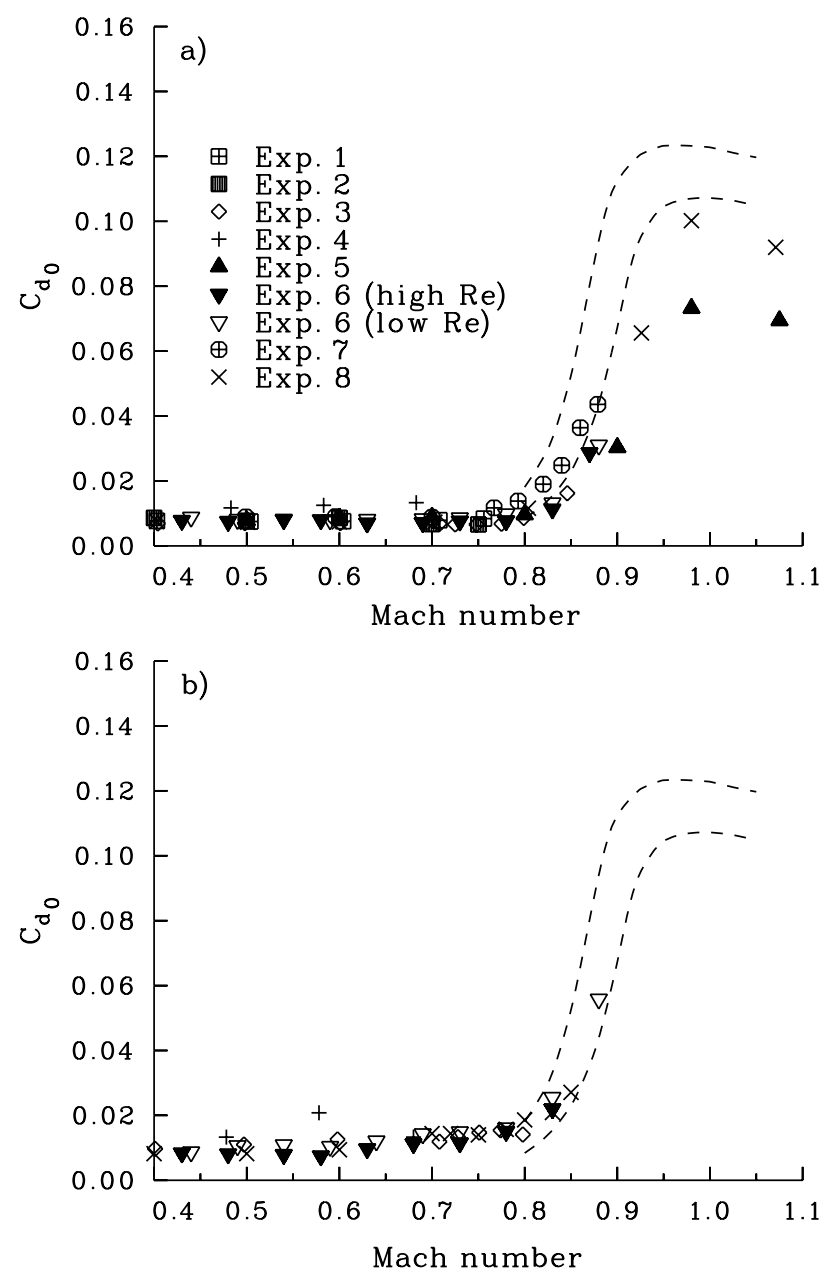

Figure 35. Drag coefficient at zero lift coefficient as a function of Mach number for expanded drag scale; all experimental datasets. a) SC1095 airfoil; b) SC1094 R8 airfoil. $C_{d_{0}}$ reference lines for NACA 0012 (ref. 13).

\section{Lift-to-Drag Ratio}

The airfoil maximum $L / D$ is independent of the angle of attack and, therefore, is not dependent upon angleof-attack corrections (or the lack thereof). However, the maximum $L / D$ will depend upon solid wall corrections, as used for experiment 1 but, as shown previously, these are quite small. The maximum $L / D$ tends to increase with Reynolds number; this dependence is illustrated in figure 36 using test conditions with $M<0.5$. The dashed lines show approximate boundaries that were determined for the NACA 0012 (ref. 13). The drag data in experiment 10 were obtained with a balance and are considered less accurate than data from the other experiments, which used a wake survey to determine the drag. The gradient of 


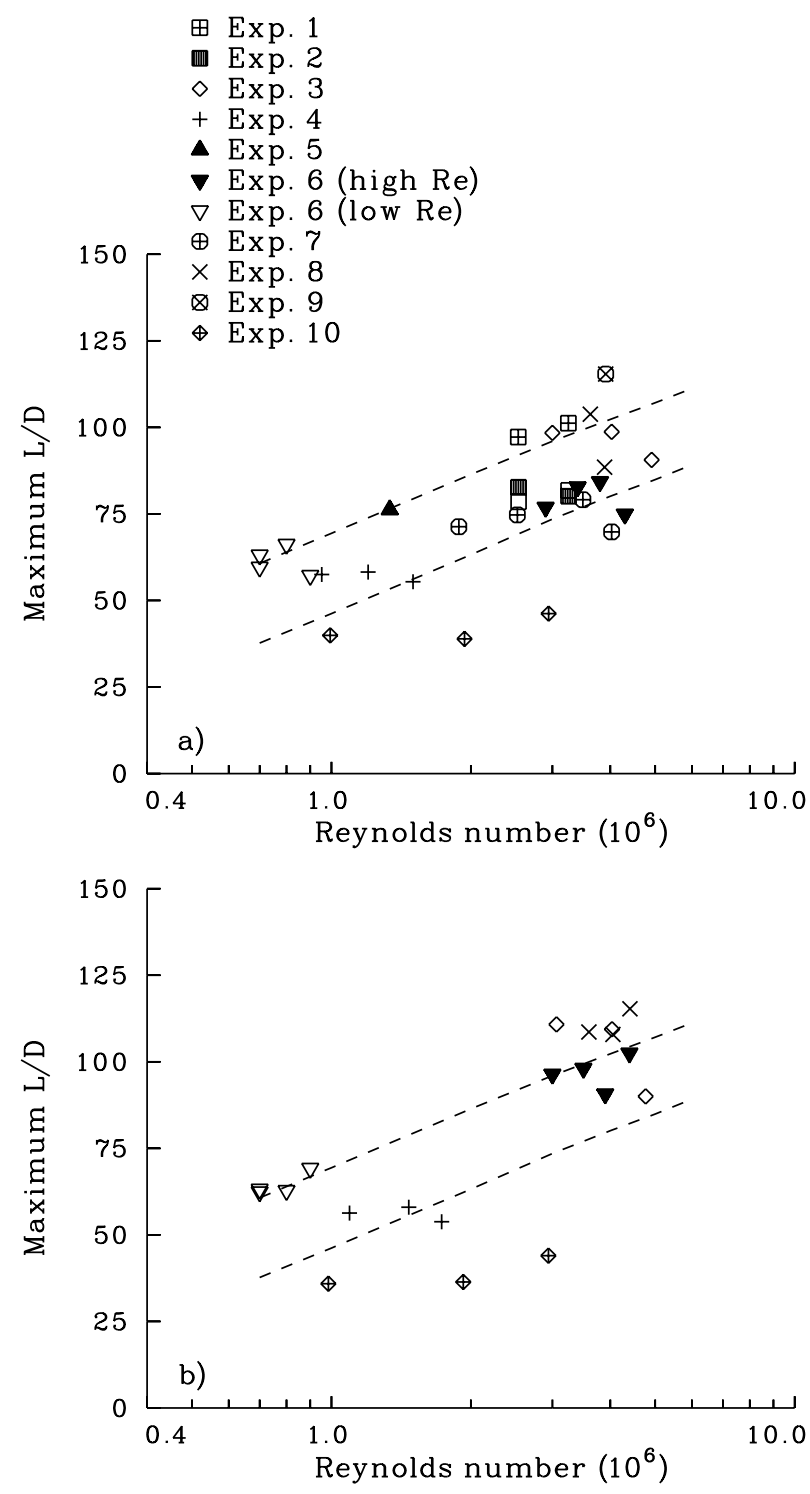

Figure 36. Maximum $L / D$ as a function of Reynolds number; all datasets; a) SC1095 airfoil; b) SC1094 R8 airfoil. Dashed lines show boundaries for NACA 0012 airfoil (ref. 13).

maximum $L / D$ with Reynolds number for the SC1095 appears slightly less than that determined for the NACA 0012. The gradient for the SC1094 R8 is similar to the NACA 0012 value.

The maximum $L / D$ is shown as a function of Mach number in figure 37 for the SC1095 and SC1094 R8 airfoils. Only test data for Reynolds numbers over 2 million are shown in the figure. At lower Mach numbers, from 0.3 to 0.5 , the maximum $L / D$ determined in these
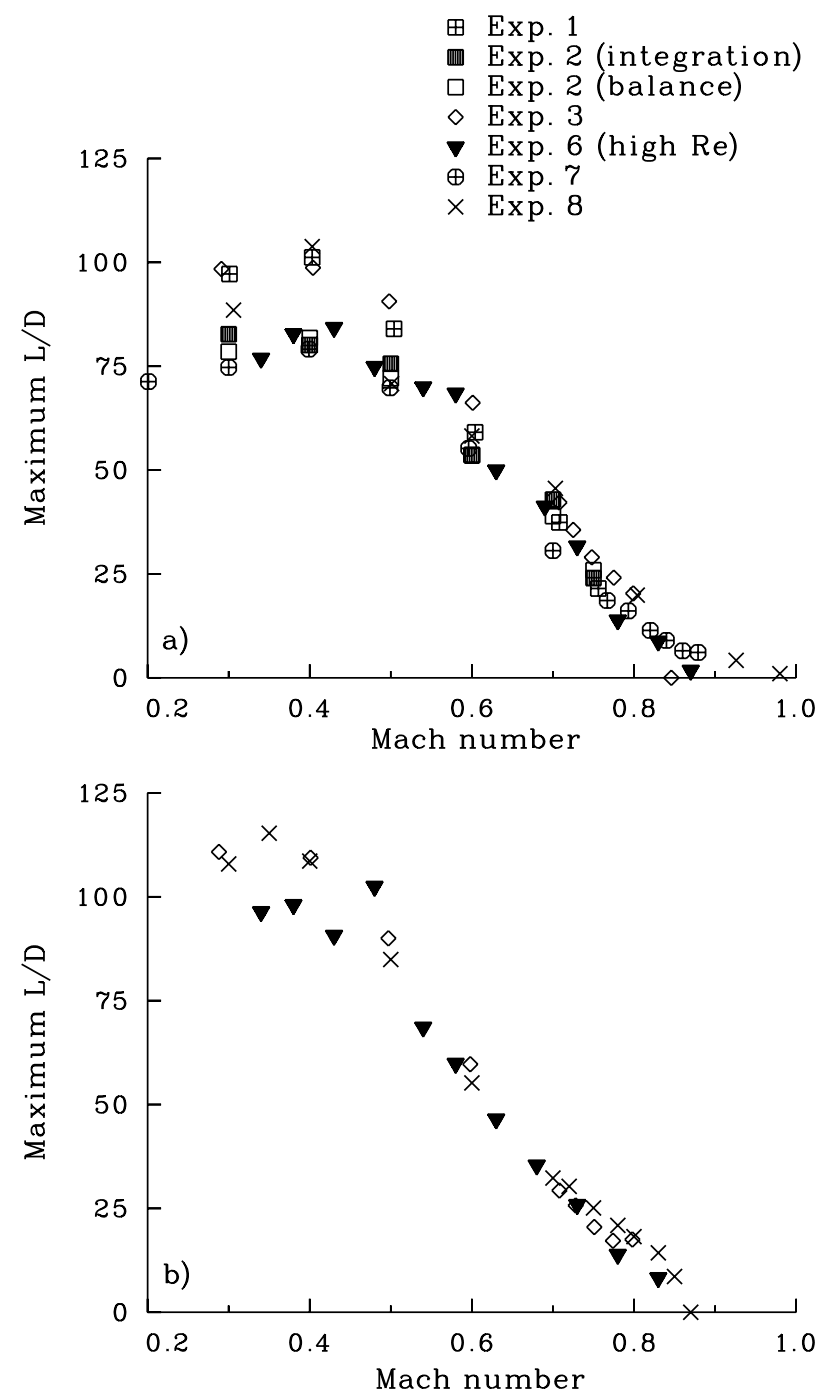

Figure 37. Maximum $L / D$ as a function of Mach number; a) SC1095 airfoil; b) SC1094 R8 airfoil.

tests ranges from 71 to 104 (mean of 84) for the SC1095 airfoil. Comparable maximum $L / D$ s for the SC1094 R8 vary from 85 to 115 (mean of 101). Above $M=0.5$, the maximum $L / D$ s of the two airfoils are nearly identical.

The angles of attack associated with the maximum $L / D$ for the two airfoils are shown as functions of Mach number in figure 38. The angles of attack are between 9 and 10 deg at low Mach numbers, and they drop monotonically to values of 1 or $2 \mathrm{deg}$ as Mach number increases to 0.8 . The similarity between the angle-ofattack variation for best $L / D$, as shown in figure 38 , and the calculated angles of attack in level flight, shown in figure 6 , is striking. 

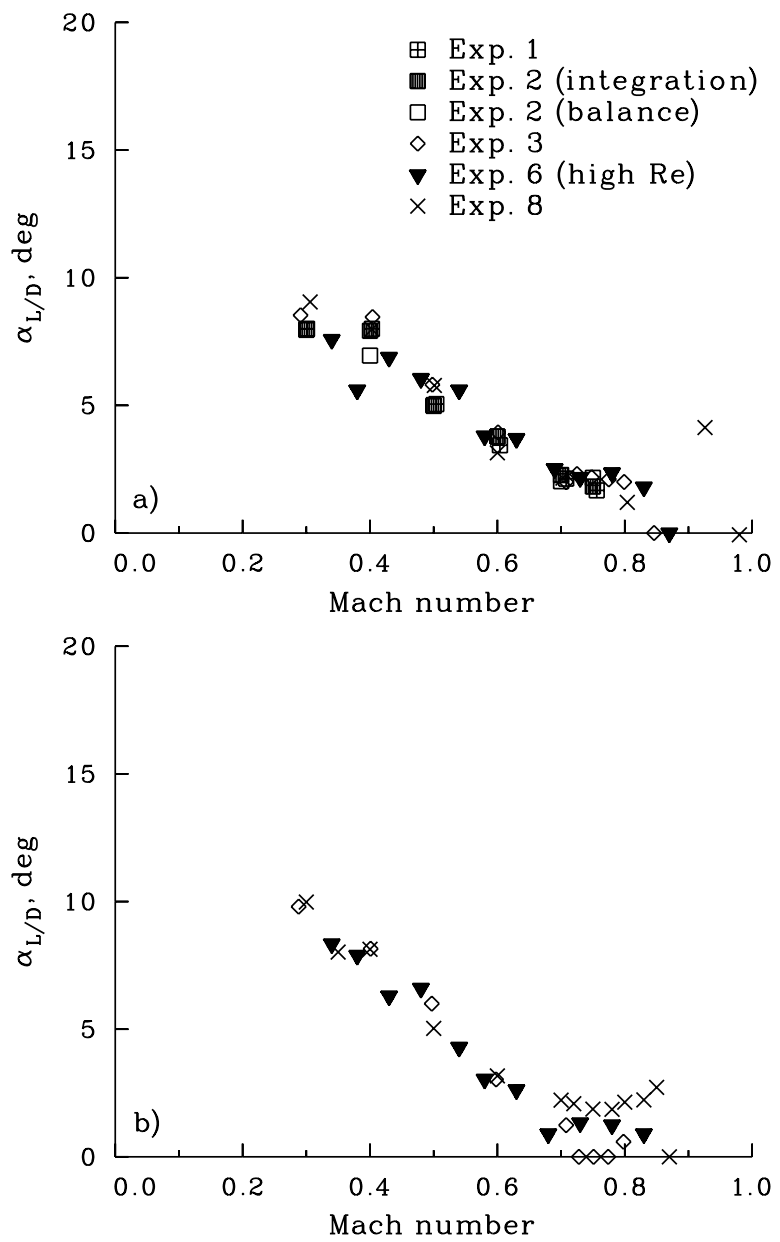

Figure 38. Angle of attack for maximum $L / D$ as a function of Mach number. a) SC1095 airfoil; b) SC1094 R8 airfoil.

\section{Pitching Moment Coefficient}

The effect of the positive camber on these airfoils is to shift the pitching moment at zero lift, $C_{m_{0}}$, to negative values. The zero-lift pitching moment coefficients of the SC1095 and SC1094 R8 airfoils are shown in figure 39. The data from experiment 6 have been shifted by -0.015 to account for the -3 -deg trailing edge tab. The SC1095 zero-lift pitching moment coefficient varies between -0.015 and -0.020 for Mach numbers below 0.7 , and then becomes progressively more negative as Mach number is increased. More scatter is seen in the pitching moment coefficient for the SC1094 R8 airfoil and, at lower Mach numbers, values range from -0.020 to -0.035 . The increased camber of this airfoil has a greater effect on the coefficient in the nonlinear transonic regime, and by $M=0.8$, the coefficient is -0.040 to -0.050 .

The section aerodynamic center is related to the slope of the pitching moment coefficient at zero lift,

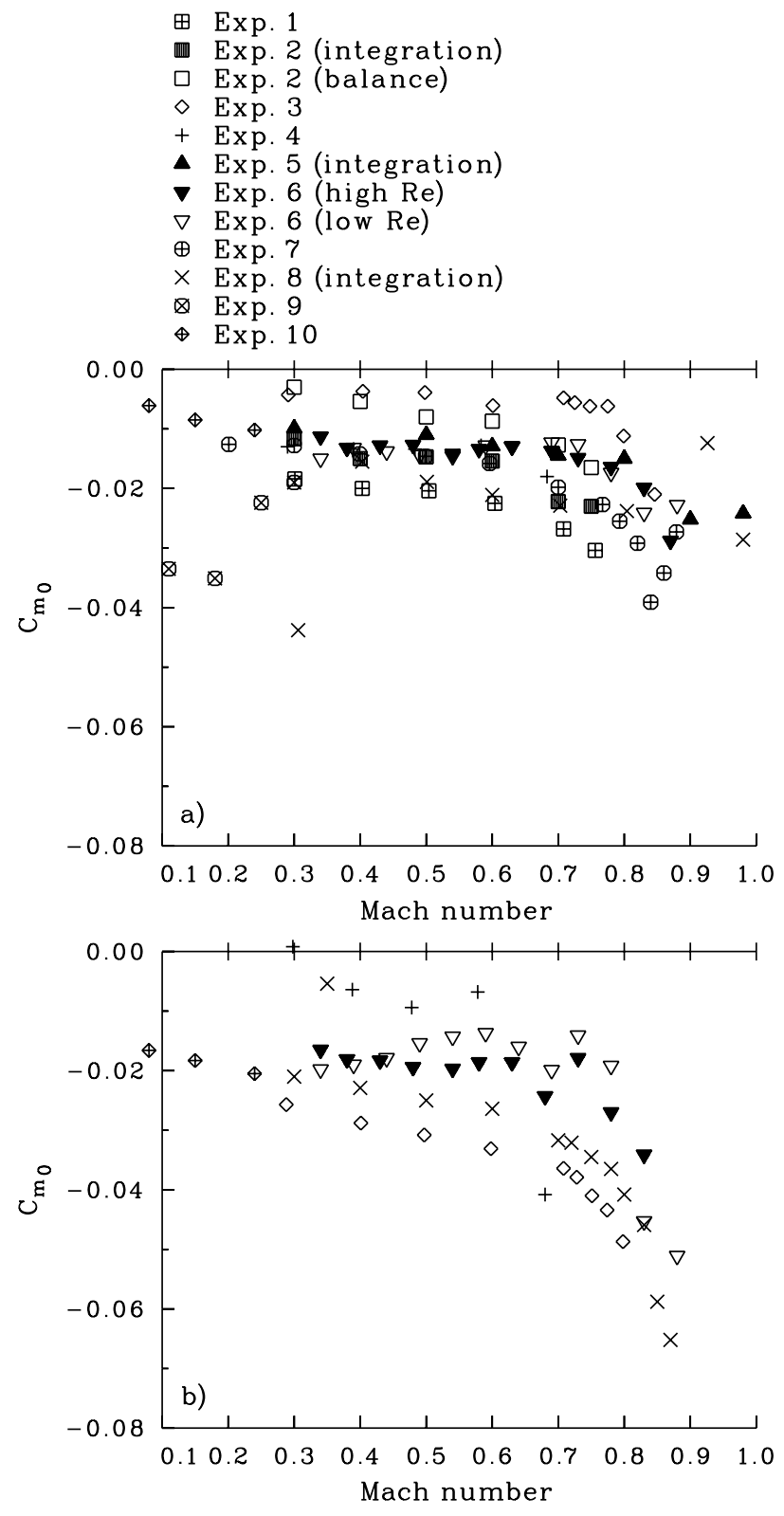

Figure 39. Pitching moment coefficient at zero lift as a function of Mach number. a) SC1095 airfoil; b) SC1094 R8 airfoil.

$d C_{m} / d \alpha$ or $C_{m_{\alpha}}$

$$
\left(\frac{x}{c}\right)_{a c}=0.25-\left(\frac{d C_{m}}{d C_{l}}\right)\left(\frac{d C_{l}}{d \alpha}\right)
$$

As shown in figure $40, C_{m_{\alpha}}$ is close to zero at lower Mach numbers, but near the pitching moment break, between $M=0.7$ and $M=0.8$, the slope becomes strongly negative and the aerodynamic center moves aft. Generally good agreement is seen between the various datasets; however, the actual pitching moment break, as 

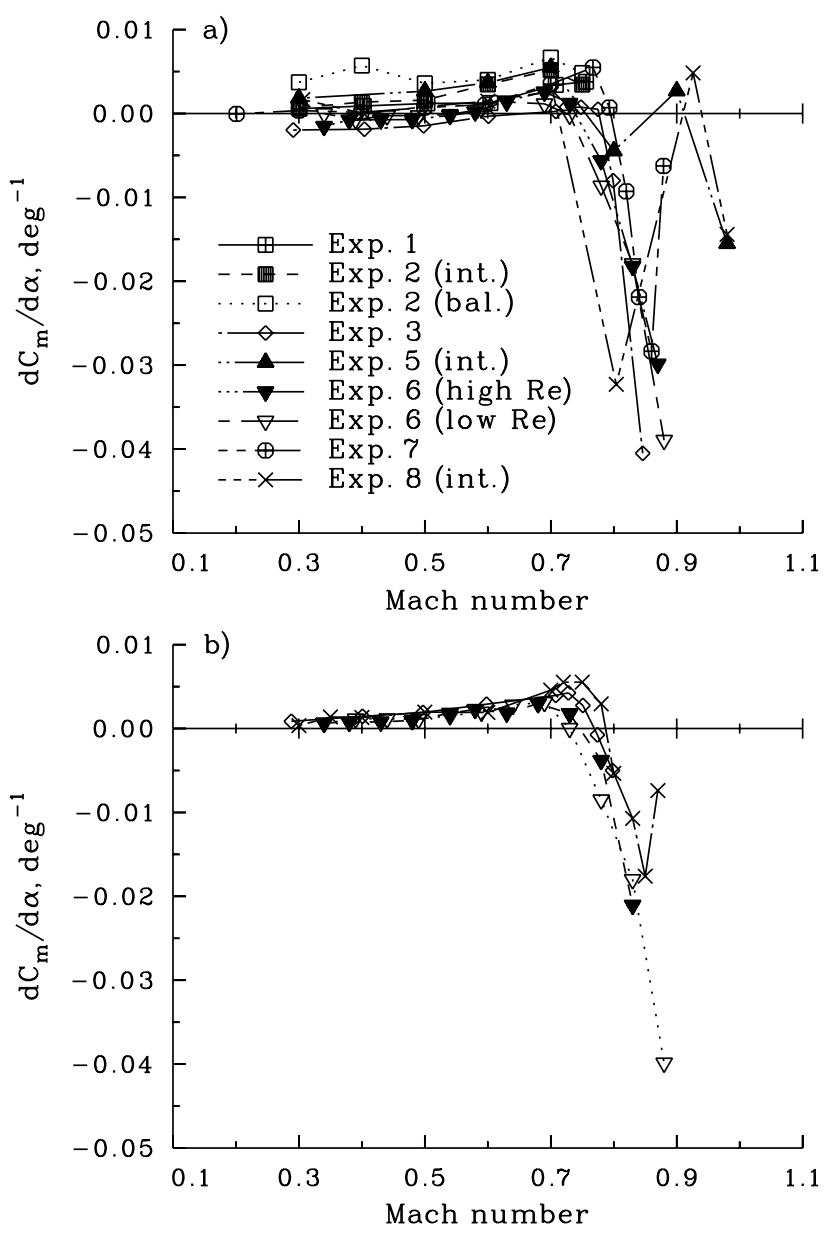

Figure 40. Pitching moment curve slope at zero lift as a function of Mach number. a) SC1095 airfoil; b) SC1094 $R 8$ airfoil.

indicated by a value of 0 , varies between the various experiments by 0.08 in Mach number.

\section{ASSESSMENT}

Figure 41 shows the test boundaries for the ten sets of experimental data examined here. Where test data were obtained on both the SC1094 R8 and SC1095 airfoils, the boundaries are shown with a dashed line and open circles (except for experiment 10, where the two airfoil test boundaries are identical). The drag-divergence Mach number for the SC1095 is included in figure 41 as a marker for the compressible drag rise regime.

McCroskey's assessment of experimental data for the NACA 0012 airfoil provides a useful framework for the examination of the SC1095 and SC1094 R8 airfoils. However, where McCroskey had experimental data from more than 40 wind tunnels for his assessment, only 10 experimental datasets are available for the SC1095 airfoil (5 for the SC1094 R8 airfoil). The results of the data assessment performed here, therefore, are necessarily more tentative, and the use of McCroskey's hierarchy of "groups" is not considered feasible.

Experiment 1. Only the SC1095 airfoil section was tested during this experiment. The Reynolds numbers tested were appropriate, but the highest Mach number tested, 0.76, does not allow a clear identification of drag characteristics in high-speed flight. The lift-curve slope, $\beta C_{l_{\alpha}}$, compared to that for the NACA 0012, is lower than the group 2 boundary and is probably unsatisfactory for the calculation of lift. The measured drag is well within the grouping showed by the other datasets and appears satisfactory. However, the highest Mach number tested was too low to clearly define divergence Mach number and drag rise characteristics. The best $L / D$ at lower Mach numbers appears on the high side as compared to the other datasets. The zero-lift pitching moment obtained is at the lower boundary of the scatter for all tests. In general, this set of data appears to have limited utility.

Experiment 2. As in experiment 1, only the SC1095 airfoil section was tested. The Reynolds numbers tested were appropriate, but the highest Mach number tested, 0.75 , does not allow a clear identification of drag characteristics in high-speed flight. Lift and pitching moment were obtained from pressure integration and from a metric section, and both types of measurements have been examined here. In terms of the lift-curve slope, the value from integration is slightly high, while the balance value agrees with the NACA 0012 reference. The zero-lift drag-coefficient data, based on a wake survey, agree well with other datasets and appear trustworthy. As with experiment $1, M=0.75$ was the highest Mach number tested, and the drag rise is not captured in the data. The best $L / D$ data show good agreement with other datasets and appear satisfactory. Comparison of the pressureintegrated and balance values for $C_{m_{0}}$ and $C_{m_{\alpha}}$ show something of a split between the two measurements, and this ambiguity is difficult to resolve. The basic pitching moment behavior, however, appears to be captured with both measurements. These data are considered useful for Mach numbers below 0.75 .

Experiment 3. This experiment obtained data for the SC1095 and SC1094 R8 airfoils over an appropriate range of Reynolds and Mach numbers. The measured lift-curve slope for the SC1095 shows good agreement with the NACA 0012 reference line. Data obtained at higher Mach numbers show the increasing lift-curve slope in the region of nonlinear transonic flow, and there is general agreement with the other datasets. The angle of attack for zero 

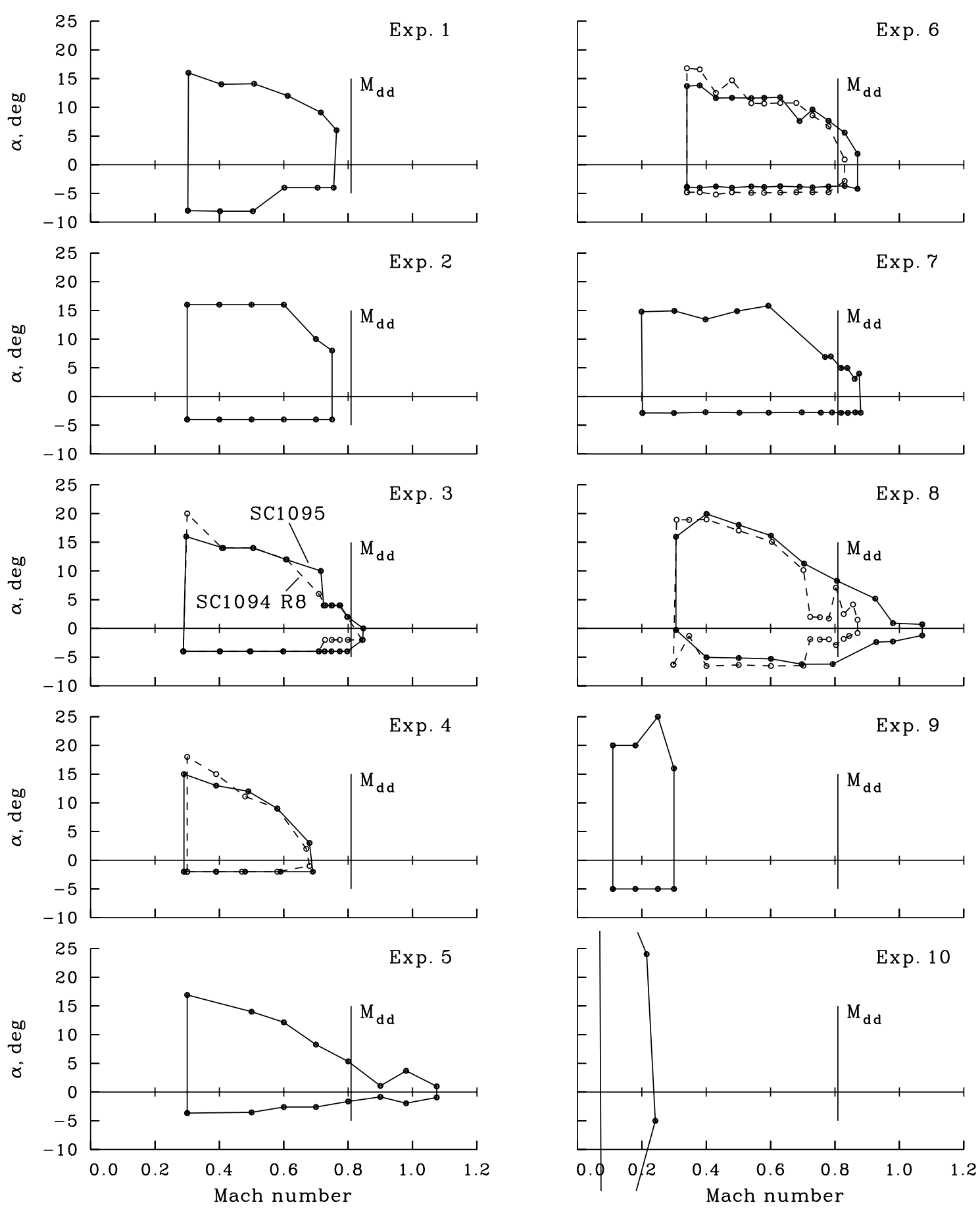

Figure 41. Comparison of angle of attack-Mach number test boundaries for ten experiments. SC1095 and SC1094 R8 airfoils tested for identical conditions in experiment 10. Drag-divergence Mach number indicator is for SC1095.

lift, $\alpha_{0}$, is at the upper edge of the scatter band compared to the other datasets. The zero-lift drag-coefficient data appear to match the other datasets. The Mach number range tested provides a good definition of the divergence Mach number and the associated drag rise. The estimate of $M_{d d}$ is on the low side of estimates from the other datasets but is within the scatter band. For $M<0.55$, the $L / D$ for this experiment is grouped with the experiments 1 and 8 data and is on the high side. At higher Mach numbers, good agreement is obtained with the other datasets. The pitching moment coefficient at zero lift is more positive than obtained by the other experiments, 
perhaps by 0.01 , and this is a bit too high. If the Mach number at the pitching moment break is defined by when $C_{m_{\alpha}}$ is zero, then this occurs at about 0.77 , which is on the high side compared to the other datasets.

Although the subsonic lift-curve slope for the SC1095 showed good agreement with the NACA 0012 reference line, the value for the $\mathrm{SC} 1094 \mathrm{R} 8$ is below the group 2 bounds for the NACA 0012 reference. At higher Mach numbers, however, the lift-curve slope matches results from the other datasets. The angle of attack for zero lift, $\alpha_{0}$, for this airfoil shows very good agreement with the other datasets. The zero-lift drag coefficient, $C_{d_{0}}$, appears to be well outside the appropriate bounds for the SC1094 R8 airfoil. However, if the comparison is based on the minimum drag coefficient, $C_{d_{\min }}$, then these data show good agreement with the other datasets. This suggests that a comparison of the lift-drag polar from this experiment with lift-drag polars from the other datasets would show the drag rise at low and negative angles of attack as occurring sooner for these tests. The dragdivergence Mach number estimated from these test data agrees closely with estimates from the other datasets. Only three of the experiments obtained data for the maximum $L / D$ for the SC1094 R8 airfoil. Below $M=0.55$, the data from this test and experiment 8 generally show good agreement, while the experiment 6 data are lower. The zero-lift moment measured on the SC1094 R8 airfoil is more negative than was observed with any of the other datasets. Curiously, the opposite effect was seen for the SC1095 airfoil. The pitching moment break for the SC1094 R8 occurs at about $M=$ 0.77 , just as with the SC1095. In general, both sets of data obtained in experiment 3 appear to be valuable for defining the airfoil characteristics, although the measurement of the zero-lift moment may not be satisfactory.

Experiment 4. Data in experiment 4 were obtained on both airfoils incidental to icing tests. The lift-curve slope measured on the SC1095 airfoil is slightly high and outside the bounds of the NACA 0012 data. More importantly, the measured drag coefficients are about 40-percent higher than the coefficients from the other datasets, and these data are not suitable for general use. Similar differences are seen in the drag-coefficient data for the SC1094 R8, and the lift-curve slope values are much too low. These data should not be used in evaluations of these airfoils for normal operating conditions.

Experiment 5. Only the SC1095 airfoil was tested in experiment 5. Data were obtained at Reynolds numbers appropriate for model scale, but not for full scale. The Mach number range for testing extended to 1.08 ; only experiment 8 obtained data over a comparable range. The data in experiment 5 were published without corrections, although an angle-of-attack correction was discussed. The assessment here has shown that the uncorrected data are unsatisfactory based on differences seen in the lift-curve slope. The correction for angle of attack discussed in reference 6 has been used for all the experiment 5 data, and the conclusions here are based on these corrected data. The lift-curve slope for these data lies on the lower group 2 bound compared to the NACA 0012 reference. At higher Mach numbers these data show rough agreement with the boundaries that have been delineated in the transonic regime for the NACA 0012. The angle of attack for zero lift, $\alpha_{0}$, shows good agreement with the other datasets and is roughly in the middle of the data scatter. The zero-lift drag coefficient data show quite good agreement with the other datasets in terms of Reynolds number dependence. Data were obtained at only six Mach numbers between 0.6 and 1.09, and this spacing is too coarse to allow a reasonable prediction of the divergence Mach number. However, these data do provide drag data at high Mach numbers, which are of value. There are large differences in the measured drag at high Mach numbers, compared to the experiment 8 data, and these differences are not clearly understood. The maximum $L / D$ data from these tests were not evaluated because the Reynolds number was considered too low. The zero-lift pitching moment shows good agreement with the other datasets, generally falling near the center of the data scatter. The test Mach number spacing appears to be too coarse to provide an adequate description of the pitching moment break. This dataset appears to be generally useful after angle-of-attack corrections have been applied. However, the fairly coarse gradations in test Mach numbers probably require that the dataset be used in combination with other datasets obtained on a finer grid.

Experiment 6. Test data were obtained for both the SC1095 and SC1094 R8 airfoils in this experiment. Test data were obtained at Mach numbers up to 0.88 and at two different Reynolds numbers. Both airfoils were tested with a $0.03 c$ tab with the angle set to $-3 \mathrm{deg}$ (reflexed). For this assessment it has been assumed that the effect of the tab length can be neglected, but the reflex of the tab will influence measured characteristics. Based on an examination of numerous previous tests with and without reflexed tabs, corrections have been added to $C_{l_{\text {max }}}(+0.06)$, the angle of attack at zero lift, $\alpha_{0}(-0.705)$, and the pitching moment, $C_{m_{0}}(-0.015)$. No other airfoil characteristics have been modified.

The SC1095 lift-curve slope shows good agreement with the NACA 0012 reference case, particularly at low Reynolds numbers. At higher Mach numbers the data appear to be in the center of the data 
scatter and provide an indication of the nonlinear break in lift-curve slope that occurs for $M>0.8$. After correcting for the reflex tab, the angle of attack for zero lift falls in the middle of the data scatter for the other datasets. The drag coefficient at zero lift appears to agree well with the other test data at the high Reynolds number. The dragcoefficient data appear reasonable for the lower Reynolds number test conditions; however, very little data are available from the other tests for comparison. The range of Mach numbers tested provides a good delineation of the divergence Mach number and the drag rise. The estimated $M_{d d}$ is slightly higher than the mean value computed for all datasets. No correction was made for the reflexed tab for the maximum $L / D$, although comparative data show some shift in the L/D polars in this case. This might explain why the $L / D$ values were lower than the comparable measurements from experiments 1,3 , and 8 , but this is only observed for $M<0.55$. The corrected $C_{m_{0}}$ for this airfoil is centered in the data scatter of the other datasets and appears satisfactory. The pitching moment break, as defined by $C_{m_{\alpha}}=0$, is at a Mach number of 0.74 , which is about the center of the range seen in the other datasets.

The lift-curve slope of the SC1094 R8 airfoil is above the NACA 0012 reference, and a few points exceed the group 2 bounds. At higher Mach numbers the liftcurve slopes appear to be well within the scatter of the other datasets. The corrected zero-lift angle of attack agrees well with the other datasets. There is fairly good agreement between the zero-lift drag coefficient computed here and the other datasets. However, because there are fewer tests of the SC1094 R8 airfoil, it is more difficult to judge the comparisons. If the basis of comparison is $C_{d_{\text {min }}}$ rather than $C_{d_{0}}$, better agreement is observed because the experiment 3 data then coincide with the experiment 6 data. Considerable scatter is seen in the comparisons of $C_{d_{0}}$ as a function of Mach number; part of this scatter is caused by the Reynolds number variation for this dataset. Using only the high Reynolds number data, a divergence Mach number is estimated that is quite close to the mean of all the datasets. Below $M=0.5$, the maximum $L / D$ is less than the values computed for the experiment 3 and 8 datasets, but at higher Mach numbers there is good agreement. A comparison of the zero-lift pitching moment shows a good bit of scatter for the various datasets, indicating, perhaps, the difficulty of accurately deriving the pitching moment from the pressure measurements. The experiment 6 data tend to lie on the high side of the scatter (less negative). The pitching moment break occurs at about $M=0.74$.

The high Reynolds number data from the tests of the two airfoils are considered useful, after corrections are made for the reflexed tab. The extensive data at both high and low Reynolds number provide the best dataset for the evaluation of Reynolds number effects on these airfoils.

Experiment 7. Only the SC1095 airfoil was tested for this experiment. The test Mach number range extended to 0.88 and, above $M=0.75$, test data were obtained for small increments in Mach number. Reynolds number was between 2 and 4 million. Totah (ref. 12) considered these data to be inaccurate and, therefore, unsuitable for evaluation purposes. It appears that this lack of suitability was caused by the use of inappropriate angleof-attack corrections in the original test report. For the evaluation here these corrections were removed and the uncorrected data were used instead. Comparison of the lift-curve slope with the NACA 0012 reference indicates that the values are too low and outside the group 2 bounds. At higher Mach numbers it appears that the liftcurve slope remains too low, although the data do delineate the highly nonlinear character of the lift-curve slope in the Mach number range from 0.78 to 0.88 . The measured angle of attack for zero lift falls in about the center of the data scatter from the other experiments. The zero-lift drag coefficient data appear too high compared to the other datasets. The estimated divergence Mach number is slightly low, but within the scatter of the other datasets. The maximum $L / D$ shows good agreement with the other datasets for $M>0.55$. At lower Mach numbers the $L / D$ agrees well with experiments 2 and 6 . Although the zero-lift drag coefficient data are too high, this does not appear to have seriously impacted the $L / D$ values. The zero-lift pitching moment values are toward the lower (more negative) side of the scatter band for the other datasets. The pitching moment break is well defined for these data, occurring at about $M=0.80$. This value is higher than is seen in the other datasets. The utility of this dataset is unclear. It appears that an angle-of-attack correction for the tunnel wall porosity is required for these data, although the correction used by the original investigators is unsatisfactory. The zero-lift drag coefficients appear too high, but based on the $L / D$ results the drag data may be better at higher angles of attack. Compared to the other experiments, this test used finer increments in angle of attack and Mach number for much of the test matrix, and the greater density of data points may provide limited use for evaluation purposes.

Experiment 8. Both the SC1095 and SC1094 R8 airfoils were tested in this experiment. Test data were obtained up to a Mach number of 1.07 for the SC1095 and up to 0.87 for the SC1094 R8. The Reynolds numbers for the tests were somewhat less than full scale. The lift-curve slope for the SC1095 airfoil at lower subsonic Mach numbers is low for this experiment and is below the group 2 bounds, as compared to the NACA 0012 reference lift-curve slope. The original investigators noted this problem (ref. 9) and 
suggested that the lack of appropriate angle-of-attack corrections was the cause of the reduced lift-curve slope. The lift-curve slope at higher Mach numbers also appears low. No data were obtained between $M=0.80$ and $M=$ 0.93 , which is the region of greatest nonlinear variation in the lift-curve slope behavior. The angle of attack at zero lift appears to fall within the scatter of the other datasets. Although there is some scatter in the zero-lift drag coefficient, most values show good agreement with the other datasets, as a function of both Reynolds number and Mach number. The available data provide a good estimate of the divergence Mach number, which is below the estimate of the other datasets. The data above the drag rise show higher drag levels than observed for the experiment 5 data, but lower drag than measured in NACA 0012 experiments. The maximum $L / D$ for the SC1095 in this experiment agrees well with experiments 1 and 3 for $M<0.5$. At higher Mach numbers, good agreement is seen with all the datasets. The zero-lift pitching moment measurements for this airfoil show more scatter than observed in the other experiments, and the moments are on the low (more negative) side of the scatter band. The pitching moment break is not well defined, but appears lower than the other datasets.

The lift-curve slope for the SC1094 R8 airfoil is lower than the group 2 bounds for the NACA 0012 reference lift-curve slope. As mentioned previously, this low value of the lift-curve slope was observed by the original investigators (ref. 9). At higher Mach numbers, although the lift-curve slope remains low, there is good agreement with the other datasets as to the form of the lift-curve slope in the nonlinear region. Good agreement in the measurement of the angle of attack for zero lift is observed below $M=0.6$, but at higher Mach numbers there is a substantial positive shift in $\alpha_{0}$, suggesting a bias error in the measurement for these conditions. The zerolift drag coefficient shows some scatter at lower Mach numbers, but is in general agreement with the other datasets. Additional data were obtained in this test to better define the divergence Mach number, and the resulting estimate agrees well with other measurements. At Mach numbers below 0.5 , the maximum $L / D$ agrees with the experiment 3 values, but is higher than the experiment 6 measurements. At higher Mach numbers there is good agreement among all the datasets. The zerolift pitching moment for the SC1095 R8 airfoil is close to a mean value of the various datasets, but the differences between these datasets are fairly large, increasing the uncertainty as to the actual values. The pitching moment break is well defined by the experiment 8 data and occurs at about $M=0.79$.
The value of the present data is limited to a degree by the lack of suitable angle-of-attack corrections. However, despite this lack, the data can provide some useful indications of the airfoil behavior in the nonlinear transonic regime. It may be feasible to increase the utility of these data by applying empirical corrections to the angle of attack based on NACA 0012 characteristics.

Experiment 9. Only the SC1095 airfoil was tested in this experiment. Data were obtained up to a Mach number of 0.30 and, therefore, are useful only for the evaluation of subsonic airfoil characteristics. Compared to the NACA 0012 reference condition, the lift-curve slope in these tests is above the group 2 bounds and, therefore, is too high, as noted in reference 10 . Over the Mach number range tested, a shift is observed in the zero-lift angle of attack of about $0.5 \mathrm{deg}$, suggesting some bias errors in the measurements. The single zero-lift drag coefficient test point obtained $(M=0.30)$ shows good agreement with the other datasets. The zero-lift pitching moments at low Mach numbers show excessive scatter compared to the other datasets. The limited Mach number range of these data along with the problems noted with the zero-lift angle of attack and pitching moment suggest that these data have little utility for the evaluation of static SC1095 airfoil characteristics.

Experiment 10. Both the SC1095 and SC1094 R8 airfoils were tested in this experiment. The Mach number range was limited to about 0.24 and the data, therefore, are useful only for evaluating subsonic characteristics. These data are unique, however, in that lift, drag, and pitching moment measurements were obtained for angles of attack from 0 to $360 \mathrm{deg}$.

The lift-curve slope for the SC1095 is slightly higher than the group 2 bounds relative to the NACA 0012 reference. The zero-lift angle of attack is about $-0.1 \mathrm{deg}$ and is more positive than the scatter band from the other experiments. This is suggestive of a bias or rigging error in the data. The zero-lift drag coefficient results are slightly high compared to the other datasets. Considering the difficulty of making drag measurements with a balance, these results are quite good. However, at higher angles of attack, the balance drag increases much more quickly than observed in the other experiments that used a wake survey apparatus to determine drag. As a consequence, the maximum $L / D$ values are substantially below the other datasets. The zero-lift pitching moment shows generally good agreement with the lower Mach number data from the other experiments. 
The lift-curve slope of the SC1094 R8 is slightly higher than the group 2 bounds, as was seen for the SC1095 lift-curve slope. Unlike the SC1095, the zero-lift angle of attack agrees very well with the other datasets. The zero-lift drag coefficients appear about 20 -percent high, and this probably reflects the difficulty of making drag measurements with a balance. The zerolift pitching moments appear to agree fairly well with the other datasets at low Mach number.

The experiment 10 data are considered to have limited utility for the evaluation of these airfoils, in part because of the limited Mach number range but also because of limitations of the drag measurements at low angles of attack. However, neither of these limitations applies to the data taken at angles of attack from roughly +12 to $+180 \mathrm{deg}$ and -10 to $-180 \mathrm{deg}$, where the drag balance should provide accurate results and the low Mach numbers are appropriate.

\section{CONCLUDING REMARKS}

SC1095 and SC1094 R8 airfoil section test data from ten wind tunnel tests have been examined with the purpose of assessing their suitability for the development of two-dimensional airfoil tables for use in comprehensive analyses. The general framework of the assessment has followed the approach taken by McCroskey in his assessment of the NACA 0012 airfoil (ref. 13). In particular, the variation in the lift-curve slope and the zerolift drag coefficient as functions of Reynolds and Mach numbers has been used as a primary means of assessing the adequacy of these data.

Although the lift-curve slope and zero-lift drag coefficient have been used as the first step in the assessment of the airfoil test data, these are appropriate measures only for flow conditions below $M=0.55$. At higher Mach numbers the nonlinearity in the lift-curve slope, the drag rise associated with the divergence Mach number, and the pitching moment break all become important. Of these characters, the nonlinearity in the liftcurve slope, from about $M=0.80$ to $M=0.95$, is not adequately defined by these datasets, while both the drag rise and pitching moment break are more accurately quantified.

The ten datasets can be briefly summarized as follows. However, even in the best of circumstances, these datasets need to be used with caution.

Experiment 1. The lift-curve slope is too low and data are available only to $M=0.76$. The dataset may be used as is. (SC1095 only)
Experiment 2. Data generally are of good quality and available to $M=0.75$. The dataset may be used as is. (SC1095 only)

Experiment 3. Data generally are of good quality and available to $M=0.84$. The dataset may be used as is. (SC1095 and SC1094 R8)

Experiment 4. Data generally are of poor quality. The data are available to $M=0.68$, but are of limited utility. (SC1095 and SC1094 R8)

Experiment 5. Data are of poor quality as published. The data are available to $M=1.08$. Use of angle-of-attack corrections as discussed in the original test report provide improved results. (SC1095 only)

Experiment 6. Data are generally of good quality, but many section characteristics are influenced by the reflexed tab used in these tests. Data are available to $M=0.86$ over two Reynolds number ranges. Corrections empirically based on reflexed tab data should be used for these data. (SC1095 and SC1094 R8)

Experiment 7. Original data quality is poor, but if angleof-attack corrections are removed the data have more utility. However, the lift-curve slope is too low and the zero-lift drag coefficient is too high. Data are available to $\mathrm{M}=0.98$. An empirically based angle-of-attack correction is recommended. (SC1095 only)

Experiment 8. The lift-curve slope is too low; otherwise data quality appears good. Data are available to $M=1.07$. An empirically based angle-of-attack correction is recommended. (SC1095 and SC1094 R8)

Experiment 9. The lift-curve slope is too high and data are available only to $M=0.3$. Data have limited utility. (SC1095 only)

Experiment 10. The data are useful for lift, drag, and pitching moment data for angles of attack from 0 to 360 deg. (SC1095 and SC1094 R8)

\section{REFERENCES}

1. Crawford, Charles C., Jr.: Rotorcraft Analytical Improvement Needed to Reduce Developmental Risk-The 1989 Alexander A. Nikolsky Lecture, American Helicopter Soc., vol. 35, no. 1, Jan. 1990, pp. 3-22.

2. Griffin, T.: Wind Tunnel Tests of Sikorsky SC-1095 Two-Dimensional Airfoil with Various Surface Irregularities. UARL Report M432170-1, Oct. 1973. 
3. Vogt, P. G.: An Evaluation of NACA 0012 and SC 1095 Airfoil Tests in the UTRC Large Subsonic Wind Tunnel. UTRC75-121, Dec. 1975.

4. Lednicer, D.; Owen, S.; and Culver, E.: An Evaluation of Eleven Helicopter Airfoil Sections in the Ohio State University 6 x 22 Transonic Facility. SER-760603, Nov. 1985.

5. Flemming, R. J.; and Lednicer, D. A.: High Speed Ice Accretion on Rotorcraft Airfoils. NASA CR3910, 1985.

6. Jepson, W. D.: Two Dimensional Test of Four Airfoil Configurations with an Aspect Ratio of 7.5 and a 16 Inch Chord up to a Mach Number of 1.1. SER-50977, Apr. 1977.

7. Noonan, K. W.; and Bingham, G. J.: Aerodynamic Characteristics of Three Helicopter Rotor Airfoil Sections at Reynolds Number from Model Scale to Full Scale at Mach Numbers from 0.35 to 0.90. NASA TP-1701, 1980.

8. Hicks, R. M.; and Collins, L. J.: An Evaluation of Three Helicopter Rotor Sections. NASA TM86719, 1985.

9. Flemming, Robert J.: An Experimental Evaluation of Advanced Rotorcraft Airfoils in the NASA Ames Eleven-Foot Transonic Wind Tunnel. NASA CR-166587, 1984.

10. McCroskey, W. J.; McAlister, K. W.; Carr, L. W.; and Pucci, S. L.: An Experimental Study of Dynamic Stall on Advanced Airfoil Sections. NASA TM-84245, 1982.

11. Robinson, Keith W.; and Leishman, J. G.: Effects of Ballistic Damage on the Aerodynamics of Helicopter Rotor Airfoils. Aircraft, vol. 35, no. 5, Sept.-Oct. 1998, pp. 695-703.

12. Totah, Joseph: A Critical Assessment of UH-60 Main Rotor Blade Airfoil Data. AIAA Paper 933413, presented at 11th AIAA Applied Aerodynamics Conference, Monterey, Calif., Aug. 9-11, 1993.

13. McCroskey, W. J.: A Critical Assessment of Wind Tunnel Results for the NACA 0012 Airfoil. AGARD Fluid Dynamics Panel Symposium on Aerodynamic Data Accuracy and Quality; Requirements and Capabilities in Wind Tunnel Testing, Naples, Italy, Sept. 28-Oct. 2, 1987; also, NASA TM-100019, USAAVSCOM TM 87-A-5, Oct. 1987.
14. Harris, C. D.: Two-Dimensional Aerodynamic Characteristics of the NACA 0012 Airfoil in the Langley 8-Foot Transonic Pressure Tunnel. NASA TM-081927, 1981.

15. Cross, J.; Brilla, J.; Kufeld, R.; and Balough, D.: The Modern Rotor Aerodynamic Limits Survey: A Report and Data Survey. NASA TM-4446, 1993.

16. Bousman, William G.; and Maier, Thomas H.: An Investigation of Helicopter Rotor Blade Flap Vibratory Loads. American Helicopter Society 48th Annual Forum Proceedings, Washington, D.C., June 3-5, 1992, pp. 977-999.

17. Maier, Thomas H.; and Bousman, William G.: An Examination of the Aerodynamic Moment on Rotor Blade Tips Using Flight Test Data and Analysis. Paper No. 48, Eighteenth European Rotorcraft Forum, Avignon, France, Sept. 15-18, 1992. Also: NASA TM-104006, 1993.

18. Johnson, W.: A Comprehensive Analytical Model of Rotorcraft Aerodynamics and Dynamics, Vol. 1: Theory Manual. Johnson Aeronautics, Palo Alto, Calif., 1988.

19. Allen, H. Julian; and Vincenti, Walter G.: Wall Interference in a Two-Dimensional-Flow Wind Tunnel, with Consideration of the Effect of Compressibility, NACA Report 782, 1944.

20. Pontezeire, J.; and Bernard-Guelle, R.: A Critique of Transonic Aerofoil Testing Techniques, Part II: Experimental Study of Wall Corrections in R1Ch. L'Aeronautique et l'Astronautique, No. 32, 1971-1978, pp. 9-20.

21. Dadone, L. U.: U.S. Army Helicopter Design Datcom, Volume I: Airfoils. NASA CR153247, 1976.

22. Keys, Charles N.; McVeigh, Michael A.; Dadone, Leo; and McHugh, Francis J.: Estimation of Full-scale Rotor Performance from Model Rotor Test Data. American Helicopter Soc. vol. 30, no. 4, Oct. 1985, pp. 22-29. 
